5102-125

Thermal Power Systems

Advanced Solar Thermal Technology Project
DOE/JPL-1060-24

Distribution Category UC-62

\title{
Evaluation of Cellular Glasses for Solar Mirror Panel Applications
}

\section{MASitK}

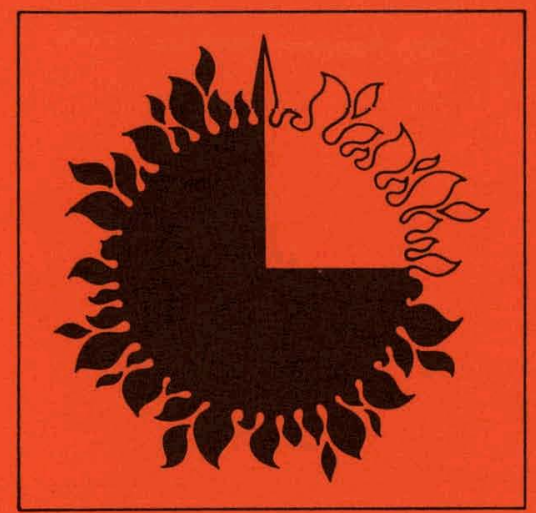

June 15,1979

Prepared tor

U.S. Department of Energy

Through an agreement with

National Aeronautics and Space Administration

by

Jet Propulsion Laboratory

California Institute of Technology

Pasadena, California

(JPL PUBLICATION 79-61) 


\section{DISCLAIMER}

This report was prepared as an account of work sponsored by an agency of the United States Government. Neither the United States Government nor any agency Thereof, nor any of their employees, makes any warranty, express or implied, or assumes any legal liability or responsibility for the accuracy, completeness, or usefulness of any information, apparatus, product, or process disclosed, or represents that its use would not infringe privately owned rights. Reference herein to any specific commercial product, process, or service by trade name, trademark, manufacturer, or otherwise does not necessarily constitute or imply its endorsement, recommendation, or favoring by the United States Government or any agency thereof. The views and opinions of authors expressed herein do not necessarily state or reflect those of the United States Government or any agency thereof. 


\section{DISCLAIMER}

Portions of this document may be illegible in electronic image products. Images are produced from the best available original document. 
5102-125

Thermal Power Systems

Advanced Solar Thermal Technology Project
DOE/JPL-1060-24

Distribution Category UC-62

\title{
Evaluation of Cellular Glasses for Solar Mirror Panel Applications
}

\author{
M. Giovan \\ M. Adams
}

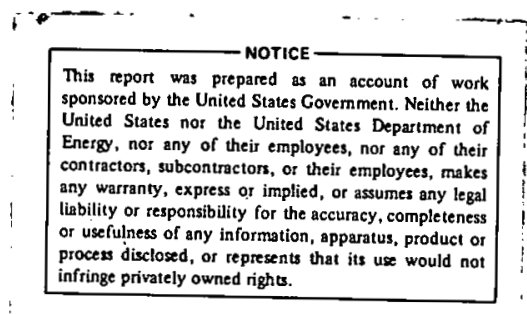

June 15, 1979

Prepared tor

U.S. Department of Energy

Through an agreement with

National Aeronautics and Space Administration

by

Jet Propulsion Laboratory

California Institute of Technology

Pasadena, California

(JPL PUBLICATION 79-61) 
Prepared by the Jet Propulsion Laboratory, California Institute of Technology, for the U.S. Department of Energy through an agreement with the National Aeronautics and Space Administration.

I he JPL Solar Ihermal Power Systems Project is sponsored by the U.S. Department of Energy and forms a part of the Solar Thermal Program to develop low-cost solar thermal electric generating plants.

This report was prepared as an account of work sponsored by the United States Government. Neither the United States nor the United States Department of Energy, nor any of their employees, nor any of their contractors, subcontractors, or their employees, makes any warranty, express or implied, or assumes any legal liability or responsibility for the accuracy, completeness or usefulness of any information, apparatus, product or process disclosed, or represents that its use would not infringe privately owned rights. 


\section{ABSTRACT}

An analytic technique is developed to compare the structural and environmental performance of various materials considered for backing of second surface glass solar mirrors. Metals, ceramics, dense molded plastics, foamed plastics, forest products and plastic laminates are surveyed. Cellular glass is determined to be a prime candidate due to its low cost, high stiffness-to-weight ratio, thermal expansion match to mirror glass, evident minimal environmental impact and chemical and dimensional stability under conditions of use. While applications could employ this material as a foam core or compressive member of a composite material system, the present analysis addresses the bulk material only, allowing a basis for simple extrapolations.

The current state of the art and anticipated developments in cellular glass technology are discussed. Material properties are correlated to design requirements using a Weibull weakest link statistical method appropriate for describing the behavior of such brittle materials. A mathematical model is presented which suggests a design approach which allows minimization of 1 ife cycle cost; given adequate information for a specific application, this would permit high confidence estimates of the cost/performance factor.

A mechanical and environmental testing program is outlined, designed to provide a material property basis for development of cellular glass hardware, together with methodology for collecting lifetime predictive data required by the mathematical treatment provided herein.

Preliminary material property data from measurements is given. Microstructure of several cellular materials is shown, and sensitivity of cellular glass to freeze-thaw degradation and to slow crack growth is discussed. The effect of surface coating is addressed. Conventional manufacturing refinements are considered which, while not generally applied as yet to cellular glass, nevertheless lend themselves readily to this material. They are tentatively seen as promising to answer design needs even using present cellular glass chemistry, for a high performance, low environmental impact, medium cost solar mirror system. 
The authors gratefully acknowledge the contributions from many individuals in government that made this program possible. Special recognition is given to $\mathrm{Dr}$. David Rostoker and Mr. Randolph Gerrish of the Pittsburgh Corning Corporation and to Mr. Bill Mitchell of Solaramics, Incorporated. Commendations are given to members of the JPL solar-thermal power advanced material development team, including Dr. Jim Zwissler of the JPL Materials Research and Technology Group and Mr. Edward Cleland of the JPL Materials Applications Group.

This work was performed by the Materials Research and Technology Group in the Applied Mechanics Division of the Jet Propulsion Laboratory, California Institute of Technology. 
TABLE OF CONTENTS

I. Introduction $\ldots \ldots \ldots \ldots \ldots \ldots \ldots \ldots \ldots \ldots \ldots \ldots$

II. Structural Material Survey $\ldots \ldots \ldots \ldots \ldots \ldots \ldots \ldots \ldots \ldots$

III. Current Cellular Glass Technology ................ 17

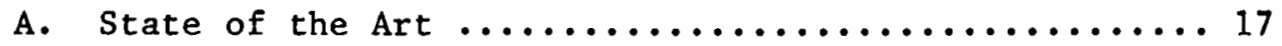

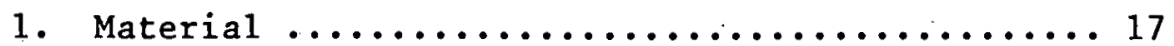

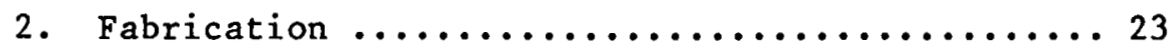

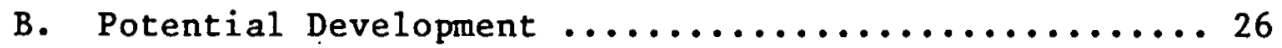

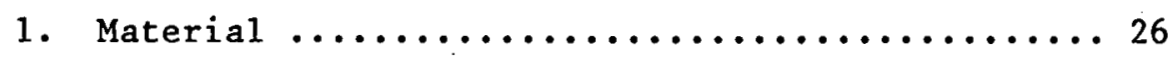

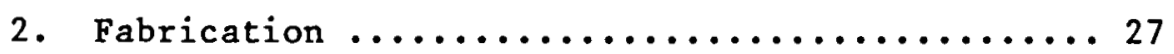

IV. Cellular Glass Material Design Consideration ......... 31

V. Mechanical and Environmental Testing Program ......... 43

A. Purpose ............................. 43

B. Cellular Glass Microstructure and Density Variation 44

C. Testing Techniques and Data Reduction............ 46

1. Four-Point Bend with Displacement Determination 46

2. Dynamic Fatigue $\ldots \ldots \ldots \ldots \ldots \ldots \ldots \ldots \ldots \ldots \ldots$

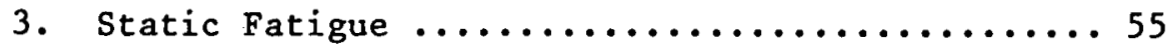

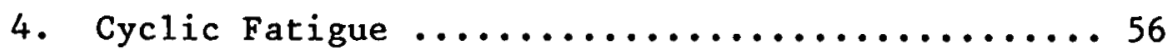

5. Compressive Test with Displacement Determination 56

6. Torsion Test with Displacement Determination ...61

7. Volume/Strength Relationship ............61 61

8. Fracture Toughness ....................62

9. Double Torsion ......................662

10. High Temperature/High Humidity Cycling .......66 63

11. Freeze/Thaw Cycling .................663

D. Test Procedure and Results .................6 64

1. Tensile Strength ..................... 64

2. Elastic Modulus .....................67

3. Stress Corrosion Constant ..............67 
4. Static Fatigue $\ldots \ldots \ldots \ldots \ldots \ldots \ldots \ldots \ldots \ldots \ldots \ldots \ldots \ldots \ldots \ldots$

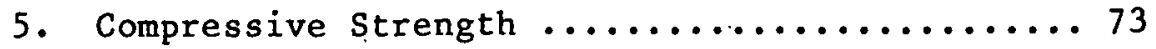

6. Volume/Strength Relationship ............ 73

7. Double Torsion ...................... 78

8. Freeze/Thaw Cycling $\ldots \ldots \ldots \ldots \ldots \ldots \ldots \ldots \ldots$

E. Discussion $\ldots \ldots \ldots \ldots \ldots \ldots \ldots \ldots \ldots \ldots \ldots \ldots \ldots \ldots \ldots \ldots \ldots$

VI. Conclusions $\ldots \ldots \ldots \ldots \ldots \ldots \ldots \ldots \ldots \ldots \ldots \ldots \ldots \ldots . \ldots \ldots$

VII. References $\ldots \ldots \ldots \ldots \ldots \ldots \ldots \ldots \ldots \ldots \ldots \ldots \ldots \ldots \ldots \ldots$ 
1. Mirrored Cellular Glass Panel $\ldots \ldots \ldots \ldots \ldots \ldots \ldots \ldots \ldots, 4$

2. The Three-Point Flexural strength of Aluminoborosi1icate Foamsi1-70ß Cellular Glass as a Function of

Density .................................... 19

3. The Elastic Modulus of Aluminoborosilicate

Foamsil-70 Cellular Glass as a Function of

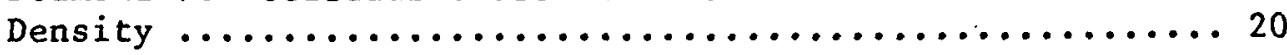

4. Failure Probability of Soda Lime Silicate Insulating

Grade Cellular Glass as a Function of Stress .......... 36

5. Failure Probability as a Function of Time for Soda

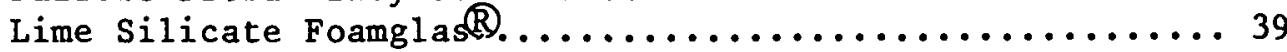

6. An Illustration of the Development of Design

Philosophy ................................ 41

7. The Influence of Design Philosophy on the Total

Life Cycle Cost ........................... 42

8. Scanning Electron Micrograph of (a) Closed Ce11

Aluminoborosilicate and (b) Open Cell Soda Lime

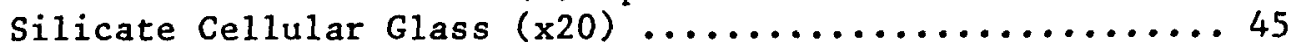

9. Pores in Cell Walls of (a) Aluminoborosilicate and

(b) Soda Lime Silicate Cellular Glass (x1000) .........4 47

10. Cells Formed at the Intersection of Several

Larger Cells $(x 100) \ldots \ldots \ldots \ldots \ldots \ldots \ldots \ldots \ldots \ldots \ldots \ldots$

11. Particles on and Embedded in the Walls of Open

Cell Soda Lime Silicate Cellular Glass $(x 1000) \ldots \ldots \ldots .48$

12. Density Variation of Three Blocks of

Aluminoborosilicate Cellular Glass ...............4 49

13. Four-Point Bend Test Configuration $\ldots \ldots \ldots \ldots \ldots \ldots \ldots \ldots$

14. Determination of the Stress Corrosion Constant $n$,

Under Dynamic Fatigue Utilizing Weakest Link

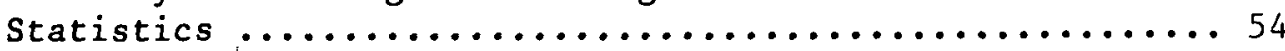

15. Static Fatigue Design Criteria .................. 57

16. Failure Probability as a Function of Time

Under Static Fatigue ...................... 57

17. Uniaxial Compression Specimen $\ldots \ldots \ldots \ldots \ldots \ldots \ldots \ldots \ldots$

18. Redesigned Uniaxial Compression Specimen ............. 60 
19. Four-Point Bend Specimen to Block Orientation ........ 64

20. Four-Point Bend Test Fixture With Failed Specimens ......65

21. Stressing Rate Effect on the Tensile Strength of

Several Cellular Glass Materials ................ 70

22. The Stress Corrosion Constant as a Function of

Failure Probability ....................... 71

23. Failure Time as a Function of Applied

Static Stress for Soda Lime Silicate Foamglas $\$ . . \ldots \ldots 72$

24. Static Fatigue Design Criteria for Soda Lime

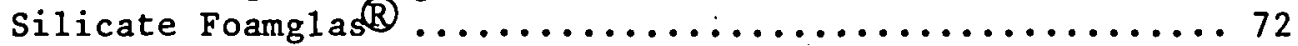

25. Compression Test Fixture With Failed Specimen ......... 74

26. Intermediate Size Four-Point Bend Test Fixture

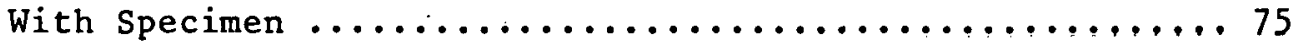

27. Large Size Four-Point Bend Test Fixture With Specimen .... 76

28. Strength to Volume Effect for Soda Lime Silicate

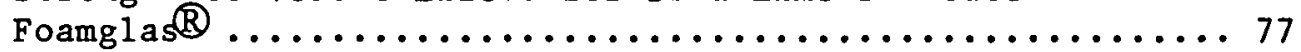

29. Double Torsion Test Fixture and Failed Specimen ........ 79

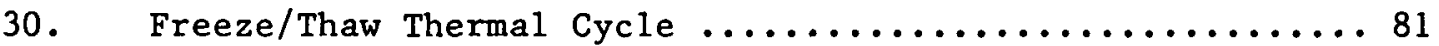

31. Tensile Strength of Several Cellular Glass

Materials as a Function of Density and Orientation ..... 82

32. Elastic Modulus in Bending of Several Cellular

Glass Materials as a Function of Density

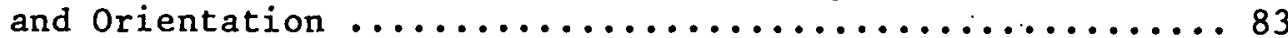


1. Comparison of Structural Efficiency of Candidate Panel

Materials ...............................10, 11

2. Structural Efficiency of Cellular Glass Material

as Compared to Structural steel $\ldots \ldots \ldots \ldots \ldots \ldots \ldots \ldots$

3. Figure-of-Merit for Several Materials in a Slab or

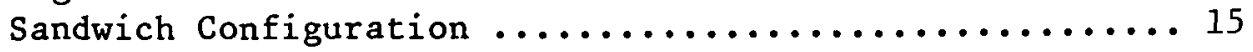

4. Influence of Chemistry, Density and Microstructure on the Properties and Fabrication of Cellular Glass .... 21

5. Properties of Commercially Available Cellular Glass .... 22

6. Properties of Aluminoborosilicate Foamsil-70ß

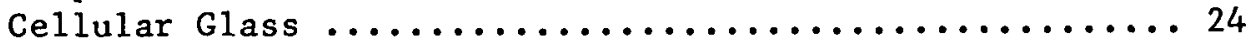

7. Properties of Solaramics' Prototype Soda Lime Silicate

Cellular Glass ............................ 24

8. Density Variation $\ldots \ldots \ldots \ldots \ldots \ldots \ldots \ldots \ldots \ldots \ldots$

9. Tensile Strength of Several Cellular Glass Materials ... 66

10. Elastic Modulus of Several Cellular Glass Materials

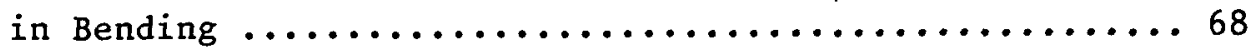

11. Stress Corrosion Constant for Several Cellular

Glass Materials ..........................69 69

12. Failure Time at a Static Stress for Soda Lime Silicate

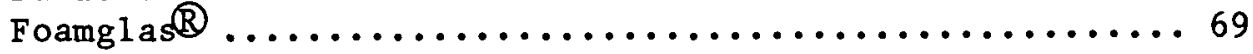

13. Compressive Strength of Soda Lime Silicate Foamglas

at Two Stressing Rates ........................ 73

14. The Tensile Strength of Soda Lime Silicate Foamglas as a Function of the Stressed Surface Area ......... 77

15. Results of Freeze/Thaw Environmental Testing on Several Cellular Glass Materials .................... 80

16. Results of Strength Measurements on Coated Soda Lime Silicate Foamglas After Environmental Freeze/Thaw Testing 


\section{INTRODUCTION}

Efforts to develop alternative energy sources which can be economically competitive with coal, oil, natural gas, or nuclear power systems have led to active investigation, invention and rapid development in the field of solar energy technology. A prime concern for all solar energy systems, including the JPL program for development of point focus, distributed receiver solar thermal power systems, in the intermediate and far-term energy market place, is one of total system installed cost, maintenance and long term high performance, affecting cost effectiveness. The relatively high projected costs for solar energy are a result of the initial high capital investment in the required equipment and, to an unknown extent, the operating and maintenance costs. The cost/performance ratio over the operating lifetime of such systems is of primary concern; data on which to make predictions are scarce to nonexistent. It is clear that substantial cost reductions for solar energy systems can be realized by the application of low cost/high performance structural materials coupled with a method for low cost mass production manufacturing techniques which yield precision reflector systems. The paraboloidal solar concentrators required for point-focusing solar thermal power systems are of major concern since they can represent $50 \%$ of the total system's cost. One design tradeoff is whether to use lower cost, lower performance concentrators or high cost, higher performance ones. The JPL designs utilizing cellular glass material are targeted to be high performance while falling in the moderate cost range.

Another prime concern is environmental, lending weight to low toxicity and low overall energy manufacturing/use/decay cycles. The raw materials are abundant and noncritical. If high lifetime and maintainability values are also achieved, the benefits to the environment of the inherently clean solar concept can be realized with means which are not contradictory to the conceptual advantages.

An activity to determine candidate, low cost structural materials for the mirror support in point focusing distributed systems was undertaken at JPL. Cellular glass, which is a low density, foamed, 
inorganic glass was selected as an attractive candidate for the mirrored panel structural application due to its low cost, high stiffness-toweight ratio, thermal expansion coefficient which can be made to match the mirror glass, and chemical and dimensional stability. Environmentally, the material and its manufacture can be classified among the most benign options, being nearly inert and possibly subject to recycling at both ends of its use cycle. An ongoing activity to determine the state of the art of cellular glass technology and to characterize the mechanical and environmental properties of several cellular glass materials is under way.

The purpose of this interim report is to disseminate the current, preliminary information which has been obtained during the initial phase of the structural cellular glass development activity at JPL, which is a part of the Advanced Solar Thermal Technology Project which supports the DOE Advanced Technology Subprogram. This study is directed at exploring the feasibility of using cellular glass as the structural mirror support material for point focusing, paraboloidal concentrators. This report presents the results of a low cost structural material survey which identified cellular glass as a prime candidate for such applications, outlines the present state of the art of cellular glass technology, and presents preliminary test results on the mechanical and environmental properties of several cellular glass materials which are judged to be serious candidates for mirror panel applications. For completeness, material property data supplied by cellular glass manufacturers is also included. The advantages and disadvantages of using cellular glass as a load bearing material for solar thermal power system applications are also addressed.

There are currently two domestic suppliers of cellular glass materials: Pittsburgh Corning Corporation (PCC), P1tisburgh, $\mathrm{Pa}$. and Solaramics, Inc., El Segundo, Ca. PCC has, for over 35 years, supplied cellular glasses in large volume (currently $10^{8} \mathrm{bd}-\mathrm{ft.} / \mathrm{yr}$. ) primarily to the self supported insulation market but also for a variety of other 
applications in smaller volumes. Their principal product has been Foamglas, an $8.51 \mathrm{~b} / \mathrm{ft}^{3}$, soda lime, silicate glass material which is produced in a few locations by large scale manufacturing processes.

More recently PCC has been augmenting their product line with a series of new glass compositions and densities including Foams $\mathbb{R}_{12}$, 23, 35 and, under contract to JPL, an aluminoborosilicate structural cellular glass which can be made with a thermal expansion coefficient that can range from 60 to $90 \times 10^{-7} /{ }^{\circ} \mathrm{C}$ and which can be produced in various densities. There is potentially a wide range of insulating and other applications for these products. Solaramics is a small business. which has been developing soda lime silicate cellular glasses over approximately the past five years. Their production capability at present is small, essentially that of a pilot plant. They are not, at present, supplying cellular glass commercially in volume. Solaramics also is heavily involved in the development of heliostats for solar thermal power systems and their cellular glass development program is targeted specifically at developing a low cost, high performance structural cellular glass mate-ial which can be fabricated at low cost into the required shapes. Other than government funded work at universities (e.g., I.B. Cutler, Ref. 1) no other organizations are known to be currently involved in developing or supplying cellular glass.

The present evaluation program at JPL is specifically aimed at: a) identifying the critical material properties required of cellular glass materials for their successful application to point-focusing, distributed power converter system, mirror panel applications; and, b) evaluating these properties for selected current production and developmental materials to determine how well each qualifies for these applications. By October 1979, design data will be available for the candidate cellular glasses. This data will still be preliminary in the sense that commercialization of this material technology will require statistical design data to be developed on the mass producej material, not the laboratory or pilot plant produced material which is being 
investigated this fiscal year. Judging from the uniformity in properties (small dispersion in values) observed in the High Load Bearing (HLB) Foamglas material which is produced in large volume by $P C C$, it is expected that the design allowables for a mass produced material will be greater than those determined for the developmental material, if adequate quality control of manufactured parts is realized.

The use of cellular glass plates as the structural backing for silvered glass mirrors (for example, see Figure 1), requires that the material function in a variety of environments. Careful consideration must be given to all mechanical and environmental stresses to which the material will be subjected. These stresses include gravity forces, wind loads, particle impact, and temperature and humidity cycling, which can involve coincident humidity and temperature extremes and temperature excursions through the freezing point of water, with or without puddled water present. To withstand these stresses and maintain an acceptably low failure rate the cellular glass must exhibit minimal values of several

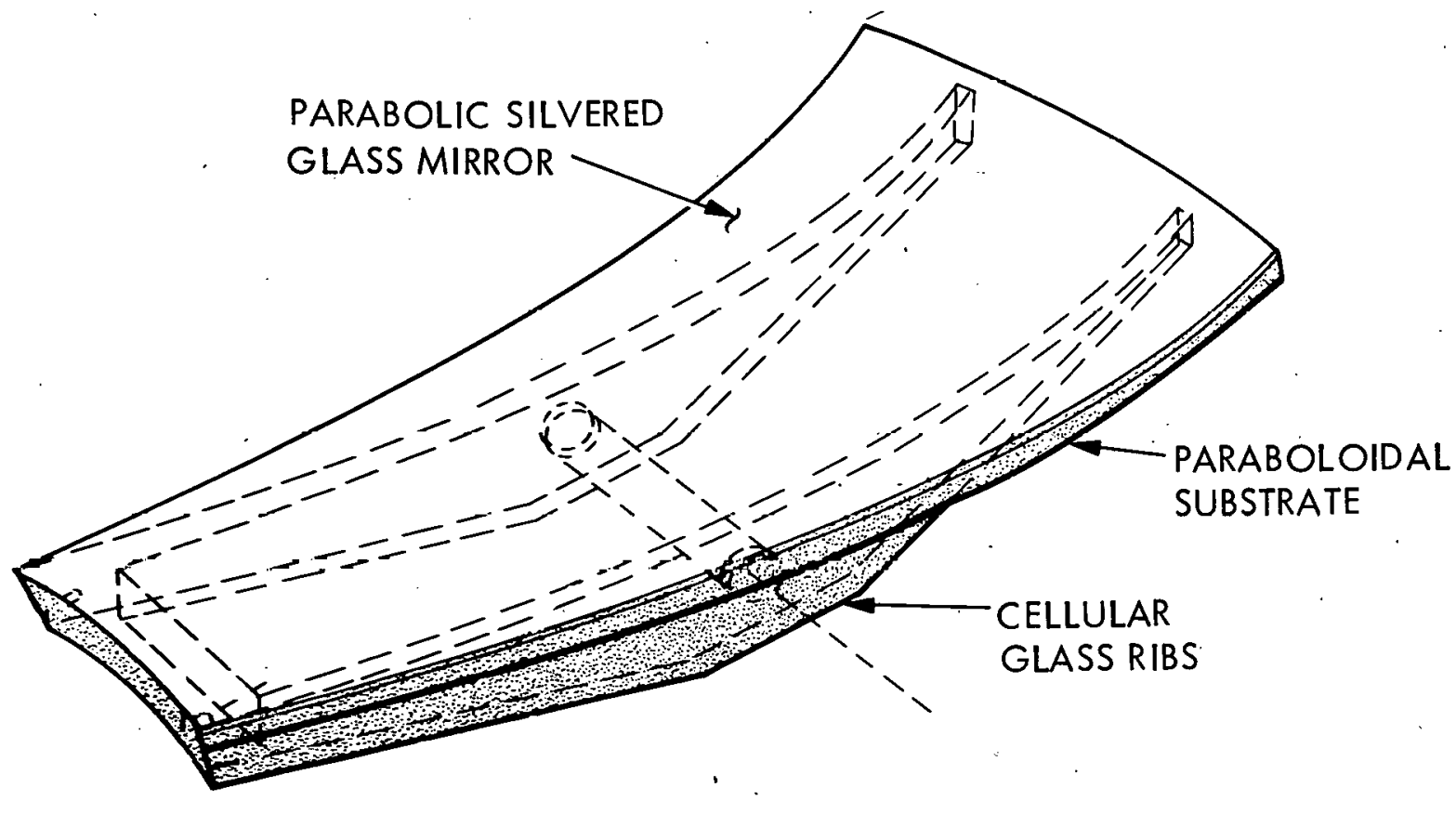

Figure 1. Mirrored Cellular Glass Panel 
critical properties. These properties are identified in the body of the report and an appropriate experimental program to evaluate the properties for the selected group of cellular glasses is described. Most of the properties have not as yet been adequately characterized; this is to be done during the course of the program as resources become available. To date much of the effort has been spent identifying the current state of the art and its limitations, developing testing techniques for evaluating the materials, and in developing a design philosophy for using the material in a structural application. New cellular glass compositions, microstructures, and methods of fabrication, all of which are planned under JPL programs, will not be described in detail in this report. 
THIS PAGE

\section{WAS INTENTIONALLY LEFT BLANK}


Materials utilized as mirrored panel substrates must provide stiffness adequate to maintain the mirror surfaces within tolerance and strength necessary to ensure survival under wind loading and during handling. In addition, a match in the coefficient of thermal expansion between the substrate and the mirror element is desirable to minimize thermal stresses as well as thermal distortion. Depending on whether driven mirror weight or wind load forces are design critical, reduced weight of the mirror panel configuration can lead to a reduction in the size and cost of the support structure as well as the drive mechanism.

A study was conducted to determine candidate materials which satisfied the aforementioned structural requirements. Metals, ceramics, molded plastics, forest products, and plastic laminates were evaluated. A technique was developed to compare the structural efficiency between materials as to strength, stiffness, weight and cost criteria (assuming they were used as a simply supported flat plate). Ribbed panels, or plates with dense face skins and low density cores can greatly increase the structural efficiency of cellulated (foam) materials but are not treated here due to the large number of design options available.

The stiffness of the mirror support structure is a function of the component thickness and the modulus of elasticity for the material:

$$
\delta \equiv E t^{3}
$$

$$
\text { where } \begin{aligned}
\delta & =\text { bending stiffness coefficient } \\
t & =\text { thickness } \\
E & =\text { modulus of elasticity }
\end{aligned}
$$


The load bearing ability of the structure is a function of the component thickness and the material strength:

$$
S=\sigma t^{2}
$$

where $S$ = bending strength coefficient

$$
\sigma=\text { tensile strength }
$$

$A$ relative cost and weight comparison between any two materials, $A$ and $B$, for the same structural stiffness $\left({ }_{A}={ }_{B}\right)$ and strength $\left(S_{A}=S_{B}\right)$

can be determined. By definition the relative stiffness-to-cost ratio is:

$$
C_{R \delta} \equiv\left(\frac{E_{A}}{E_{B}}\right)^{1 / 3} \cdot \frac{C_{B}}{C_{A}}
$$

where

$$
\begin{aligned}
& \mathrm{C}_{\mathrm{R}}=\text { relative stiffness/cost ratio } \\
& \mathrm{E}_{\mathrm{A}}=\text { elastic modulus of material } \mathrm{A} \\
& \mathrm{E}_{\mathrm{B}}=\text { elastic modulus of material } \mathrm{B} \\
& \mathrm{C}_{\mathrm{A}}=\text { cost/volume of material } \mathrm{A} \\
& \mathrm{C}_{\mathrm{B}}=\text { cost/volume of material } \mathrm{B}
\end{aligned}
$$

The relative strength-to-cost ratio is defined as:

$$
C_{R S} \equiv\left(\frac{\sigma_{A}}{\sigma_{B}}\right)^{1 / 2} \frac{C_{B}}{C_{A}}
$$

where $C_{R S}=$ relative strength/cost ratio

$\sigma_{A}=$ strength of material $A$

$\sigma_{\mathrm{B}}=$ strength of material $\mathrm{B}$

The relative stiffness-to-weight ratio is

$$
\mathrm{W}_{\mathrm{R} \delta} \equiv\left(\frac{\mathrm{E}_{\mathrm{A}}}{\mathrm{E}_{\mathrm{B}}}\right)^{1 / 3} \frac{\rho_{\mathrm{B}}}{\rho_{\mathrm{A}}}
$$

and the relative strength-to-weight ratio is

$$
W_{\mathrm{RS}} \equiv\left(\frac{\sigma_{\mathrm{A}}}{\sigma_{\mathrm{B}}}\right)^{1 / 2} \frac{\rho_{\mathrm{B}}}{\rho_{\mathrm{A}}}
$$


where

$$
\begin{aligned}
& \mathrm{W}_{\mathrm{R} \delta}=\text { relative stiffness/weight ratio } \\
& \mathrm{W}_{\mathrm{RS}}=\text { relative strength/weight ratio } \\
& \rho_{A}=\text { density of material } \mathrm{A} \\
& \rho_{B}=\text { density of material } \mathrm{B}
\end{aligned}
$$

This technique was used to compare the relative structural efficiency of various materials with fixed plane geometry under uniform bending loads and deflections.

A comparison of the relative structural efficiency of various materials with respect to a standard reference material (1020 low carbon stee1) is presented in Table 1. As illustrated in the table, the analyses show that soda lime silicate cellular glass and forest products have the best structural efficiency. However the environmental stability of wood products under the field operating conditions of the solar thermal systems is marginal.

Cellulated polymer materials offer stiffness and strength with reduced weight; however, these materials demonstrate a sensitivity to water penetration and absorption (Ref. 2). McDonnell Douglas Astronautics Company utilized a styrofoam core sandwiched between a mirrored glass reflector and galvanized steel for their heliostat panel design. This reflector panel assembly failed due to the absorption of large amounts of water into the styrofoam.

Second surface silvered glass has demonstrated the highest performance of all candidate mirror systems for solar concentrators. The coefficient of thermal expansion of cellular glass materials can be tailored to match that of the desired mirror glass over the temperature range of interest. A matched thermal expansion coefficient for the mirror and substrate will minimize or eliminate thermal stress and thermal distortion. 
Table 1. Comparison of Structural Efficiency of Candidate Panel Materials

\begin{tabular}{|c|c|c|c|c|c|c|c|c|c|c|c|}
\hline \multirow[b]{2}{*}{ Materi I I } & \multirow[b]{2}{*}{$\begin{array}{c}\operatorname{cost} \\
s / \mathrm{ft}^{3}\end{array}$} & \multirow[b]{2}{*}{$\begin{array}{l}\text { Density } \\
1 \mathrm{~b} / \mathrm{in}^{3}\end{array}$} & \multirow{2}{*}{$\begin{array}{c}\text { MOD of } \\
\text { Elasticity } \\
10^{6} \mathrm{psi}\end{array}$} & \multirow{2}{*}{$\begin{array}{l}\text { Flexural } \\
\text { Strungth } \\
10^{3} \mathrm{psi}\end{array}$} & \multirow{2}{*}{$\begin{array}{l}\text { Coef of } \\
\text { Ther Exp } \\
10^{-5}, f^{\circ} \text { r }\end{array}$} & \multirow{2}{*}{$\begin{array}{l}\text { Specific } \\
\text { Stiffness } \\
10^{6} \mathrm{in.}\end{array}$} & \multirow{2}{*}{$\begin{array}{l}\text { Specific } \\
\text { Strength } \\
=0^{3} \text { in. }\end{array}$} & \multicolumn{2}{|c|}{ Bend Stiffness } & \multicolumn{2}{|c|}{ Bend Strength } \\
\hline & & & & & & & & 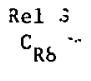 & $\begin{array}{l}\text { Rel Wt. } \\
W_{\mathrm{R} \delta}\end{array}$ & $\begin{array}{l}\operatorname{Re1} s \\
C_{\mathrm{RS}}\end{array}$ & $\begin{array}{l}\text { Rel Wr. } \\
W_{\text {RS }}\end{array}$ \\
\hline Metalミ & & & & & & & & & & & \\
\hline Aluninum, 3003 & 133 & 0.099 & 10 & $27^{1}$ & 1.29 & 101 & 273 & 2.23 & 0.50 & 2.06 & 0.47 \\
\hline 1020 Steel & 86 & 0.283 & 30 & $48^{1}$ & 0.84 . & 106 & 170 & 1 & 1 & 1 & 1 \\
\hline$\underline{\text { Ceramizs }}$ & & & & & & & & & & & \\
\hline Concrete & 1.38 & 0.09 & 3. 5 & 0.59 & 0.6 & 39 & 6.6 & .0 .03 & 0.65 & 0.14 & 2.87 \\
\hline Borosilinate cell-1ar glass & 30.60 & 0.007 & 0.18 & $0.1=$ & 0.16 & 26 & 16 & 1.95 & 0.14 & 7.43 & 0.52 \\
\hline $\begin{array}{l}\text { Soda lime silicats cellular } \\
\text { glass }\end{array}$ & 3.72 & 0.005 & 0.15 & 0.08 & 0.46 & 30 & 16 & 0.25 & 0.10 & 1.06 & 0.43 \\
\hline Soda lime glass & 3.90 & 0.089 & $10 . \hat{z}$ & 13 & 0.52 & 115 & 146 & 0.05 & 0.45 & 0.09 & 0.60 \\
\hline Corning's 0317 fusion glass & 50 & 0.088 & 10 & $\sim 13$ & 0.48 & 114 & 148 & $0.8 ;$ & 0.45 & 1.12 & 0.60 \\
\hline Forest Probucts & & & & & & & & & & & \\
\hline Plywood & 8 & 0.022 & 1.0 & 12 & - & 45 & 545 & 0.27 & 0.24 & 0.19 & 0.16 \\
\hline Hardboard & 7 & 0.032 & 1.0 & 12 & - & 31 & 375 & 0.25 & 0.35 & 0.16 & 0.23 \\
\hline Paperboard & $\cdot 12$ & 0.028 & 0.62 & 16.5 & - & 22 & 589 & 0.51 & 0.36 & 0.24 & 0.17 \\
\hline Chipboard & 6 & 0.031 & 0.5 & 5 & - & 16 & 161 & 0.27 & 0.43 & 0.22 & 0.34 \\
\hline Dense Molded Plastics & & & & & & & & & & & \\
\hline Ethylcellulose & 55 & 0.041 & 0.3 & 8 & 6.9 & 7.3 & 195 & 2.97 & 0.67 & 1.57 & 0.35 \\
\hline Cellulose acetate propionate-1 & 70 & 0.044 & 0.2 & 7 & 7.8 & 4.5 & 159 & 4.32 & 0.83 & 2.13 & 0.41 \\
\hline $\begin{array}{l}\text { Polypropylenc, gless } \\
\text { reinforced }\end{array}$ & 41 & 0.041 & 0.6 & 8 & 2.0 & 15 & 195 & 1.76 & 0.53 & 1.17 & 0.35 \\
\hline PVC, acetate & 26 & 0.052 & 0.4 & 13 & 3.0 & 7.7 & 250 & 1.27 & 0.77 & 0.58 & 0.35 \\
\hline
\end{tabular}

$1_{\text {Tensile yield }}$ 
Table 1. Comparison of Structural Efficiency of Candidate Panel Materials (Continuation 1)

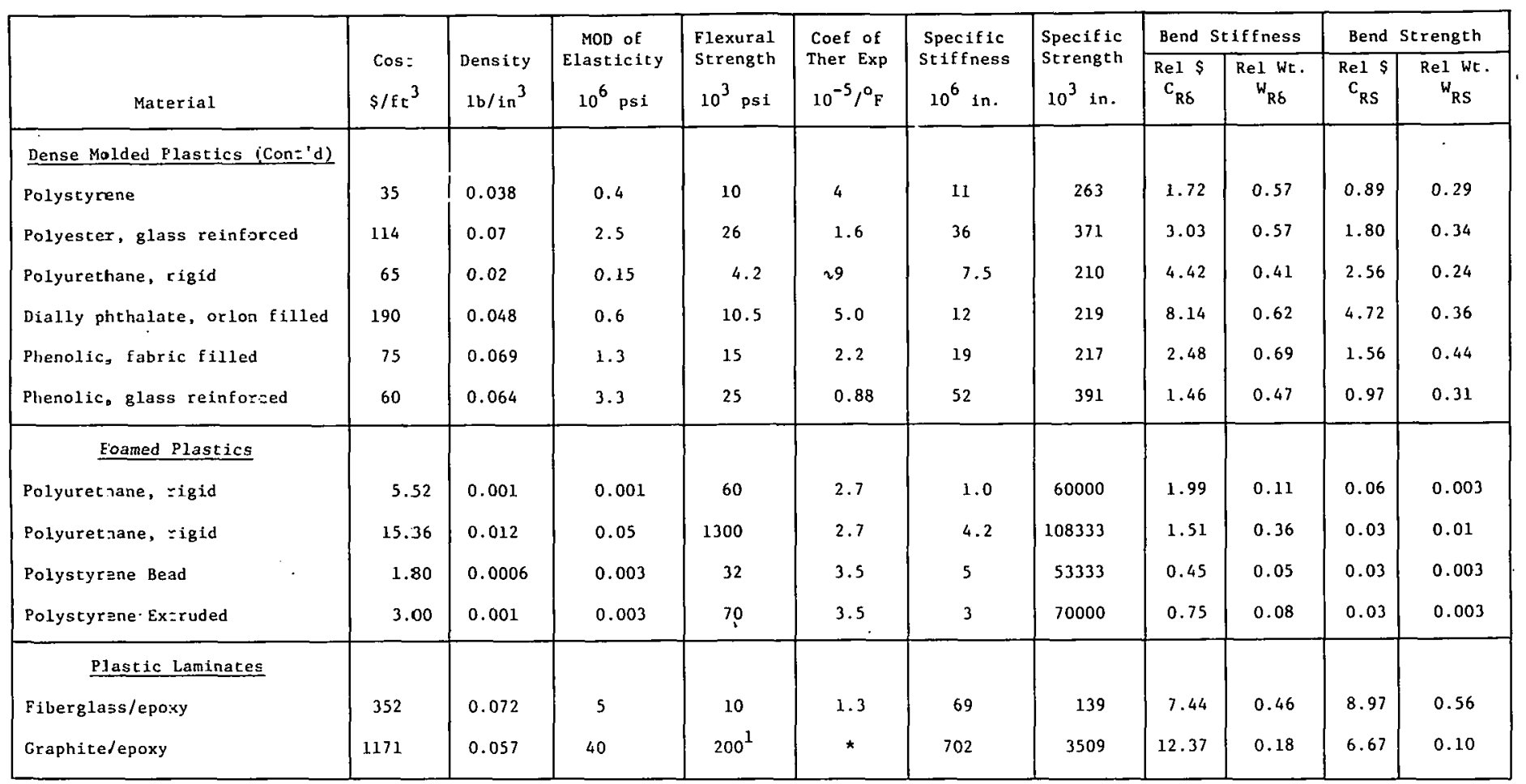

$1_{\text {Tensile yield }}$

${ }^{*}$ Can be zailored to the application requirements 
A comparison of the structural efficiency between low carbon steel and several cellular glass materials is presented in Table 2 . In its present form, the structural efficiency of Foamglas, which is the only mass produced cellular glass on the market, is excellent when compared to structural steel.

An analytical tool was formulated at Sandia Albuquerque whereby material and structural properties could be separated resulting in a "figure-of-merit" ranking for reflector structure candidate materials (Ref. 3). The formulation is given as

$$
\frac{E}{\rho^{3}\left(1-v^{2}\right)} \stackrel{12 D}{=}=A
$$

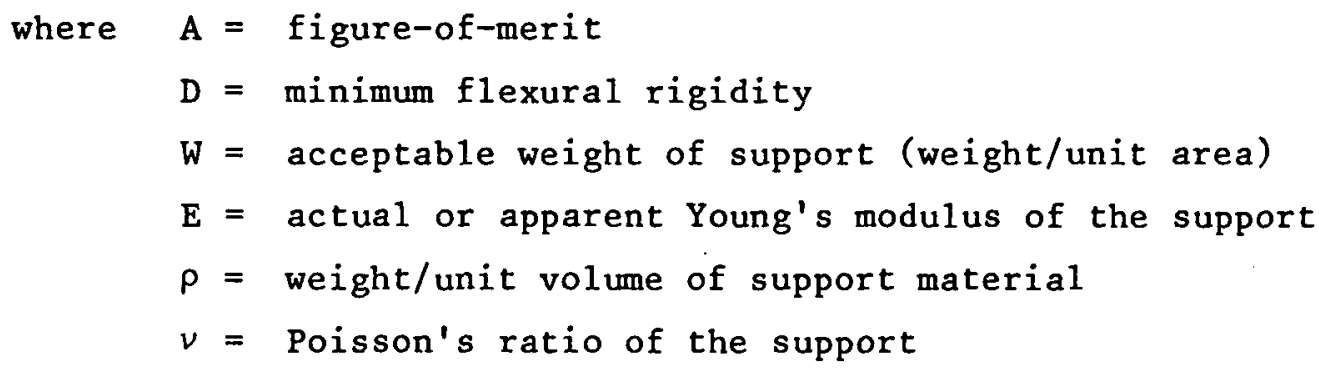

This allows the material properties (elastic modulus, density, and Poisson's ratio) to be compared to the required structural design parameters (minimum flexural rigidity and minimum acceptable weight). The figure-of-merit of several materials in a slab configuration and in a sandwich configuration is presented in Table 3 .

Based on work as reported to date by Sandia Albuquerque on their prototype advanced trough, a reasonable value of $D$ is $0.5 \times 10^{6} 1 \mathrm{~b} . / \mathrm{in}$. and a desirable value of $\mathrm{W}$ is approximately $.021 \mathrm{lb} . / \mathrm{in}^{2}{ }^{2}$, giving a minimum value of $A=6.64 \times 10^{11} \mathrm{in.} 7 / 1 \mathrm{~b} .^{2}$. Foamglas $\mathbb{R}$ is the 
Table 2. Structural Efficiency of Cellular Glass Material as Compared to Structural Steel

\begin{tabular}{|c|c|c|c|c|c|c|c|c|c|c|}
\hline \multirow[b]{2}{*}{ Material } & \multirow[b]{2}{*}{$\begin{array}{c}\operatorname{Cost} \\
{\left[\$ / \mathrm{ft}^{3}\right]}\end{array}$} & \multirow[b]{2}{*}{$\begin{array}{l}\text { Density } p \\
{\left[1 \mathrm{bs} / \mathrm{ft}^{3}\right]}\end{array}$} & \multirow[b]{2}{*}{ 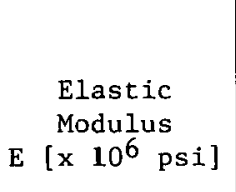 } & \multirow[b]{2}{*}{$\begin{array}{c}\text { Flexura1 } \\
\text { Strength } \\
\sigma:[\text { psi] }\end{array}$} & \multirow{2}{*}{$\begin{array}{c}\text { Specific } \\
\text { Stiffness } \\
\text { E } / \rho\left[\begin{array}{lll}\mathrm{x} & 10^{8} & \text { in. }]\end{array}\right.\end{array}$} & \multirow[b]{2}{*}{ 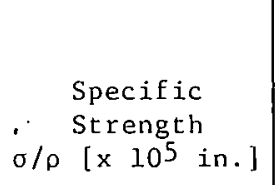 } & \multicolumn{2}{|c|}{$\begin{array}{l}\text { Bend Stiffness } \\
\text { Criteria }\end{array}$} & \multicolumn{2}{|c|}{$\begin{array}{l}\text { Bend Strength } \\
\text { Criteria }\end{array}$} \\
\hline & & & & & & & $\begin{array}{l}\text { Relative } \\
\text { Cost }\end{array}$ & $\begin{array}{l}\text { Relative } \\
\text { Weight }\end{array}$ & $\begin{array}{l}\text { Relative } \\
\text { Cost }\end{array}$ & $\begin{array}{l}\text { Relative } \\
\text { Weight }\end{array}$ \\
\hline $\begin{array}{l}1020 \\
\text { Structural } \\
\text { Steel }\end{array}$ & 86 & 489 & 30 & $48 \times 10^{3}$ & 1.06 & 1.70 & 1.00 & 1.00 & 1.00 & 1.00 \\
\hline Foamg1as @ & 3.72 & 8.5 & 0.15 & 80 & 0.30 & 0.16 & 0.25 & 0.10 & 1.06 & 0.43 \\
\hline $\begin{array}{l}\text { Foamsil-70 } \mathbb{R} \\
\text { (Predicted } \\
\text { Values) }\end{array}$ & $3.72 \star$ & 12.0 & 0.24 & 120 & 0.35 & 0.12 & 0.22 & 0.12 & 0.87 & 0.49 \\
\hline $\begin{array}{l}\text { Solaramic's } \\
\text { Soda Lime }\end{array}$ & $2.01 t$ & 15.6 & 0.19 & 125 & 0.21 & 0.14 & 0.13 & 0.17 & 0.46 & 0.63 \\
\hline $\begin{array}{l}\text { Silicate } \\
\text { (Predicted }\end{array}$ & $2.13+$ & 21.8 & 0.28 & 215 & 0.22 & 0.17 & 0.12 & 0.21 & 0.37 & 0.67 \\
\hline Values) & $2.34 t$ & 32.8 & 0.48 & 430 & 0.25 & 0.23 & 0.11 & 0.27 & 0.29 & 0.71 \\
\hline
\end{tabular}

* 25 million board feet minimum, density not to exceed $12 \mathrm{lbs} / \mathrm{ft}^{3}$

${ }^{\dagger} 20$ million board feet per year 
only material which satisfies this design requirement as illustrated in Table 3 in slab form while the other materials surveyed must be utilized in sandwich or ribbed configurations. 
Table 3. Figure-o=-Merit for Several Materials in a Slab or Sandwich Configuration

\begin{tabular}{|c|c|c|c|c|c|c|c|}
\hline Material & Configuration & $\begin{array}{l}\text { Density } \\
\left(1 \mathrm{~b} / \text { in }^{3}\right)\end{array}$ & $\begin{array}{c}\text { Elastic } \\
\text { Modulus } \\
\text { (x } 10^{6} \text { psi) }\end{array}$ & $\begin{array}{c}\text { Poisson's } \\
\text { Ratio }\end{array}$ & $\begin{array}{c}\text { Weight } \\
\text { Area } \\
\left(1 \mathrm{~b} / \mathrm{in}^{2}\right)\end{array}$ & $\begin{array}{l}\text { Flexural } \\
\text { Rigidity } \\
\text { (lb-in.) }\end{array}$ & $\begin{array}{c}\text { Figure of } \\
\text { Merit } \\
\left(i^{7} / 1 b^{2}\right)\end{array}$ \\
\hline Aluminum & Slab & 0.099 & 10 & 0.33 & - & - & $1.2 \times 10^{10}$ \\
\hline Foamglas $\mathbb{R}$ & Slab & 0.005 & 0.15 & $0.21 *$ & - & - & $8.4 \times 10^{12}$ \\
\hline Plywood & Slab & 0.022 & 1.0 & 0.30 & - & - & $1.0 \times 10^{8}$ \\
\hline Steel & Slab & 0.283 & 30 & 0.30 & - & - & $1.5 \times 10^{9}$ \\
\hline $\begin{array}{l}\text { Aluminum/ } \\
\text { Aluminum** }\end{array}$ & Sandwich & - & - & - & $4.86 \times 10^{-3}$ & $0.5 \times 10^{6}$ & $5.2 \times 10^{13}$ \\
\hline $\begin{array}{l}\text { Steel/ } \\
\text { Aluminum**** }\end{array}$ & Sandwich & - & - & - & $4.65 \times 10^{-3}$ & $0.5 \times 10^{6}$ & $6.0 \times 10^{13}$ \\
\hline
\end{tabular}

\footnotetext{
*Assumed value
}

** Aluminum face sheet thickness of 0.008 inches with aluminum honeycomb core

$* * *$ Steel face sheet thickness of 0.003 inches with aluminum honeycomb core 
THIS PAGE

\section{WAS INTENTIONALLY LEFT BLANK}




\section{CURRENT CELLULAR GLASS TECHNOLOGY}

A. STATE OF THE ART

1. Material

The glass industry uses the convention of identifying a specific glass by the weight percent of the oxides present in the final glass chemistry. The identification of a cellular glass material is not only dependent upon the chemical composition of the glass which may contain residual amounts of the foaming agent but also on the pore gas chemistry, the material density, and the microstructure.

Cellular glass manufacturers do not identify their materials by specifying the glass chemistry; instead they code them by thermal expansion and gross glass chemistry. No institutional nomenclature has been developed as yet to identify these products in a uniform way. The cellular glass materials produced to date can be classified into generic families as soda lime silicate, borosilicate, and aluminoborosilicate. Pittsburgh Corning Corporation identifies their cellular glass materials under two registered trade names: Foamglas and Foamsi $\mathbb{R}$. The Foamsi trade name is followed by a two digit number which identifies the thermal expansion coefficient of the specific cellular glass material (e.g., Foamsil-28, $=28 \times 10^{-7} /{ }^{\circ} \mathrm{C}$ ). Solaramics simply calls their material soda lime silicate cellular glass.

The parameters which identify specific cellular glass materials also influence the properties of the material and its fabrication. The thermal expansion of the materials is dependent on the glass chemistry. The glass chemistry, pore gas chemistry, and density govern the thermal conductivity of the material. The resistivity of cellular glass materials to aqueous attack is a function of its chemical composition and 
microstructure (open or closed cell). The strength and elastic modulus of cellular glass materials increase with increasing density (see Figure 2 and 3 ). Open cell materials absorb large amounts of liquid while closed cell materials have demonstrated little or no absorption of moisture under ASTM test standards as long as freeze/thaw conditions are not encountered (Ref. 4). The anisotropic behavior of cellular glass materials relates to pore geometry which is influenced by fabrication techniques. The chemical composition of the material affects the achievable range of densities, the time/temperature profile needed to cellulate the material, the temperature range over which it may be plastically worked, the stress relief temperature, the elastic constants and the resistance to chemical attack. Materials with lnwer thermal conductivity require longer annealing cycles. The machinability including tolerance control, material removal rates and tool ware is sensitive to the material's density, composition and microstructure. Table 4 is presented to summarize the influence of chemistry, density and microstructure on the properties and fabrication of cellular glass materials.

Cellular glass materials have been developed primarily for thermal insulation applications. The development of material and its commercial availability have been determined almost solely by its use as a thermal insulation material. Two types of cellular glass are commercially available: (1) Foamglas, a soda lime silicate glass which is manufactured by Pittsburgh Corning Corporation in large volume for insulation applications, and (2) Foamsil-28(R), a borosilicate glass manufactured by (Pittsburgh Corning which is used in specialty applications where its higher cost is acceptable because of its increased corrosion resistance and/or lower thermal expansion. Two grades of Foamglas are available. These grades, Foamglas $\mathbb{R}$ Standard Insulation and Foamglas High-Load-Bearing Insulation, differ in regard to their compressive load bearing ability. Pittsburgh Corning reports that the guaranteed average compressive strength of High Load Bearing Insulation exceeds by $33 \%$ the compressive strength of standard Foamglas $\mathbb{R}$. 
Properties of the commercially available cellular glass materials as published by the manufacturer are presented in Table 5. In addition to the commercially available material, several prototype cellular glass materials are currently under development.

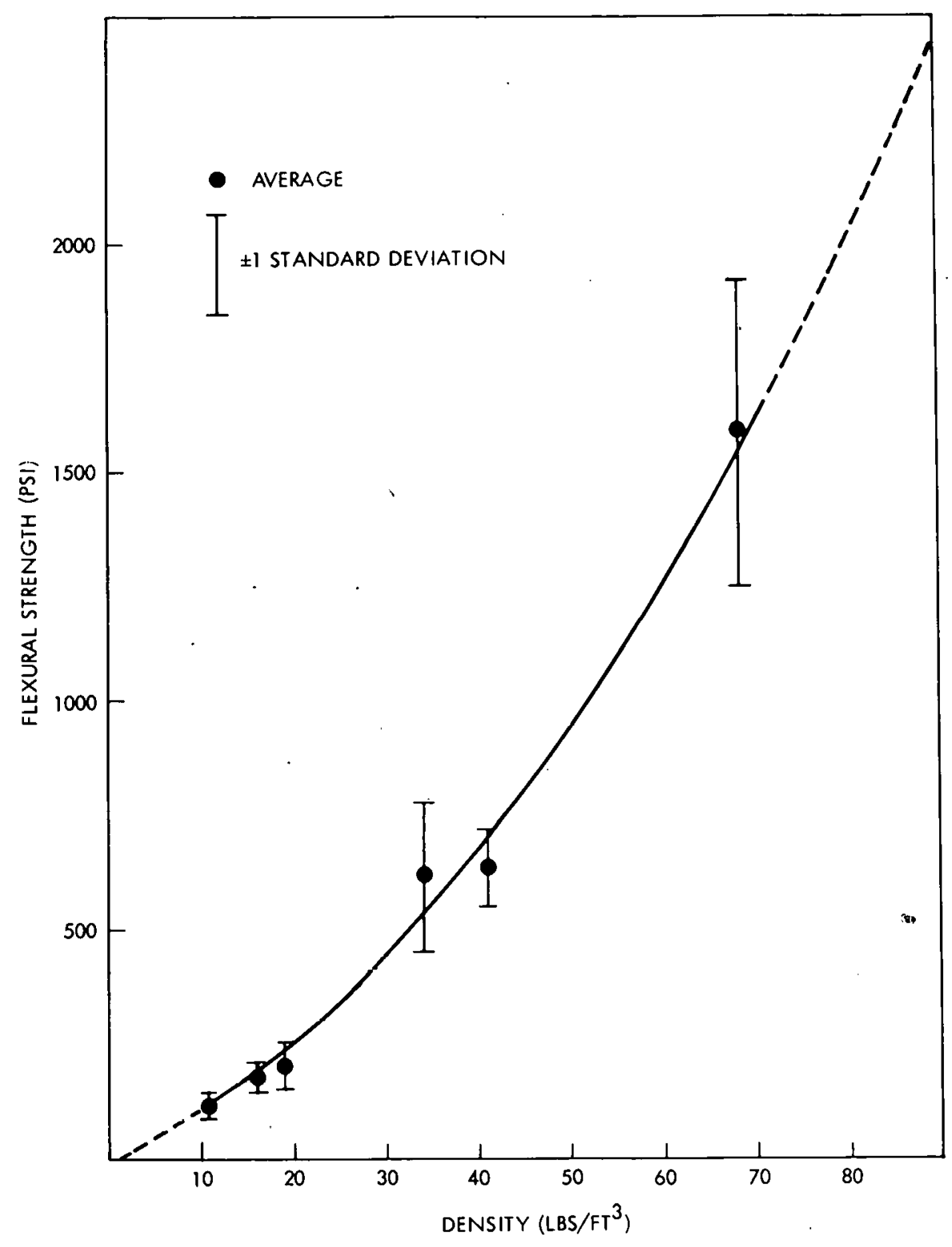

Figure 2. The Three-Point Flexural Strength of Aluminoborosilicate Foamsil-70@Cellular Glass as a Function of Density (Data Supplied by Pittsburgh Corning) 


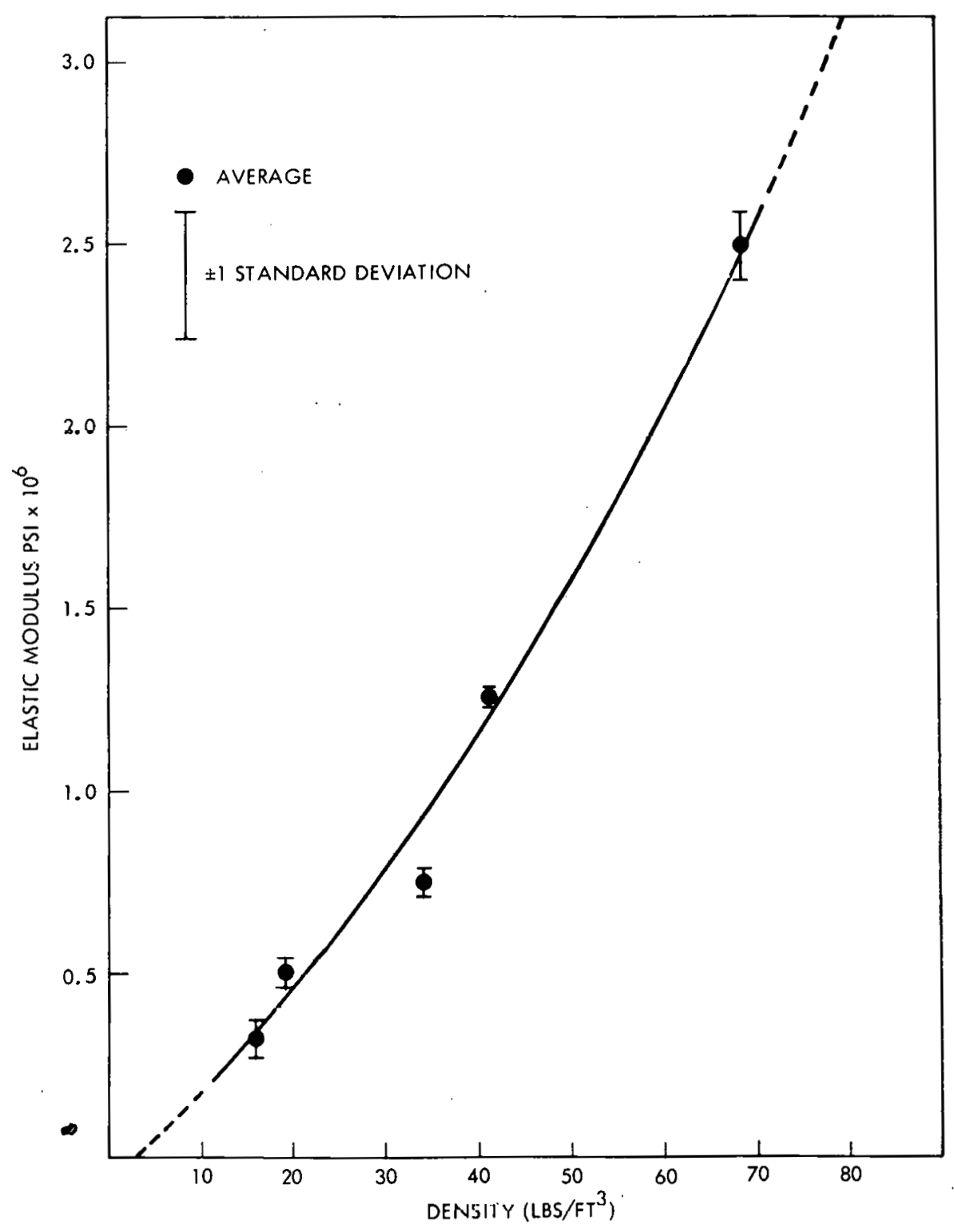

Figure 3. The Elastic Modulus of Aluminoborosilicate Foamsi1-70 Cellular Glass as a Function of Density (Data Supplied by Pittsburgh Corning) 
Table 4. Influence of Chemistry, Density and Microstructure on the Properties and Fabrication of Cellular Glass

\begin{tabular}{|c|c|c|c|c|c|c|c|c|c|c|}
\hline $\begin{array}{l}\text { Pore Gas } \\
\text { Chemical } \\
\text { Composition }\end{array}$ & NL & $\mathrm{NI}$ & $\mathrm{N}$ & $\mathrm{s}$ & $\mathrm{IU}$ & $\mathrm{NI}$ & NI & NI & $\mathrm{s}$ & NI \\
\hline Density & $\mathrm{s}$ & $s$ & $\mathrm{~N} \Sigma$ & $\mathrm{s}$ & $\mathrm{IU}$ & NI & NI & NI & $\mathrm{s}$ & s \\
\hline Microstructure & IU & s & $N \Sigma$ & $\mathrm{s}$ & IU & s & $\mathrm{s}$ & s & IU & IU \\
\hline
\end{tabular}
S - Sensitive
IU - Influence unknown
NI - No influence 
Table 5. Properties of Commercially Available Cellular Glass

\begin{tabular}{|c|c|c|c|c|c|c|c|c|}
\hline Material & $\begin{array}{l}\text { Density } \\
\left(1 \mathrm{l} / \mathrm{ft} \mathrm{t}^{3}\right)\end{array}$ & $\begin{array}{l}\text { Modulus of } \\
\text { Elasticity } \\
\text { (x } 10^{5} \text { psi) }\end{array}$ & $\begin{array}{l}\text { Average } \\
\text { Flexture } \\
\text { Strength } \\
\text { (psi)** }\end{array}$ & $\begin{array}{l}\text { Average } \\
\text { Compressive } \\
\text { Strength } \\
\text { (psi) }\end{array}$ & $\begin{array}{l}\text { Average } \\
\text { Shear } \\
\text { Strength } \\
\text { (psi) }\end{array}$ & $\begin{array}{l}\text { Coeff. of } \\
\text { Thermal } \\
\text { Expansion } \\
\left(\mathrm{x} 10^{-6} \text {;of }\right)\end{array}$ & $\begin{array}{c}\text { Dimensional } \\
\text { Stability }\end{array}$ & $\begin{array}{l}\text { Cost } \\
(\$ / \text { Board } \\
\text { Foot }) * * *\end{array}$ \\
\hline $\begin{array}{l}\text { Foamglas } \mathbb{R} \\
\text { (Standard) }\end{array}$ & 8.5 & 1.5 & 80 & $75 *$ & 50 & 4.6 & Excellent & 0.31 \\
\hline $\begin{array}{l}\text { Foamglas } \mathbb{R} \\
\text { (High Load } \\
\text { Bearing) }\end{array}$ & 8.5 & 1.5 & 80 & $100 *$ & 50 & 4.6 & Excellent & 0.34 \\
\hline Foamsi1-28 (B) & 12 & 1.8 & 110 & 210 & - & 1.6 & Excellent & 2.55 \\
\hline
\end{tabular}

*Guaranteed average compressive strength

***asured in Three Point Bend

$* * *$ In millions of joard feet 
Pittsburgh Corning Corporation is developing an aluminoborosilicate cellular glass which can be made in a wide range of densities (8-60 $\left.1 \mathrm{bs} / \mathrm{ft}^{3}\right)$. This material promises increased chemical resistance to water attack over that of conventional soda lime silicate materials. Its thermal expansion coefficient can be tailored between 50 and $100 \times 10^{-7} /{ }^{\circ} \mathrm{C}$. In addition, the material can be produced with large density variations within a given body. Blocks with a high density core $\left(491 \mathrm{bs} / \mathrm{ft}^{3}\right.$ ) and low density surfaces ( $151 \mathrm{bs} / \mathrm{ft}^{3}$ ) have been produced under laboratory conditions. Table 6 presents several properties of aluminoborosilicate cellular glass materials as reported by Pittsburgh Corning. Figure 2 illustrates the three point flexure strength as a function of material density and Figure 3 presents the Modulus of Elasticity in bending as a function of density.

Solaramics Incorporated has been developing a soda lime silicate cellular glass for structural applications. This material has been fabricated from scrap glass and clean cullet in a large range of densities (15 to 40 $1 \mathrm{bs} / \mathrm{ft}^{3}$ ). They have also produced material under laboratory conditions which has a dense surface skin and low density core adding to its structural efficiency. Table 7 presents several properties of soda lime silicate cellular glass as reported by Solaramics Incorporated.

2. Fabrication

Cellular glass is produced. from a mixture of finely ground glass particles and a foaming agent. This mixture is heated to sinter the glass particles together thereby encapsulating the foaming agent. The sintered batch material is then subjected to a higher temperature to promote the generation of gas from the foaming agent. With a proper balance between the sintering of the glass particles, gas generation from the foaming agent, and the softening of the glass, a cellular structure is formed. Water, carbon black, or calcium carbonate can be used as the foaming agent (Ref. 1). Other foaming agents are also possible. The resultant material density and micruslruclure are sensitive to the time temperature profile of the foaming furnace as well as the foaming agent and furnace atmosphere. 
Table 6. Properties of Aluminoborosilicate Foamsil-70 $\mathbb{B}$ Cellular Glass ${ }^{\dagger}$

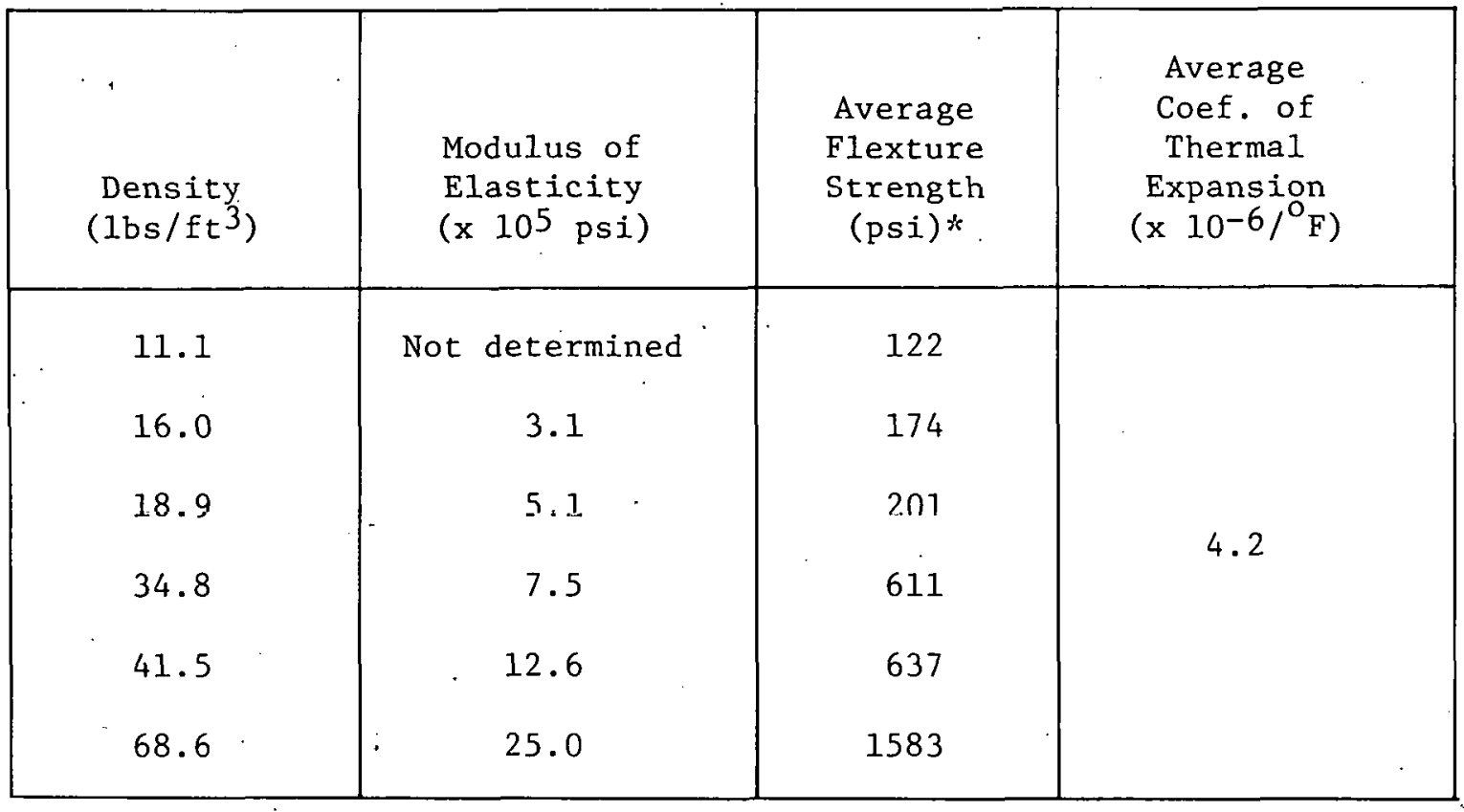

"Measured in Three-Point Bend

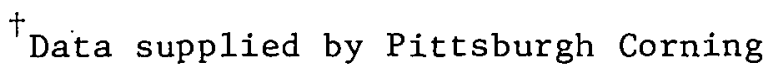

Table 7. Properties of Solaramics'Prototype Soda Lime Silicate Cellular Glass ${ }^{\dagger}$

\begin{tabular}{|c|c|c|c|c|}
\hline $\begin{array}{c}\text { Density } \\
\left(1 \mathrm{~b} / \mathrm{ft}^{3}\right)\end{array}$ & $\begin{array}{c}\text { Modulus of } \\
\text { Elasticity } \\
\text { (x 105 psi) }\end{array}$ & $\begin{array}{c}\text { Fverage } \\
\text { Stexture } \\
\text { (psi)* }\end{array}$ & $\begin{array}{c}\text { Average } \\
\text { Compressive } \\
\text { Strength } \\
\text { (psi) }\end{array}$ & $\begin{array}{c}\text { Average } \\
\text { Coet. ot } \\
\text { Thermal } \\
\text { Expansion } \\
\text { (x 10-6/\%) }\end{array}$ \\
\hline 15.6 & 1.9 & 125 & 260 & 5.3 \\
21.8 & 2.8 & 215 & 630 & 1360 \\
\hline 32.8 & 4.8 & 430 & & \\
\hline
\end{tabular}

"Measured in Four Point Bend with a Stressed Area of 128 square inches.

† Data supplied by Solaramics, Inc. 
Once the cellular material is formed, it must then undergo an annealing process to eliminate the generation of thermal stresses within the material as it cools. The annealing time varies directly as the coefficient of thermal conductivity and approximately as the square of the body thickness. Therefore, annealing time places an upper limit on the maximum body thickness which can be economically produced. Limited availability of large furnaces with adequate temperature control and lack of furnace belt materials having sufficient durability limit the planar dimensions which can be produced.

Pittsburgh Corning presently produces approximately $10^{8}$ board feet of Foamglas insulating material per year utilizing an assembly line manufacturing technique. The raw material is melted along with an oxidizing agent in large glass tanks. The resulting glass is then crushed and ground with the addition of a carbon black foaming agent. The material is then foamed in closed molds. Once the material is formed, it is stripped from the mold and annealed. Upon completion, the individual blocks are machined to the desired slab configuration utilizing conventional abrasive machining techniques. The slab dimensions are limited by the molds utilized by Pittsburgh Corning on the production line. The largest slab now produced for commercial application is 18 inches by 24 inches by 5 inches thick. In the 1950's, Pittsburgh Corning produced Foamglas slabs as large as 24 inches by 54 inches by 4 inches, but found no market that would accept the increased price.

Foamglas is easily machined into complex shapes for pipe insulation from individual slabs. Large machined parts required for liquid gas tank insulation are fabricated from slabs bonded together then machined to the required geometry. Dimensional tolerances of $1 / 16$ of an inch at high material removal rates are obtained.

Foamglae ${ }^{\circledR}$ containe hydrogen oulfide gas within the closed cell structure. The hydrogen sulfide reduces the thermal conductivity of the 
material improving its insulating properties. Hydrogren sulfide is not required to induce foaming. Aluminoborosilicate cellular glass is produced with only trace amounts of hydrogen sulfide.

Solaramics foams their prototype material in closed molds utilizing a fine mesh soda lime silicate glass and calcium carbonate. They have produced flat slabs as large as 4 feet by 10 feet. In addition, they have produced spherical concentrator substrates, 3 feet in diameter with a focal length of 60 inches.

Solaramics is currently developing a continuous processing procedure, whereby the material is foamed without the use of confining molds. A continuous sheet of cellular glass with a dense surface skin would be produced. Pittsburgh Corning has demonstrated the engineering feasibility of a continuous processing procedure on a prototype production line, manufacturing Foamglas two feet wide and four inches thick. However, they determined that the cost to construct a continuous processing production facility was not justified for insulation grade cellular glass material.

B. POTENTIAL DEVELOPMENT

1. Material

Several approaches to improving the mechanical performance and environmental durability of cellular glass materials appear feasible. Variable density materials may be produced in which areas subjected to higher stress or areas requiring greater stiffness can be fabricated to have higher density. Composite plates or beams with dense surface layers would demonstrate greater load bearing ability; increased impact resistance, and structural stiffness at a reduced weight. Dense surface skins would also improve the material's environmental performance by forming a positive integral barrier to water penetration. 
Another approach to increasing the material's tensile strength and stiffness while minimizing the component weight is to add a reinforcing structure to the cellular glass. The cellular glass could be foamed around a metallic net or fibrous material added to the prefoamed cellular glass material which could serve as reinforcement and as damage control. This approach requires a good interfacial bond between the reinforcing agent and the cellular glass. Such an interfacial bond has not, as yet, been demonstrated to be adequate but little work has been done in this area. Even without good bonding a wire net may serve to limit the damage once fracture has occurred by "holding the pieces together".

Although variable density and wire net reinforced cellular glass materials have been demonstrated, materials incorporating these improvements have not been sufficiently characterized, nor have these techniques been optimized.

Prestressing is an additional technique which can be used to increase the load bearing ability of cellular glass. Since the compressive strength for cellular glass is several times greater than the tensile strength, as described in Section $V$ of this report, the material could be prestressed in compression by the use of metallic rods similar to that used in concrete construction. This technique would be limited to simple structura1 shapes.

The influence of microstructure on the mechanical properties of cellular glass is not well understood; however, materials with finer pore size and different wall thickness could improve the load bearing ability of cellular glass materials at reduced densities. These are areas which will be addressed in the SERI supported basic R\&D study of cellular glass being conducted at JPL.

\section{Fabrication}

Commercial manufacturing techniques for cellular glass components are limited to the production of small slab configurations such as those 
required for thermal insulation applications. They do not lend themselves to the production of large monolithic complex configurations which may be required for concentiatior component applications.

Several fabrication process developments have potential for enabling the manufacture of large, complex shapes with outstanding structural properties:

- Development of large closed molds and the process to foam in them

- Continuous processing

- Hot forging

- Sag forming

The foaming of cellular glass materials in closed molds has been demonstrated and is state of the art. The limitation on mold size and shape appears to be one of cost and necessity. Large flat plates ( 4 feet by 10 feet by 4 inches) have been fabricated by Solaramics utilizing closed mold technology. A market for large cellular glass plates which would justify the construction of the required production facility is not available. In addition to the large plate fabrication, spherical plates have also been fabricated in closed molds. Therefore, the foaming of large doubly curved plates utilizing closed mold techniques appears feasible; economic considerations of such a manufacturing process are another matter. The dimensional requirements of the JPL cellular glass mirror support will, at present, require a machining operation to obtain the desired optical surface after the material is formed.

Continuous processing, whereby the material is foamed without the use of confining molds, would produce a continuous sheet of cellular glass with dense surface skins. This material could then be formed into doubly curved plates by hot forging or sag forming, followed by the required annealing and machining to obtain the desired support structure. 
The viscosity temperature relationship for glasses should allow cellular glasses to be hot worked at elevated temperatures without inducing stresses or forming cracks. Hot forging or sag forming of cellular glass at these temperatures appears feasible. The trick is in controlling the microstructure such that the interior network of bubbles is preserved. The hot forging process would employ hot dies to force the material into the required geometry. If done properly, (i.e., the controlled collapse of surface pores), a dense surface skin could be produced by this technique leaving the core material in its foamed condition. Cellular glass could also be sag formed into appropriate tooling at high temperature, promoted by its own body weight. Again controlled collapse of the cells near the surface could be used to form a dense "glaze" or skin.

The forming of cellular glass into complex shapes containing thick members which stiffen the structure is not feasible due to the required annealing process. The annealing time is proportional to the square of the thickness of the structure which significantly increases production cost for thicker sections due to the cost of furnace time. Foaming in complex shaped molds has been found to be unsatisfactory because of the way the material distributes itself during foaming. Incomplete filling of the mold and tearing and folding in areas where the section is changing appear to be unavoidable problems with current technology. Structures which require stiffening members can be fabricated in several pieces and bonded together with organic adhesives or inorganic mortars. 


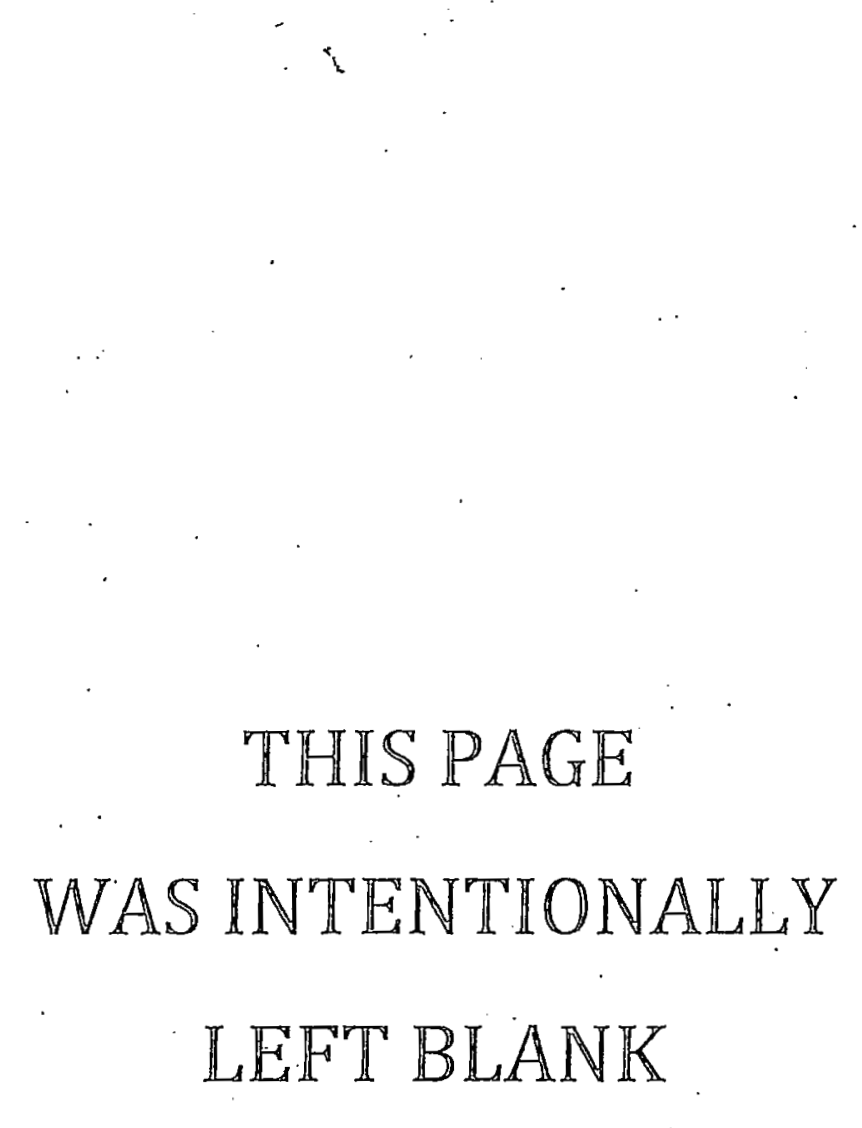




\section{CELLULAR GLASS MATERIAL DESIGN CONSIDERATION}

The development of an efficient design is dependent upon the utilization of materials to their fullest potential. This can be accomplished when all aspects of the materials performance pertaining to the design requirements are considered. The design requirements for materials utilized as the mirror support substrate structure for paraboloidal concentrators include:

1) Dimensional stability with temperature and humidity cycling

2) Resistant to chemical attack by naturally occurring agents

3) Resistant to water absorption and permeation

4) Resistant to freeze/thaw cycling

5) Compatible with the mirrored surface

6) Ability to be fabricated into required shapes

7) Adequate strength and stiffness with an acceptable panel weight

8) Low material and fabrication $\cos t$

Dimensional stability of the material is essential for the mirror panel application to ensure the maximum collection concentration of available solar energy. Materials which have low thermal expansion coefficients minimize thermal distortion of the structure and the thermal loading during thermal cycling. Cellular glass materials have small thermal expansion coefficients as: compared to other candidate panel materials (see Table 1 ). Materials. which absorb moisture due to temperature and humidity cycling, such as forest products, swell and warp resulting in large, permanent dimensional changes. Since water will not diffuse into glass under environmental conditions, cellular glass materials do not swell or warp even if they have absorbed water (e.g., in open cell foams). The utilization of cellular glass materials will ensure the development of dimensionally stable designs.

Unlike polymeric materials, glass exhibits chemical stability and inertness in natural outdoor environments. Sodium silicate is leached out of soda lime silicate glass at relatively low temperatures, however, this effect can be controlled by reducing the amount of soda in the glass 
chemistry. Aluminoborosilicate and borosilicate glass materials offer improved chemical stability. Any residual foaming agent remaining in the cellular glass matrix due to improper fabrication processes will diffuse or be leached out of open cell structures. This effect was observed on a developmental cellular glass. Properly formulated and processed cellular glass materials offer adequate chemical stability and inertness for mirror panel application.

Silvered glass mirrors are sensitive to water which rapidly causes corrosion of the mirror surface. Materials used in panel construction must prevent water from permeating or diffusing through the structure to the mirrored surface. In addition, weight gain due to water absorption may lead to structural failure. Unlike cellulated polymeric materials, closed cell cellular glasses have demonstrated no water vapor permeability under ASTM C355 test standards and only a small amount (.2 percent by volume on surfaces only) of moisture absorbed under ASTM C240 test standards (Ref. 4).

\section{Cellular glasses will degrade when exposed to temperature} excursions below $0^{\circ} \mathrm{C}$ with free standing water present on the surface of the material. The mechanism is one of surface spalling in which liquid water, present in the outer, broken pores, freezes. The resulting volumetric expansion ruptures the fragile cell walls. This results in the erosion of one or two layers of cell walls in closed cell material during each freeze/thaw cycle. The rate of degradation through the material thickness is dependent on the pore size. Material with smaller pores should degrade at a slower rate (lower inches of material per cycle eroded). A threshold of pore size below which erosion does not occur has been postulated but has not as yet been identified. Closed cell cellular glasses on which there is no free standing water appear to be unaffected by many thermal cycles through $0^{\circ} \mathrm{C}$. Open cell materials behave differently during freeze/thaw cycling with standing water present. These materials absorb and retain a large quantity of water which freezes when the temperature goes below $0^{\circ} \mathrm{C}$. The subsequent volume expansion 
of the freezing water does not appear to erode the material as evaluated by surface spalling evidence. Freeze/thaw testing of several cellular glass materials are discussed in section $\mathrm{V}$.

Organic coatings, under development at JPL, will eliminate the occurrence of free standing water in contact with bare cellular glass. surfaces in components exposed to the natural elements and subzero thermal excursions. Organic conformal coatings will greatly inhibit the penetration of water into the material. Very dense to fully dense glass surface layers are also under development. A dense glass surface layer will prevent the penetration of any water if it remains continuous.

Thermal expansion mismatch between the mirrored surface and the support. structure will cause thermal distortion and the generation of thermal stresses within the panel assembly. The thermal expansion of cellular glass materials can be tailored to match very closely that of the mirror glass over the temperature range of interest. Pittsburgh Corning Corporation has developed an aluminoborosilicate cellular glass which demonstrates a close match to the thermal expansion of $0317 \mathrm{~g} 1 \mathrm{ass}$ over the temperature range of $-30^{\circ} \mathrm{C}$ to $+50^{\circ} \dot{\mathrm{C}}$. Corning 0317 fusion glass is the prime mirror glass candidate for the JPL Prototype Advanced Solar Concentrator, ADS 非, but Corning Glass Works has no plans to produce this glass in the future; thus, it probably will not be used again.

Although commercial manufacturing techniques are not available for the production of large plates needed to fabricate a one-piece or segmented paraboloidal cellular glass mirror panel structure, illustrated in Figure 1, flat plates with the required width and length can be produced on a prototype scale. Several plates with the appropriate density can be bonded together and machined to the required configuration. Selection of the appropriate material densities for each plate can add stiffness and strength which will improve the structural performance at a reduced weight. This fabrication approach may not be cost effective for mass 
production; it was selected as the available state-of-the-art technology for demonstrating cellular glass mirror panel feasibility and performance.

The mechanical strength and elastic modulus of cellular glasses are dependent on the material density and perhaps microstructure. Preliminary data show the effect of glass chemistry to be secondary. Both strength and elastic modulus increase with increased density as indicated in Figures 2 and 3. Variable density material may be produced in which areas subjected to higher stresses or requiring greater stiffness can be fabricated to have higher density. Composite platec or beams with dense surface layers may demonstrate greater load hearing capability, greatly improved resistance to freeze/thaw degradation and increased structural stiffness at a reduced weight. The design of the density profile in the transition region may be critical to eliminating concentrations of stress in this location. Dense material at load transfer locations could be used to reduce failures from concentrated stresses in these areas.

Brittle materials such as cellular glass exhibit large variations in their strength due to the sensitivity of the strength to inherent or introduced flaws. Since cellular glass is currently manufactured in large volume only for insulation applications, the control of strength limiting flaws is less than what would be expected if the material were manufactured for structural applications. Because of the extreme sensitivity of strength to the worst flaw present, statistical approaches are necessary to adequately characterize the strength. A statistical tool (Ref. 5) which defines the failure probability as a function of the applied dynamic stress is the three parameter Weibull analysis (weakest link statistics): 


$$
P_{f}=1-\exp \left[-\left(\frac{\sigma-\sigma_{o}}{\sigma_{v}}\right)^{m}\right]
$$

$$
\text { where } \begin{aligned}
\mathbf{P}_{\mathbf{f}} & =\text { cumulative failure probability } \\
\sigma & =\text { applied dynamic stress } \\
\sigma_{0} & =\text { stress below which failure will not occur } \\
\sigma_{\mathbf{v}} & =\text { stressed volume parameter } \\
\mathbf{m} & =\text { Weibull Modulus }
\end{aligned}
$$

A three parameter Weibull analysis was conducted on a large amount of three point flexure data taken over the course of several production months of a commercial cellular glass material. The analysis (Figure 4) indicates that failure can occur at a stress level as low as 10 psi with an average strength of $110 \mathrm{psi}$. The analysis also indicates the presence of two distinct distributions of flaw size within the material. Macroflaws, or inclusions due to production methods, contribute to strength reduction below 90 psi. Closed penny-shaped flaws with a diameter of up to one inch have been observed. Since these flaws are limited in number, the probability of failure due to their presence is reduced. Smaller micro-flaws, which are present throughout the material, cause the strength variation between 90 and $160 \mathrm{psi}$. This analysis was conducted on strength data for insulation grade cellular glass. The lower strength region of the variation in the material strength can be eliminated via quality control directed toward the elimination of material containing the macro flaws. Non-destructive techniques which can detect large production flaws within the material are in need of development. Proof testing (Ref.6) could be utilized, however this technique would reduce the life of the material due to flaw extension while under the required large proofing load.

In addition to the strength variation for brittle materials, a strength-size relationship exists. Increasing the volume of material under. stress increases the probability of finding a large critical flaw, 


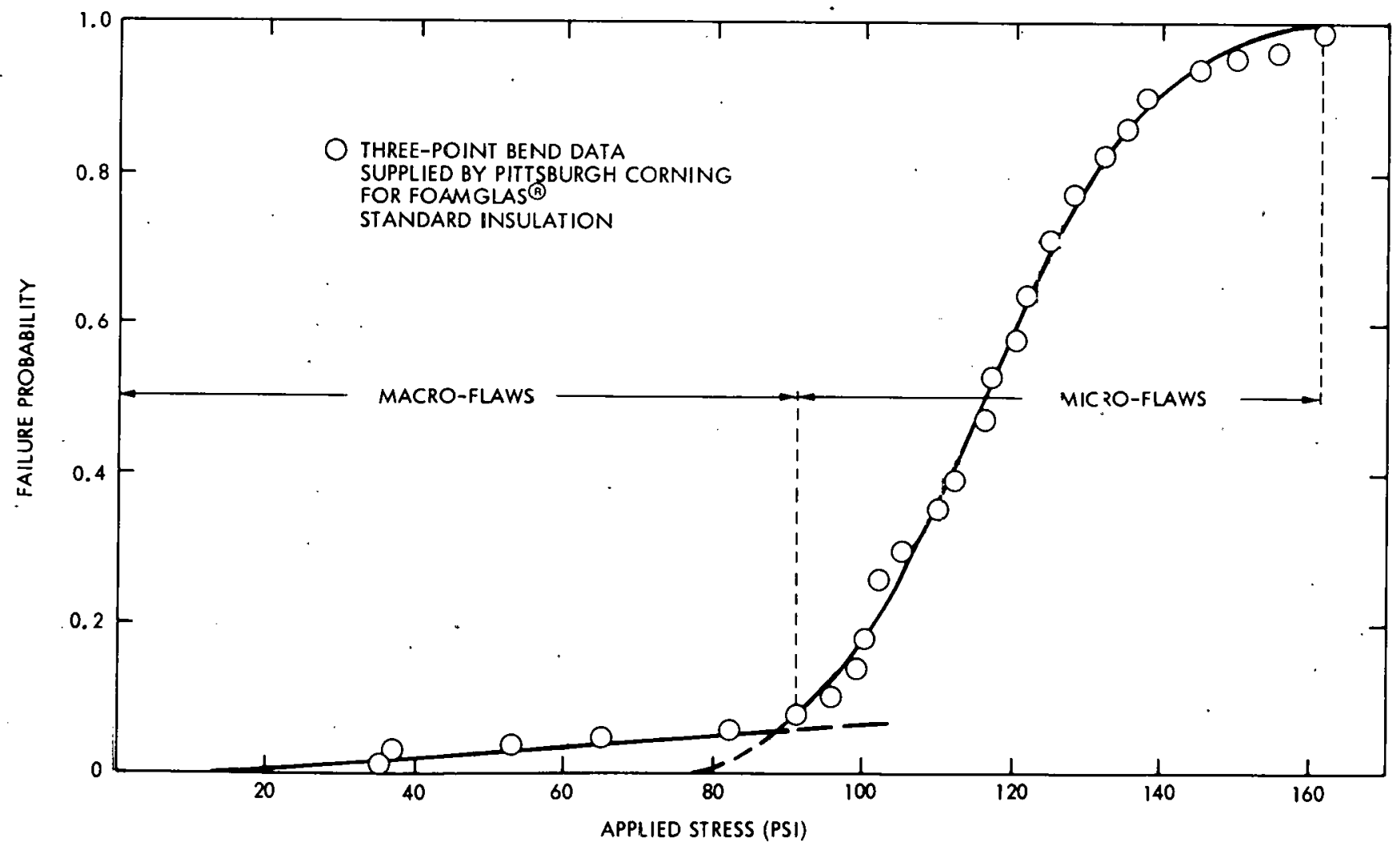

Figure 4. Failure Probability of Soda Lime Silicate Insulating Grade Cellular Glass as a Function of Stress 
thus reducing the material load bearing ability (i.e., its expected strength). Weakest link statistics coupled with appropriate mechanical test data can be used to characterize this effect for cellular glass materials such that adequate designs can be developed for structures which utilize large monolithic plates.

Glasses exhibit a sensitivity to subcritical crack growth in the presence of water (humidity) while under static, dynamic, or cyclic loading conditions (Ref. 7). This effect can lead to time-dependent catastrophic failure. The time to fail depends on the state of stress, the chemical composition and microstructure of the glass, pre-existing flaw size within the material, and the chemical environment. The failure time under static load is given by:

$$
t_{E}=\frac{1}{A Y^{n} \sigma^{n} \pi^{n / 2}\left(1-\frac{n}{2}\right)}\left[\frac{K_{I C}^{(2-n)}}{\left(\pi \sigma^{2}\right)}-a_{0}^{\left(1-\frac{n}{2}\right)}\left(1-\frac{n}{2}\right)\right]
$$

where $\sigma=$ stress

$$
\begin{aligned}
& a_{0}=\text { initial crack size } \\
& \mathrm{K}_{\mathrm{IC}}=\text { critical stress intensity factor } \\
& \mathrm{n}=\text { stress corrosion constant } \\
& \mathrm{Y}=\text { geometric factor } \\
& \mathrm{A}=\text { environmental factor }
\end{aligned}
$$

Both the critical stress intensity factor and the stress corrosion constant are considered to be material properties related to the microstructure and chemical composition of the material. A program was conducted at the University of Pittsburgh to determine the critical stress intensity factor of Foamglas (Ref. 8); however, the findings are not conclusive. A material's sensitivity to slow crack growth is dependent on chemical composition, and is quantified by its stress corrosion constant. Tests conducted by Pittsburgh Corning Corp. (Ref. 9) indicate that their developmental aluminoborosilicate material has greater resistance to aqueous attack than soda lime silicate Foamglas or 
borosilicate Foamsi1-28 which may result in improved slow crack growth resistance for this material.

Although slow crack growth has been extensively documented for dense glass materials, only a minimal amount of experimental work has been conducted on cellular glasses. The effect of stressing rate on the tension, flexure, and compressing strength of Foanglas was investigated at the Pennsylvania State University (Ref. 10). It was

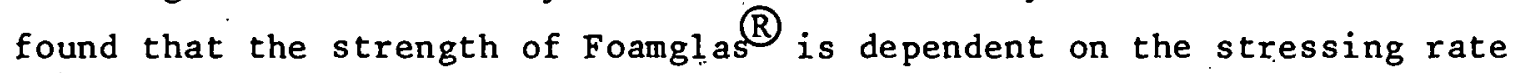
under tensile and compressive stress. This work has indicated that subcritical crack growth will occur at stress levels below the fast fracture strength.

Ceramic materials exhibit large variations (orders of magnitude) in the failure time due to subcritical crack growth at a given stress level. This is due to the statistical variation in the initial crack size in a population of specimens. The failure probability as a function of time at a given static stress level is given by (Ref. 11):

$$
P_{f t}=1-\exp \left[-\frac{\left(\log t_{f}-\log t_{o}\right)^{m}}{t_{v}}\right]
$$

when $\quad P_{f t}=$ cumulative failure probability at a static stress level

$t_{E}=$ failure time

$t_{0}=$ lower found failure time

$\mathrm{tv}=$ time scale parameter

$\mathrm{m} \quad=$ Weibul1 Modulus

A statistical analysis, using the above expression, was conducted on four point static tensile bend data for Foamglas. Figure 5 presents the results of the analyses and illustrates the variation in the failure time for cellular glasses.

Efficient cellular glass, mirror panel designs can be developed with the aforementioned material considerations coupled with appropriate material and meteorological data. The probability of occurrence of 


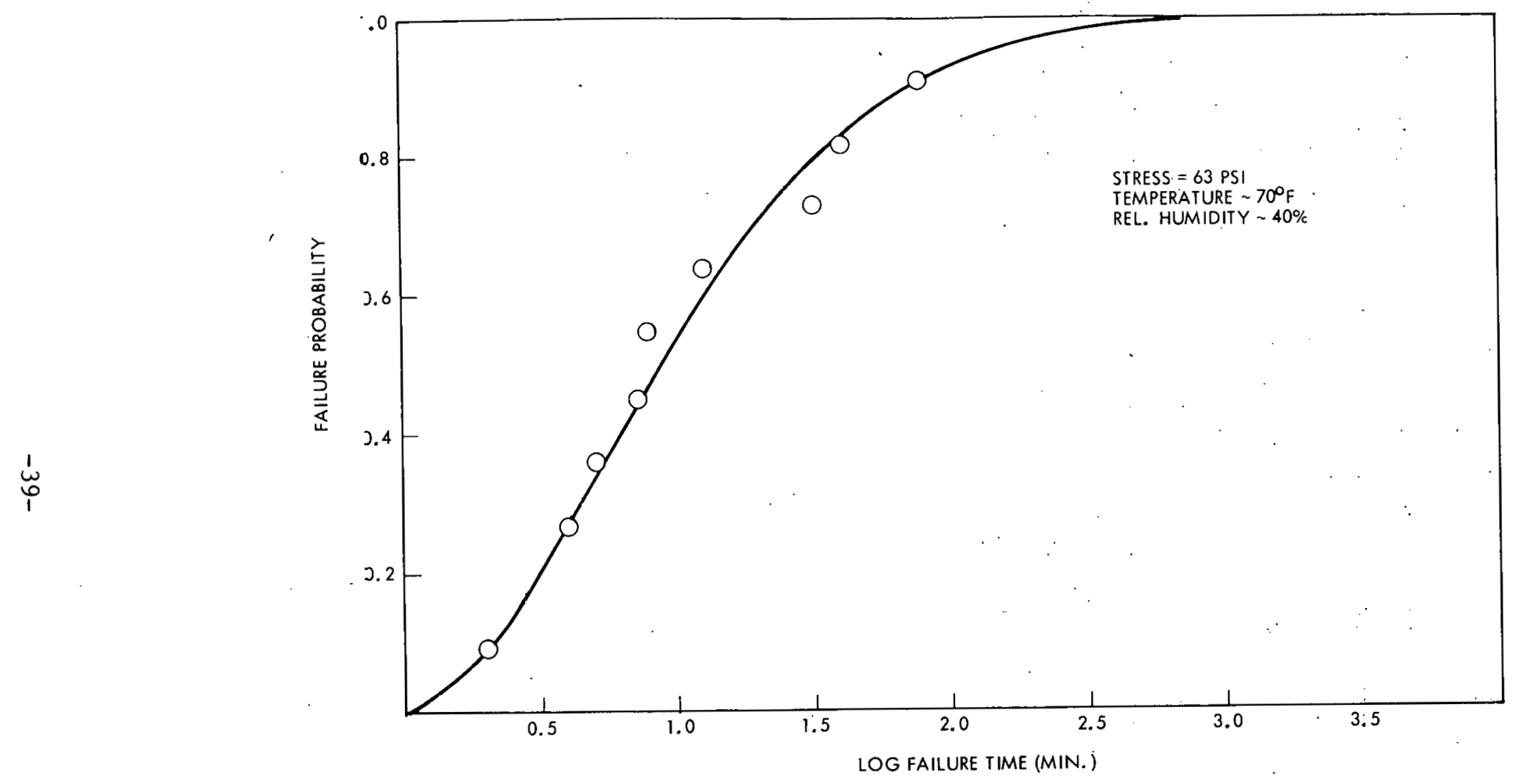

Figure 5. Failure Probability as a Function of Time for Soda Lime Silicate Foamglas ${ }^{\circledR}$ 
environmental events such as wind velocities, hail storms, freeze thaw cyclic weather, etc. as a function of the event's severity is needed (see Figure 6a). The development of designs with appropriate survival probability related to the environmental induced stresses can then be generated. Figure $6 \mathrm{~b}$ relates the survival probability of several designs ( $A, B$ and $C$ ) as a function of a given level of severity for a meteorological occurrence be it wind velocities, hail storms, etc. The survival probability increases from design $A$ to $C$ as illustrated in Figure $6 \mathrm{~b}$ which increases the initial cost of the mirror panel illustrated in Figure 6c. The design philosophy (acceptable failure rate) is dictated by the total life cycle cost of the panels (initial cost, maintenance cost, replacement cost, etc.) and their influence on the total system cost. The minimum life cycle cost occurs at a failure probability above zero as illustrated in Figure 7 . Although panel design $C$ offers the lowest failure probability, its total life cycle cost is high due to the high initial cost. The initial cost of design $A$ is low, however replacement cost and maintenance cost would increase its total life cycle cost as illustrated in Figure 7 . 

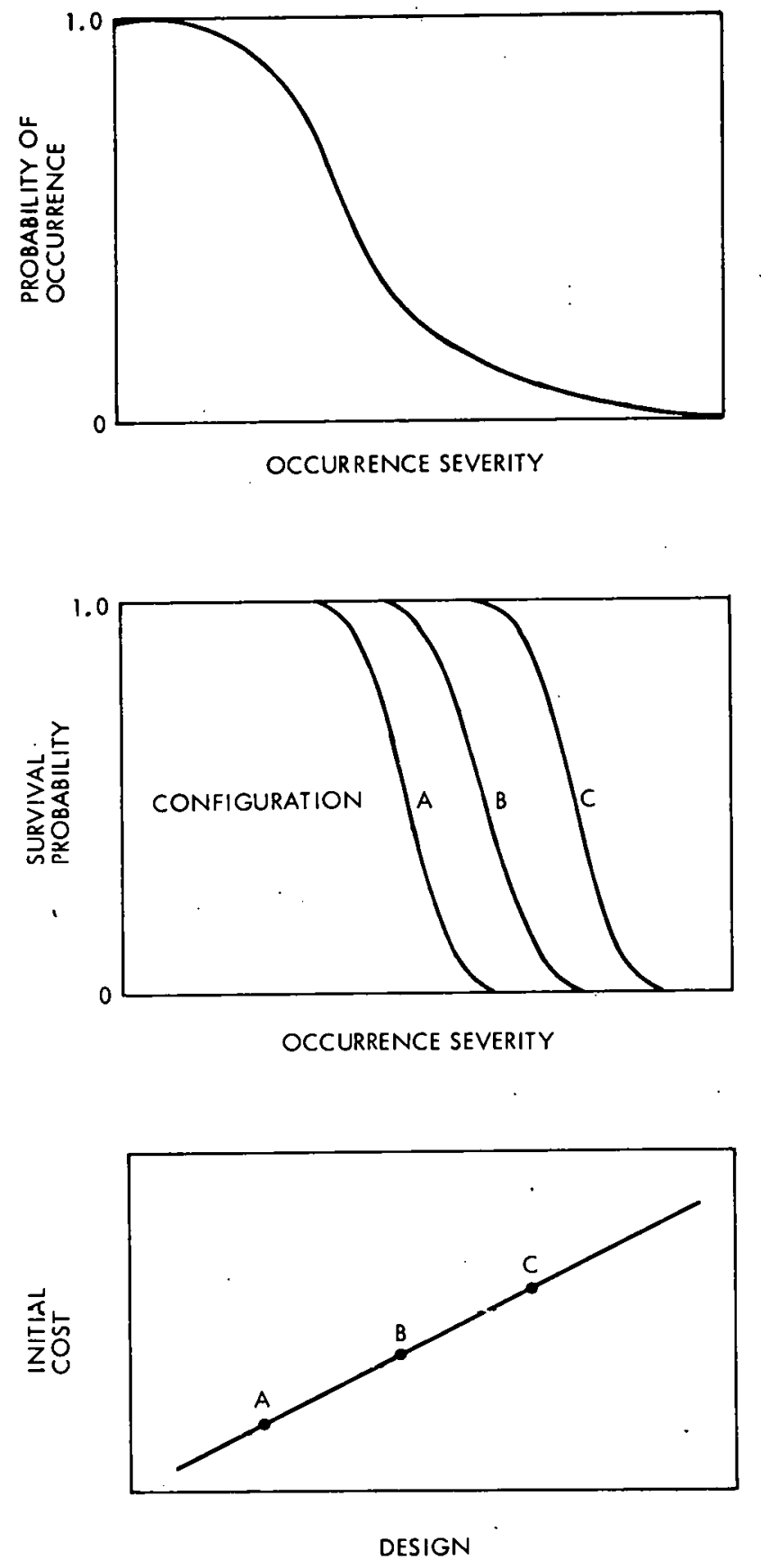

Figure 6. An Illustration of the Development of Design Philosophy 


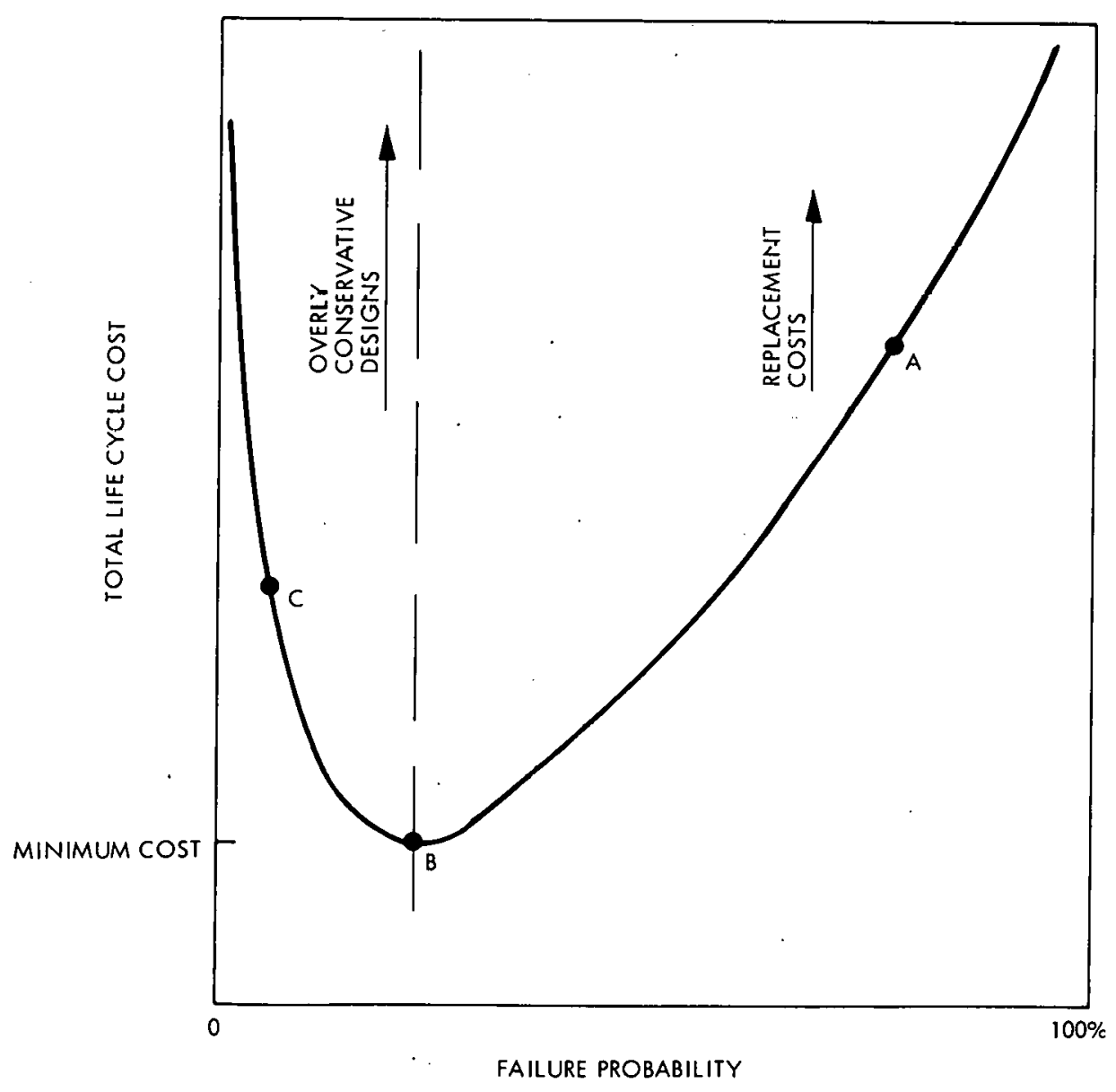

Figure 7. The Influence of Design Philosophy on the Total Life Cycle Cost 


\section{A. PURPOSE}

An ongoing activity at JPL is engaged in the characterization of the mechanical and physical properties and environmental durability of several cellular glass materials. The purpose of the investigation is to provide material data necessary for the design of cantilevered paraboloidal cellular glass mirror panels and for the prediction of long term performance of cellular glass in this application. The following properties should be evaluated:

- Strength

1. Modulus of Rupture (four-point Bend)

2. Uniaxial Compressive

3. Shear (Torsion)

4. Surface Strength (Crushing)

- Slow Crack Growth Characteristics

1. Static Fatigue Behavior (in various environments)

2. Dynamic Fatigue Behavior (ambient)

3. Cyclic Fatigue Behavior

- Elastic Constants

1. Modulus of Elasticity in Tension

2. Modulus of Elasticity in Compression

3. Shear Modulus

4. Poisson's Ratio

- Fracture Mechanics Parameters

1. Fracture Toughness ( $\left.\mathrm{K}_{I C}\right)$

2. Stress Intensity vs. Crack Velocity Relation $\left(K_{I}, V\right)$

- Particle Impact Resistance (in conjunction with composite mirror panel structure)

- Stability in Temperature/Humidity Environments

1. High Temperature/High Humidity Cycling--Degradation Raté

2. Freeze/Thaw Cycling--Degradation Rate

3. Water Permeation and Absorption 
- Thermal Expansion

- Composition and Microstructure Characterization

The following tests are planned:

1. Four-Point Bend Test with Displacement Determination

2. Dynamic Fatigue

3. Static Fatigue

4. Cyclic Fatigue

5. Compressive Test with Displacement Determination

6. Torsion Test with Displacement Determination

7. Volume/Strength Relationship

8. Fracture Toughness

9. Double Torsion

10. High Temperature/High Humidity Cycling

11. Freeze/Thaw Cycling

To the extent that analytic tools are available and appropriate, the values of the properties will be reported with statistical information adequate to allow for optimum design techniques to be used.

\section{B. CELLULAR GLASS MICROSTRUCTURE AND DENSITY VARIATION}

Since the influence of microstructure on the mechanical and environmental properties of cellular glass is of interest, but not well understood at this time, a preliminary examination of the microstructure of two cellular glass materials was conducted. An open cell soda lime silicace and a closed cell aluminoborosilicate, both with a density of approximately $16 \mathrm{1b} / \mathrm{ft}^{3}$; were examined using an SEM. The contrast between the materials is illustrated in Figure 8 . The open cell material has rough, torn and broken cell walls while the closed cell material has smooth walls which are intact. 


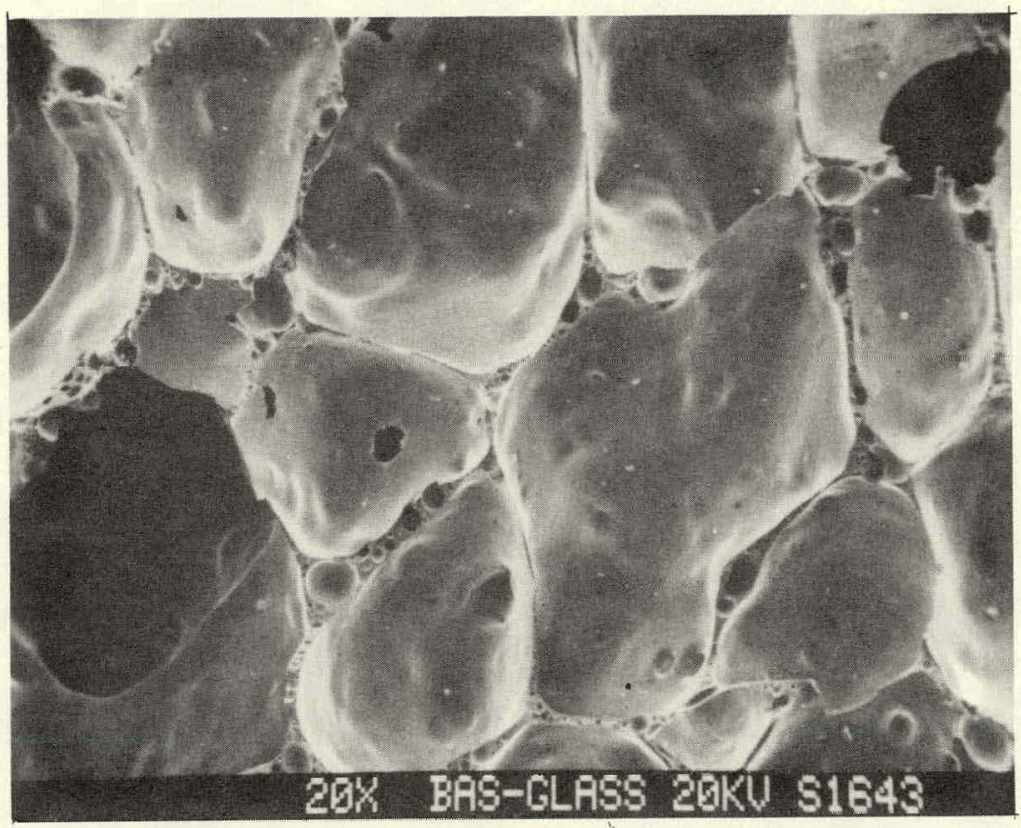

(a)

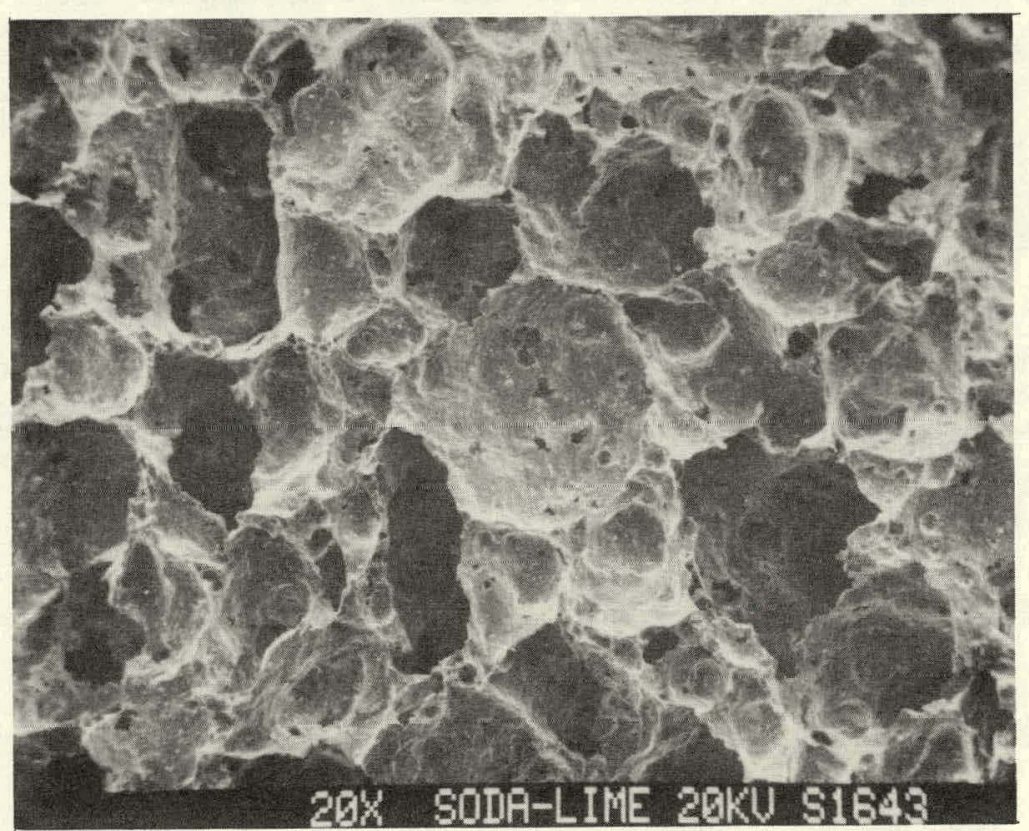

(b)

Figure 8. Scanning Electron Micrograph of (a) Closed Cell Aluminoborosilicate and (b) Open Ce11 Soda Lime Silicate Cellular Glass (x20) 
Both materials have a wide range of cell sizes. The larger typical cell size is on the order of 0.05 inches in diameter with pores as small as 0.0002 inches in diameter in the cell walls as shown in Figure 9. Cells with diameters of approximately 0.007 inches are formed at the intersections of several larger cells shown in Figure 10.

The typical wall thickness between the larger cells is 0.001 of an inch for both the open and closed cell material (see Figure 9); however, the closed cell material appears to have a more uniform wall thickness.

Particles were found on the wall surfaces and embedded in the walls of the open cell material as seen in Figure 11. These particles may be impurities from the starting materials, a second phase material, or residual foaming agent.

The variation in bulk density of monolithic blocks of aluminoborosilicate cellular glass was examined by slicing one-inch sections from the block along its length. The density of each section was determined by weighing the piece and taking dimensional measurements. Figure 12 shows the density variations along the block length for the three blocks examined as well as a graphic representation of the slicing mode. Table 8 presents the results. The density variation as a percent of the average block density is large.

The remaining portion of this section will describe the testing techniques with data reduction and the procedures and results of the tests conducted to date.

\section{TESTING TECHNIQUES AND DATA REDUCTION}

1. Four-Point Bend with Dispacement Determination

A uniaxial stress state is achieved by loading cellular glass plates in four-point bend which develops a maximum tensile stress on the 


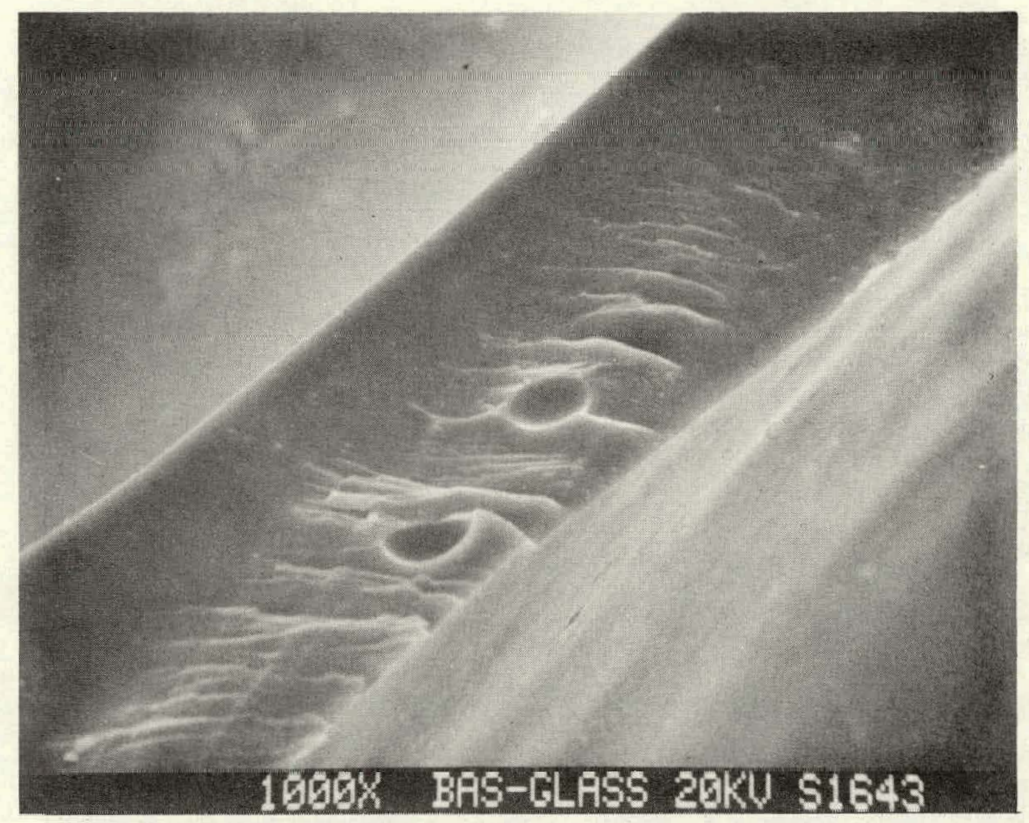

(a)

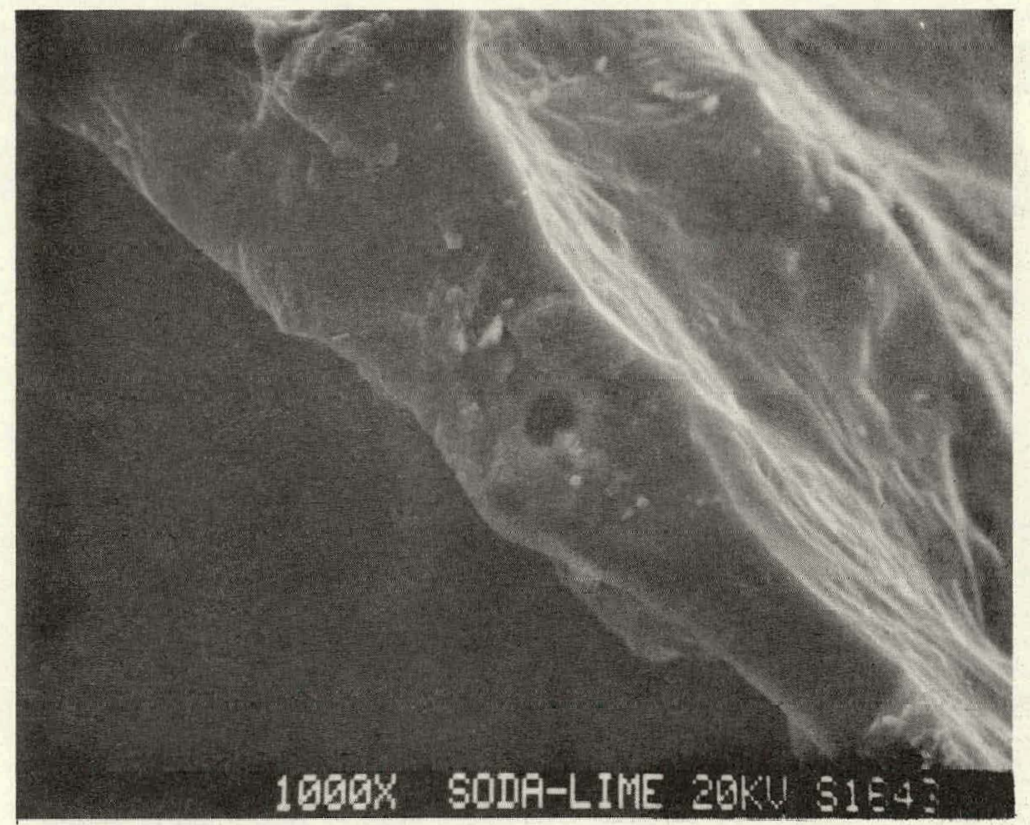

(b)

Figure 9. Pores in Cell Walls of (a) Aluminoborosilicate and (b) Soda Lime Silicate Cellular Glass (x1000) 


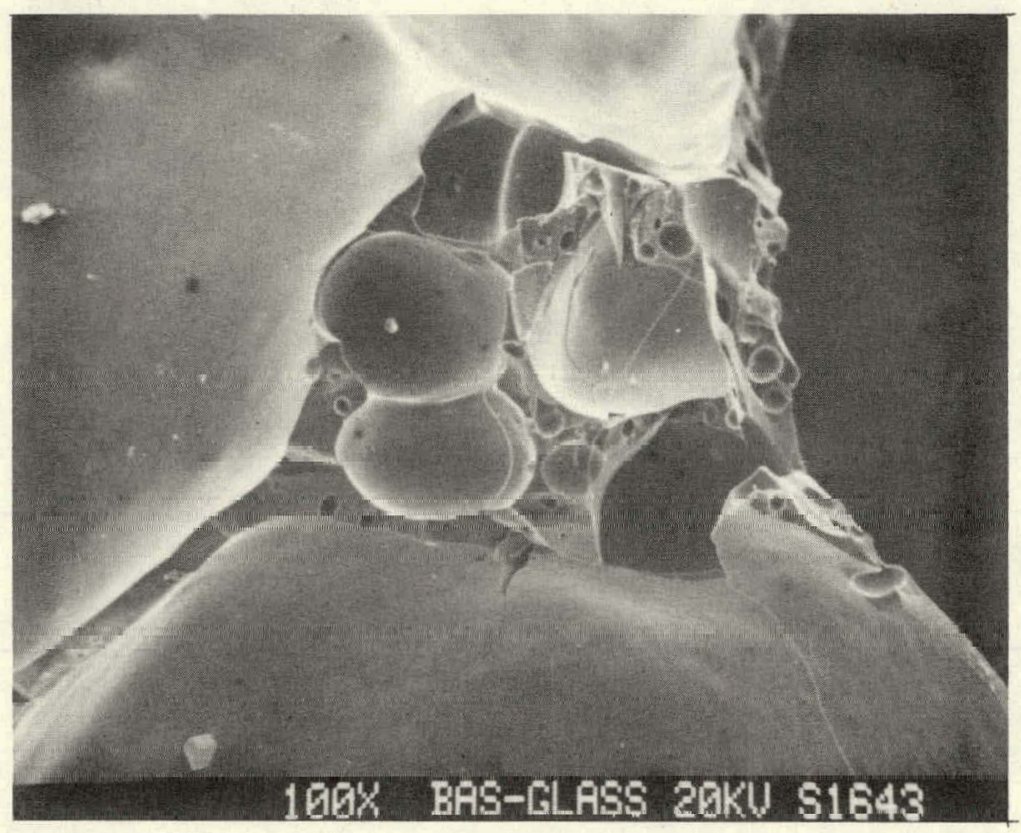

Figure 10. Cells Formed at the Intersection of Several Larger Ce11s (x100)

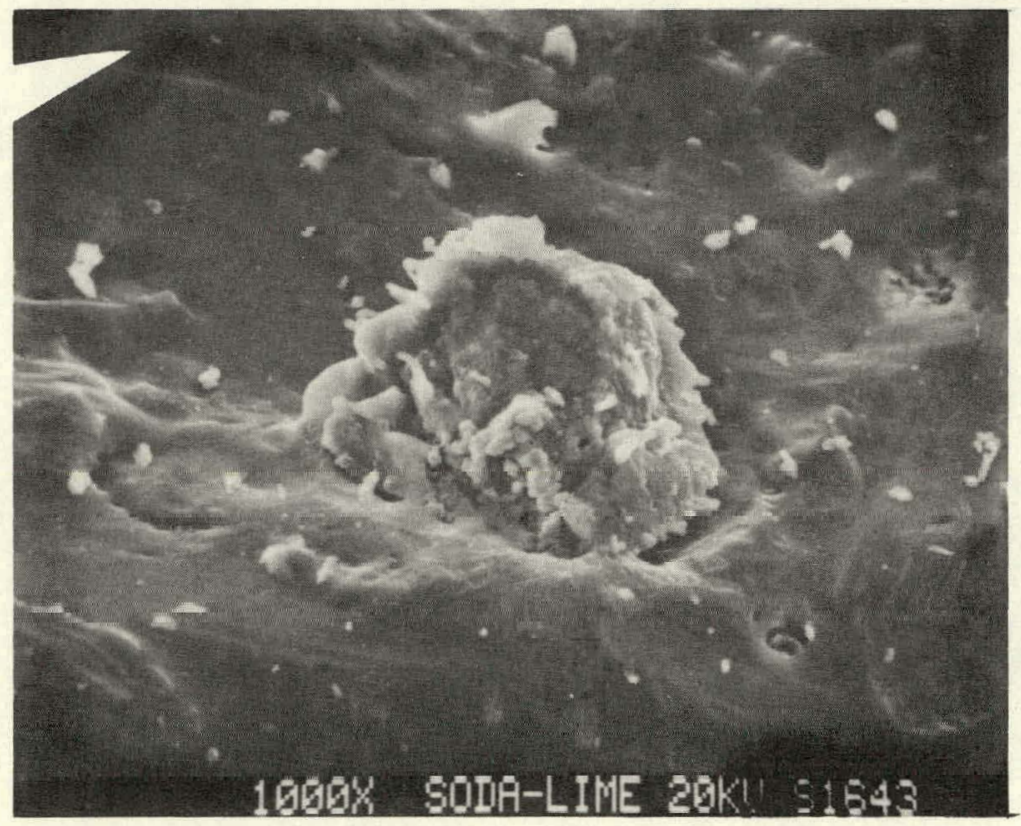

Figure 11. Particles on and Embedded in the Walls of Open Cell Soda Lime Silicate Cellular Glass (x1000) 

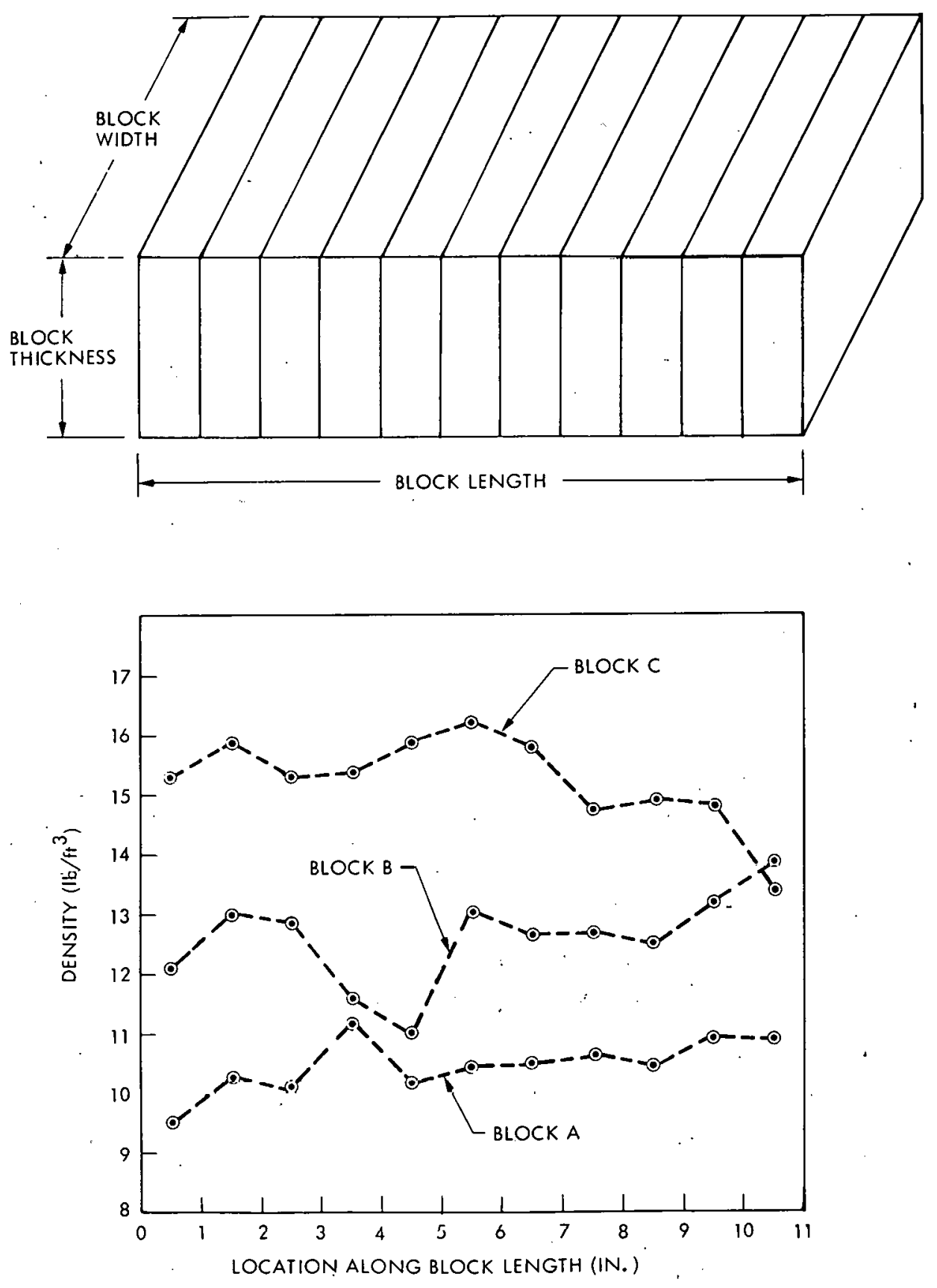

Figure 12. Density Variation of Three Blocks of Al.uminohornsilirate Cellular Glass. 
Table 8. Density Variation

\begin{tabular}{|c|c|c|c|c|}
\hline Block & $\begin{array}{c}\text { Average } \\
\text { Density } \\
\left(1 \mathrm{~b} / \mathrm{ft}^{3}\right)\end{array}$ & $\begin{array}{c}\text { Standard } \\
\text { Deviation } \\
(\text { Ib/ft })^{3}\end{array}$ & $\begin{array}{c}\text { Coefficient } \\
\text { of } \\
\text { Variation }\end{array}$ & $\begin{array}{c}\text { Extremes } \\
\text { of } \\
\text { Density } \\
\text { Variation } \\
(\%)\end{array}$ \\
\hline $\mathrm{A}$ & 10.48 & $\ldots .46$ & 0.044 & +8.9 \\
\hline $\mathrm{B}$ & 12.60 & 0.79 & 0.062 & +12.7 \\
\hline $\mathrm{C}$ & 15.26 & 0.77 & 0.051 & -9.9 \\
\hline
\end{tabular}

outermost bottom layer of the specimen shown in Figure 13. This testing technique is suitable to determine several structural properties since 1) a maximum uniform tensile stress can be placed on the outermost cell surface of the material over a large area,2) the size of the maximum stressed area and volume can be readily controlled by the placement of the test fixture loading points or by changing the specimen geometry and 3) the specimens are subjected to a stress state similar to the one which will be experienced by the cellular glass mirror panels.

Because cellular glass is a completely brittle material, inadvertent localized stresses from improper load application or specimen design are not relieved by ductile flow; this can lead to premature fracture at applied stresses below the material's nominal strength. To ensure that the proper stress state is achieved in the four-point bend test, precautions must be taken so that the applied loads are equally distributed across the width of the specimen, otherwise, a torque will produce unwanted stresses in the test section. If the loads at the two 

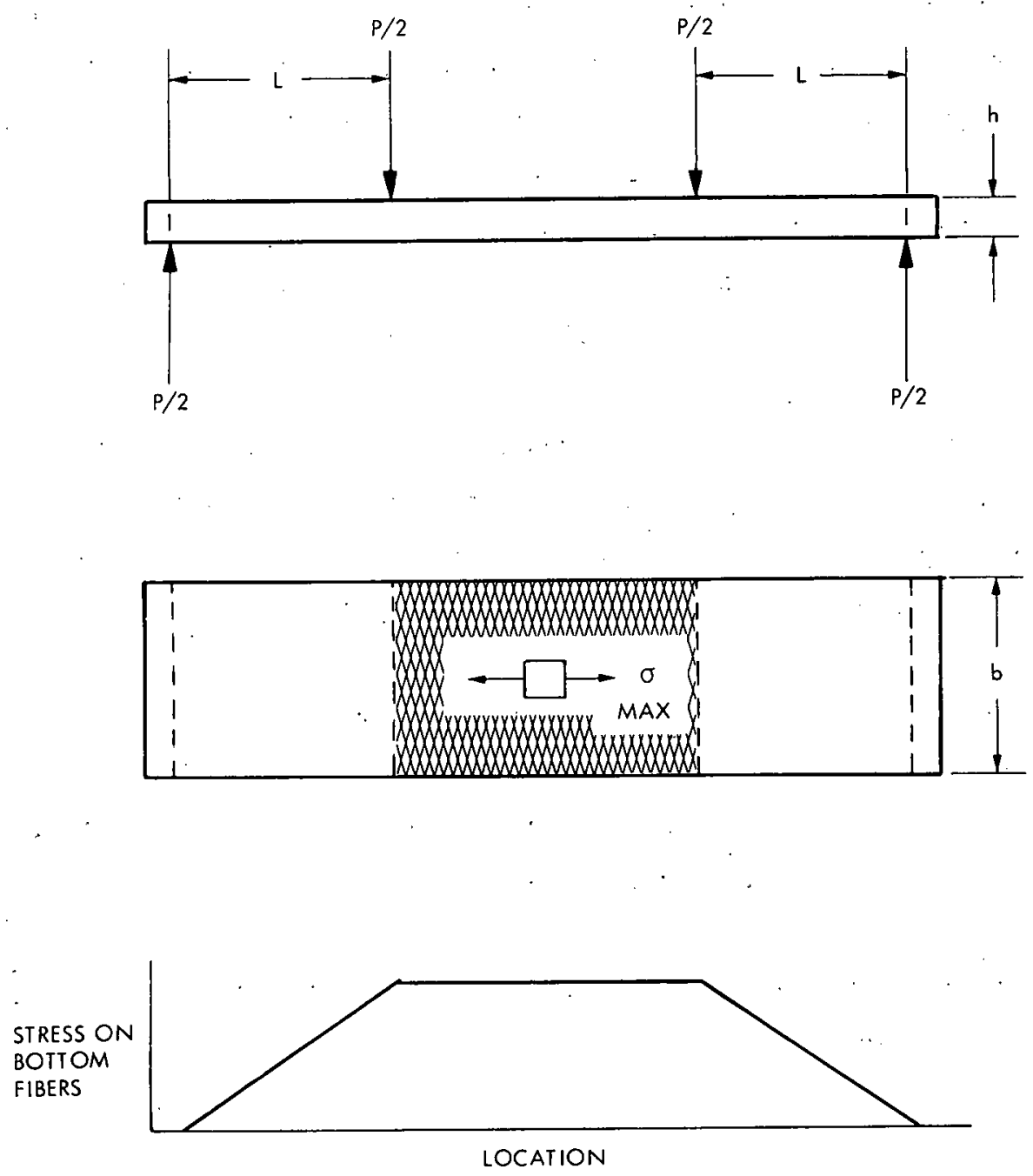

Figure 13. Four-Point Bend Test Configuration 
points of application are unequal, the stress will decrease with the longitudinal distance from the greater load. Data presented by Duckworth (Ref.12) indicates that reasonable, but not extreme care, should be taken to ensure that the loads are equal.

Localized stresses near the load lines are superimposed on the bending stresses. These localized stresses decrease the tensile bending stresses directly beneath the load lines and increases the tensile stresses on each side of the load lines on the bottom sheet geometry. Seewald (Ref.13) provides a method of solution for a beam loaded by concentrated force. This effect was examined for the specimen geometry and found to be small (less than . $2 \%$ ).

The compressive stress generated in the specimens at the loading contact points must be minimized to avoid localized crushing of the surface. Appropriate specimen geometry and load application were selected to avoid this crushing during testing.

The modulus of elasticity in bending for cellular glass materials can be determined by measuring the deflection of the specimen as a function of the applied load under four point bend test conditions. Surface crushing would cause errors in the modulus determination.

The four-point bend test technique is useful in determining the following properties:

- Modulus of Rupture
- Modulus of Elasticity in Tension

2. Dynamic Fatigue

Slow crack growth causes a stress rate dependence in the strength of cellular glass materials. By measuring the strength at various stressing rates, crack growth parameters may be obtained. Charles (Ref. 14) derived a relationship describing fatigue during dynamic loading given by: 


$$
\sigma=k_{\dot{\sigma}}\left(\frac{1}{n+1}\right)
$$

where

$$
\begin{aligned}
& \sigma=\text { failure stress } \\
& \dot{\sigma}=\text { stressing rate } \\
& \mathbf{k}=\text { environmental constant } \\
& \mathbf{n}=\text { stress corrosion constant }
\end{aligned}
$$

The stress corrosion constant for a cellular glass may be determined by obtaining the strength as a function of the stressing rates if the tests are conducted under identical conditions, i.e., $\mathrm{k}=$ constant. For this condition:

$$
\mathrm{n}=\left(\frac{\log \dot{\sigma}_{1}-\log \dot{\sigma}_{2}}{\log \sigma_{1}-\log \sigma_{2}}\right)-1
$$

when $\sigma_{1}$ and $\sigma_{2}$ are the strengths at stressing rates $\dot{\sigma}_{1}$ and $\dot{\sigma}_{2}$ respectively.

Since the strength of brittle materials such as cellular glass is sensitive to the severity of the flaw which causes failure, specimens tested at differing stress rates must have an identical initial flaw severity. Typically, the stress corrosion constant is evaluated from the average strength data at differing stress rates with a statistical confidence assigned to the evaluation. This technique does not insure that the data compared was obtained from specimens tested which possess identical or even similar flaw severities. A cleaner technique is to conduct a Weibull weakest link statistical analysis on the strength data for many tests conducted at a constant stressing rate, comparing the strength of the material for different stressing rates at equal failure probabilities. This technique is illustrated in Figure 14 . 


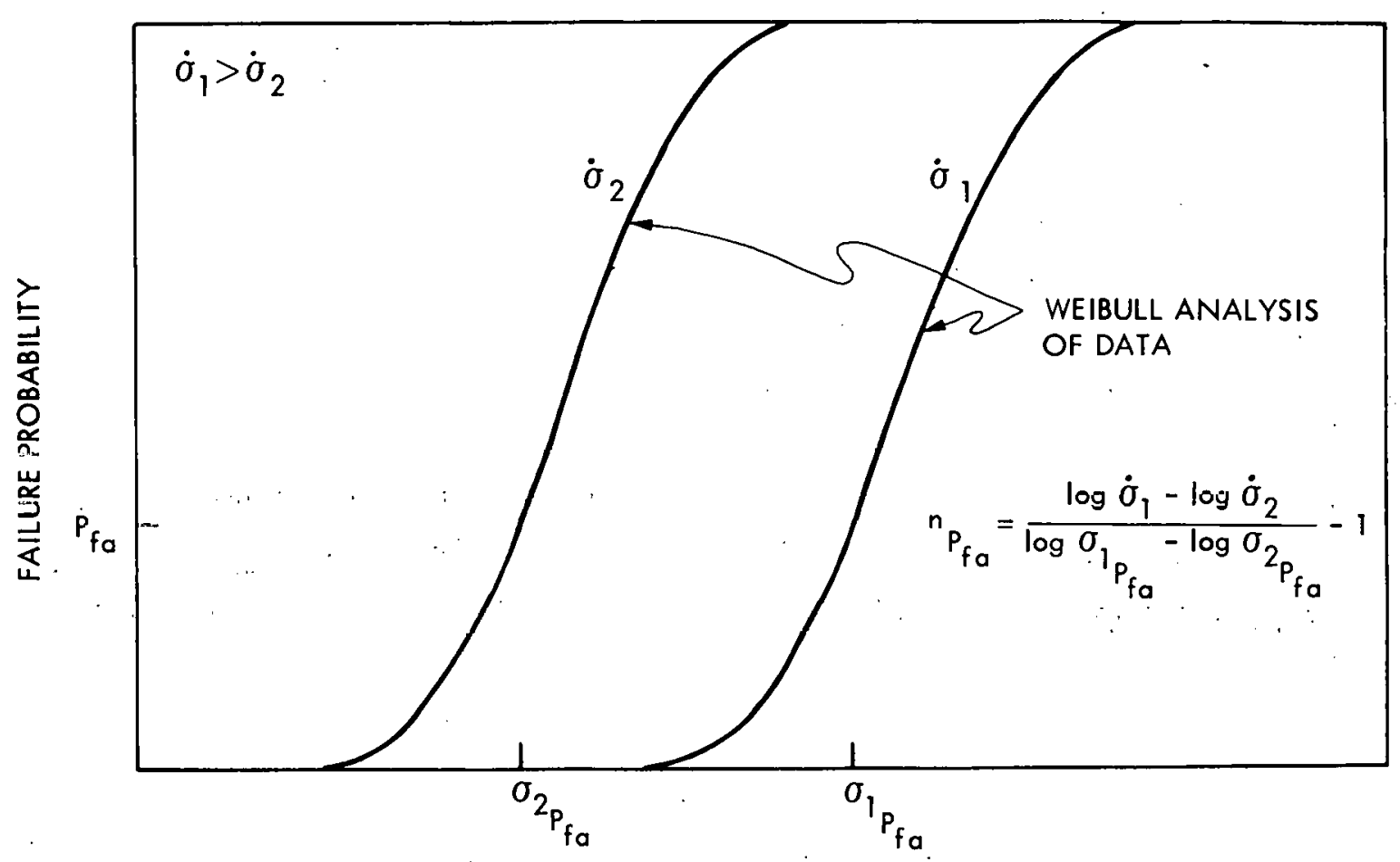

DYNAMIC FATIGUE STRENGTH

Figure 14. Determination of the Stress Corrosion Constant $n$, Under Dynamic Fatigue Utilizing Weakest Link Statistics

This weakest link statistical technique ensures that the stress corrosion constant is obtained from material which failed in a stress range where the probabilities of failure were equal. This can be determined by comparing the Weibull Modulus obtained from the statistical analysis on each set of strength data at the differing stress rates.

The Dynamic Loading Test will be conducted utilizing the four point: bend test technique described above in an ambient environment. This test will determine the following cellular glass properties:

- Modulus of Rupture as a Function of Loading Rate

- Stress Corrosion Constant in Tension 


\section{Static Fatigue}

Delayed failure under constant load due to subcritical crack growth is known as static fatigue (Ref. 15). The time to fail under static loading for glass is derived from the fracture mechanics relation for the stress intensity factor, $K_{I}=Y \sigma \sqrt{a}$ and the subcritical crack growth velocity expressed as $\mathrm{V}=\mathrm{AK}_{\mathrm{I}}^{\mathrm{n}}$ where $\sigma$ is the nominal applied tensile stress, $a$ is the flaw size, $Y$ is dependent on the flaw geometry and $\mathrm{A}$ and $\mathrm{n}$ are constant for a given material and environment. Except for very large crack lengths, $Y$ has little effect on the subcritical crack growth relationship (Ref. 16) and it can be considered as a constant. Combining the above relationships gives

$$
V=A(\sigma Y \sqrt{a})^{n}
$$

Since $\mathrm{V}=\frac{\mathrm{da}}{\mathrm{dt}}$ and failure occurs

when the flaw which causes failure grows from its initial size $\left(a_{i}\right)$ to the critical size $\left(a_{f}\right)$; then

$$
\begin{aligned}
\int^{t} \mathrm{f} d t & =\frac{1}{A Y^{n}{ }^{n}} a_{i} \int^{a_{f}} a^{-\frac{n}{2}} d a \text { or, } \\
t_{f} & =\frac{1}{A Y^{n}\left(1-\frac{n}{2}\right) \sigma^{n}}\left[a_{f}^{\left(1-\frac{n}{2}\right)}-a_{i}\left(1-\frac{n}{2}\right)\right]
\end{aligned}
$$

where $t_{f}$ is the failure time. For the case when $\left(a_{f} / a_{i}\right)\left(1-\frac{n}{2}\right)$ is small (typical of ceramic materials except for short times to failure)(Ref. 17),

$$
t_{f} \simeq \mathrm{Ca}_{i}\left(\frac{\mathrm{n}}{2}-1\right) \quad \sigma^{-n}
$$

where

$$
C=\frac{1}{A Y^{n}\left(\frac{n}{2}-1\right)} .
$$

The stress corrosion constant $n$ can be determined from the slope of the $\log$ failure time as a function of the log stress at $\mathrm{C}=$ constant. 
Large variations in the failure time for cellular glass (see Figure 5) subjected to static fatigue under identical test environments occur due to large variations in the initial crack size, $a_{i}$. However, static fatigue design criteria can be determined as illustrated in Figure 15 for cellular glass from the failure probability as a function of the failure time at different stress levels from weakest link statistical analysis of test data as illustrated in Figure 16.

The Static Fatigue Test will be conducted utilizing the four-point bend test technique described above in several environments. Thio tcot will determine the static fatigue characteristic of cellular glass materials under different environments (humidity). The stress corrosion constant $n$ will also be determined from the testing when appropriate.

\section{Cyclic Fatigue}

In addition to static fatigue and dynamic fatigue, cyclic fatigue of cellular glass must be considered. It has been shown that subcritical crack growth parameters determined under static fatigue predict crack propagation in dense soda lime silicate glass under cyclic fatigue (Ref. 17). The cyclic behavior or failure mechanism for cellular glass may differ from that of static or dynamic fatigue. Therefore, to determine the cyclic behavior of cellular glass materials, specimens will be subjected to cyclic loading utilizing the four-point bend test configuration. The number of cycles to failure at a given environment and stress cycle will relate the cyclic fatigue behavior of cellular glass to the static and dynamic fatigue behavior.

\section{Compressive Test With Displacement Determination}

A uniaxial compressive stress state is achieved by end loading a cylindrical specimen which has a reduced test section as shown in Figure 17. The maximum compressive stress is developed in the reduced test section. 


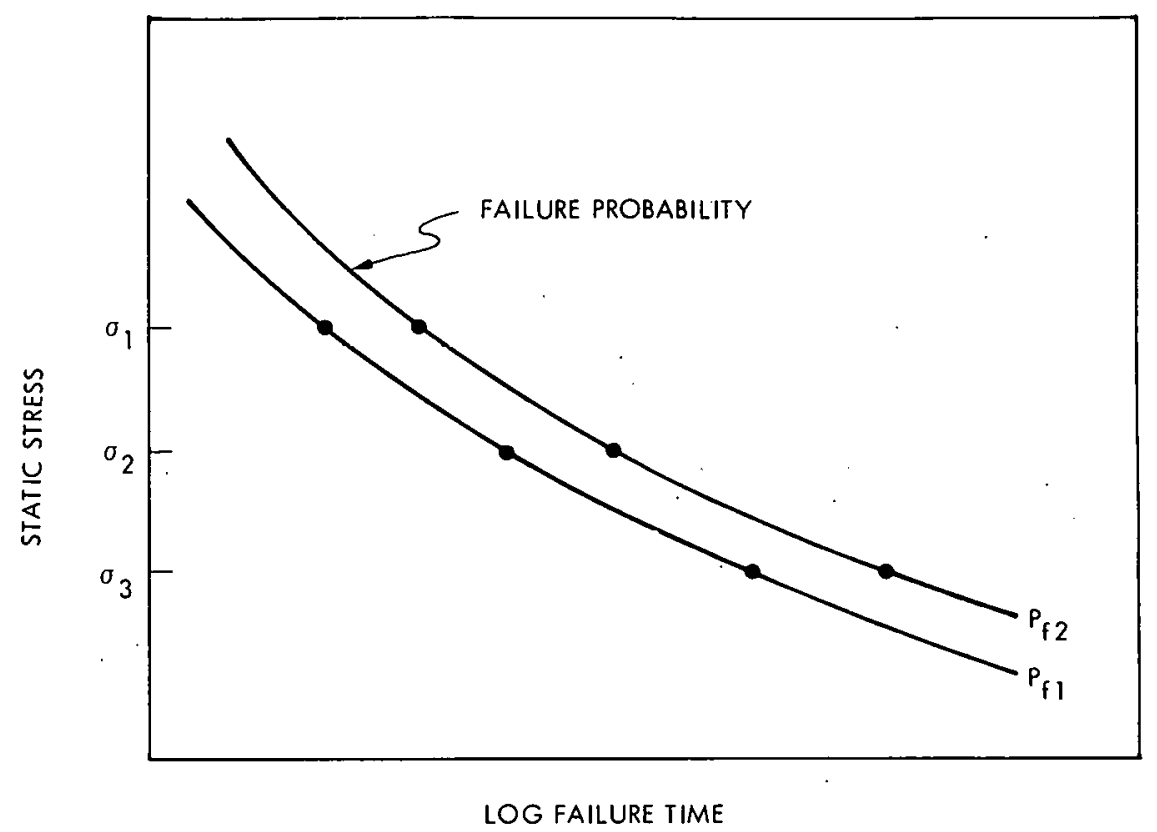

Figure 15. Static Fatigue Design Criteria

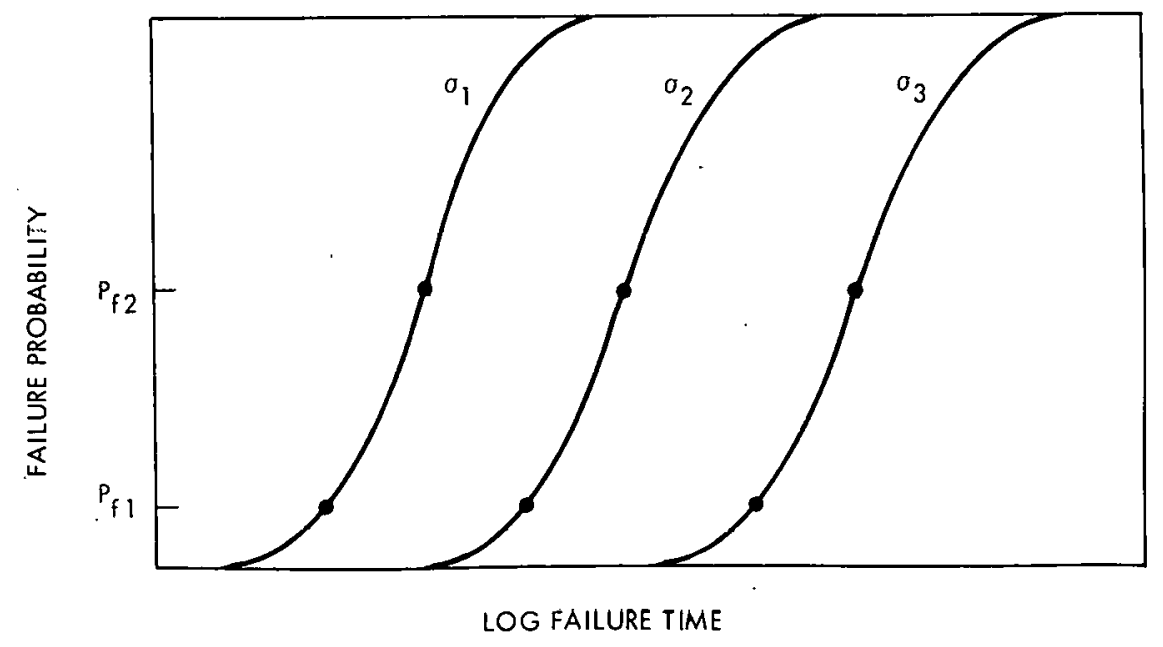

Figure 16. Failure Probability. as a Function of Time Under Static Fatigue 

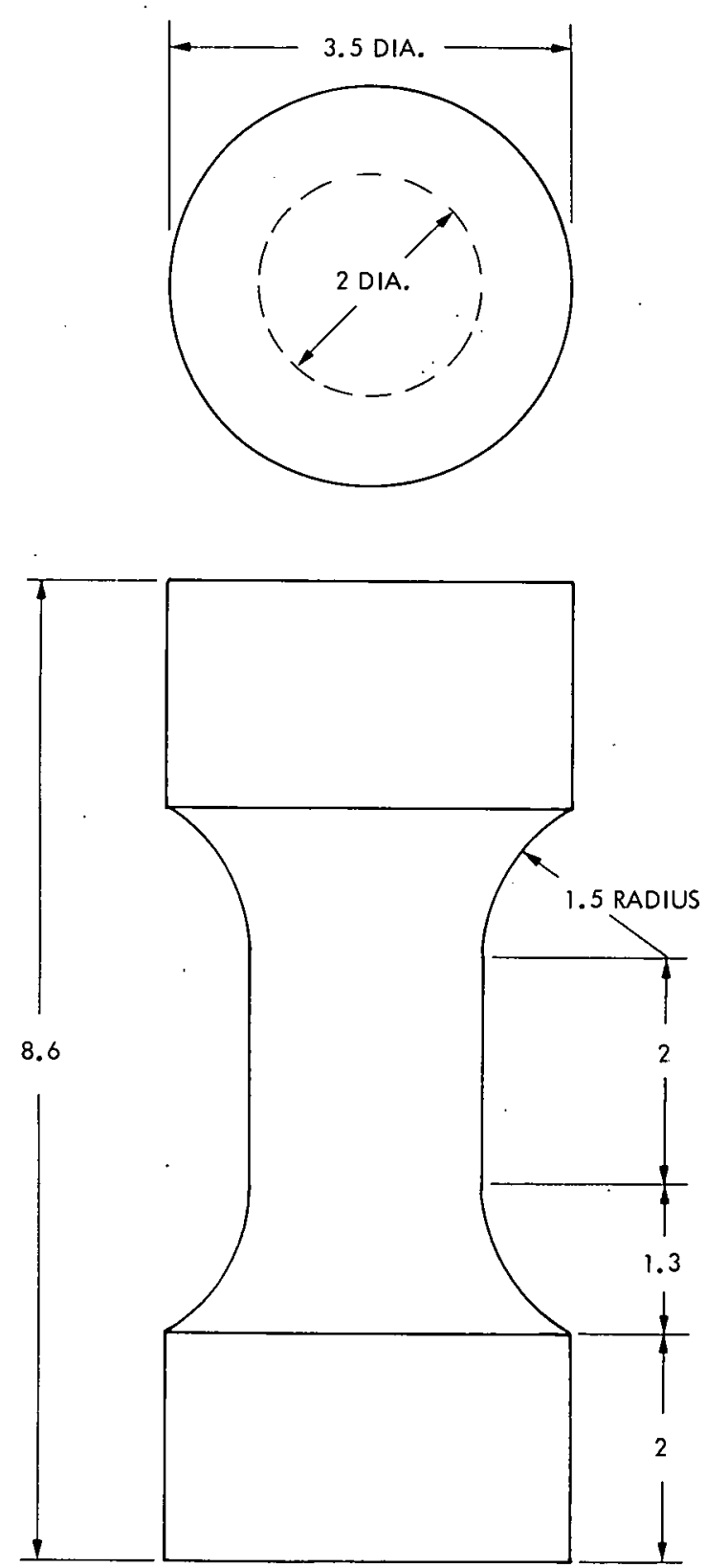
There are many problems related to the compressive testing of brittle materials (Ref. 18 ). Since britt le materials, which include cellular glasses, are many times stronger in compression than tension, unwanted tensile stresses can lead to premature failure. Large tensile stresses can be induced due to off axis loading, specimen buckling, and expansion mismatch between the test material and the loading platens. Care was taken to minimize or eliminate these tensile stresses.

The specimen geometry initially selected for preliminary compressive testing led to premature failures in the reduced section just below the radius which was caused by a stress concentration. A calculated compressive stress concentration (Ref. 19) of $20 \%$ due to the geometry shown in Figure 17 lead to these failures. A redesign of the compressive specimen as shown in Figure 18 greatly reduces this concentrated compressive stress (Ref. 20 ). The compressive data presented in the following section, which should be considered as the lower bound of compressive strength, was obtained with the original specimen and is presented to illustrate the advantages of utilizing cellular glass in compressive stress states either by design or by compressive preloading techniques.

The uniaxial compressive technique is useful in determining the following engineering compressive property data:

- Compressive Strength

- Modulus of Elastic in Compression

- Stress Rate Sensitivity of Strength

Pittsburgh Corning Corporation reports the compressive strength of their cellular glass materials as determined under ASTM C165 test standards with the material surfaces capped with hot asphalt per ASTM C240-72 (Ref. 4). This test technique imposes a complex stress state on the cellular glass material similar to that developed in insulation applications. The testing technique involves the loading of large thin plates which generates transverse stresses in the cellular glass just 

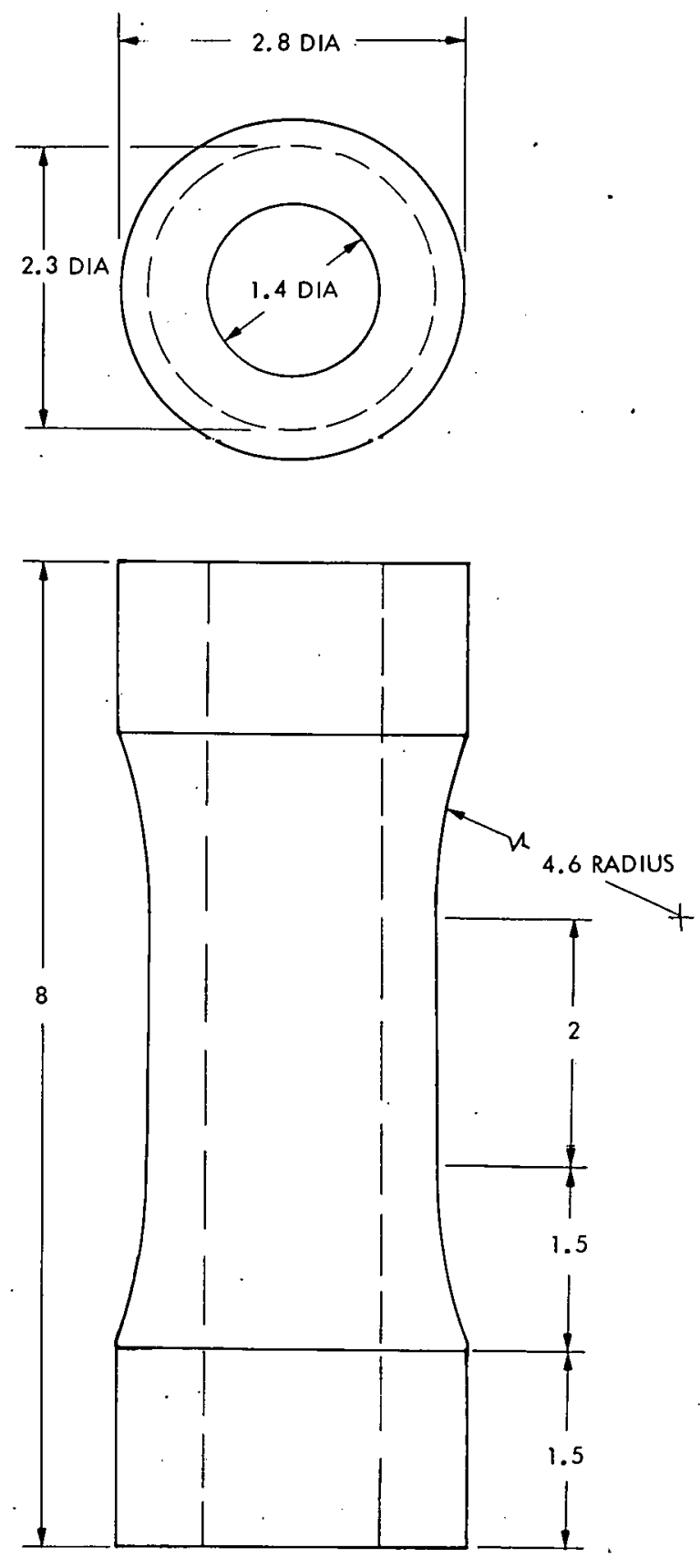

Figure 18. Redesigned Uniaxial Compression Specimen 
below the surface coating due to compliance mismatch. It also has the problem of lack of uniformity of stress over the large planar area of the test specimen. Although the failures may be tensile or related to other inadvertent stresses, which result in low compressive strength values, the compressive strengths reported by Pittsburgh Corning are realistic for design applications which develop stress states similar to that of their test configuration.

6. Torsion Test With Displacement Determination

The shear properties of cellular glass can be determined by subjecting specimens similar to the uniaxial compressive specimen shown in Figure 18 to torsional loading. Care must be taken to eliminate tensile stresses induced from bending loads. The modulus of elasticity in shear can be calculated from the torsional displacement of the specimen as a function of the applied load. Poisson's Ratio can then be calculated from the measured modulus of elasticity in tension and shear. Therefore the following properties of cellular glass materials will be determined from this test technique:

- Shear Strength as a Function of Loading Rate

- Modulus of Elasticity in Shear

- Poisson's Ratio.

7. Volume/Strength Relationship

The strength to stressed volume relationship as discussed in Section IV can be determined with appropriate statistical tools and experimental data. Experimental data is obtained by subjecting cellular glass specimens, with increasing stressed volumes to tensile loads via the four point bend testing technique described earlier. Identical test conditions (environment, stressing rate, stress state) must be preserved during the course of the testing program to ensure meaningful data. 
8. Fracture Toughness

The critical stress intensity factor $\mathrm{K}_{\mathrm{IC}}$ given by (Ref. 21)

$$
\mathrm{K}_{\mathrm{IC}}=\mathrm{Y \sigma _{ \textrm {f } }} \sqrt{\mathrm{a}_{\mathrm{f}}}
$$

where $\mathrm{Y}=$ geometric factor

$$
\begin{aligned}
& \sigma_{f}=\text { failure stress } \\
& a_{f}=\text { final flaw size }
\end{aligned}
$$

can be determined for cellular glass under dynamic loading. Since it is difficult to distinguish the flaw size and geometry which causes failure, a flaw can be machined into the test specimen giving both the geometric factor $Y$ and the critical flaw size $a_{f}$ only if no slow crack growth occurs during loading. This can be accomplished by loading the specimen. at a very fast rate in an inert environments. Any change in the strength measured at different loading rates indicates. slow crack growth is occurring; therefore specimens should be tested on several fast loading rates to ensure proper test conditions. The Fracture Toughness Test to determine $\mathrm{K}_{\mathrm{IC}}$ of cellular glass materials will be conducted under four point bend with a single edge notched specimen.

\section{Double Torsion}

It has been determined that the dynamics of slow crack growth can be described as a power function (Ref. 22) of the crack growth velocity $V$ and the applied stress intensity factor $\mathrm{K}_{I}$ given by

$$
\mathrm{V}=\mathrm{AK}_{\mathrm{I}}^{\mathrm{n}}
$$

where the stress corrosion constant $n$ and the environmental factor $A$ are assumed to be constants, both dependent on the material and the environment. The determination of these parameters will enable the prediction of time to fail due to slow crack growth for static, dynamic and perhaps cyclic fatigue of cellular glass. 
The Double Torsion Test offers an accurate technique for describing the $V, K_{I}$ relationship over a wide range of crack velocities including very low velocities ( $\left.\dot{\mathrm{e}} \cdot \mathrm{g} ., 10^{-8} \mathrm{~m} / \mathrm{sec}\right)$. which are of interest in predicting long term strength (Refs. 23, 24). This testing technique involves the torsional loading of a center grooved plate. The crack grows along the groove while under a constant $K_{I}$. The crack velocity is determined by the change in compliance of the specimen eliminating the need for optical or displacement measurements. The specimen geometry must be selected with appropriate compliance/crack length sensitivity to ensure accurate data (Ref. 25).

The Double Torsion Test conducted in several environments wili characterize the following cellular glass slow crack growth parameters:

- Stress Corrosion Constant, $\mathrm{n}$

- Environmental Factor, A

- Stress Intensity Factor/Crack Velocity Relationship $\left(K_{I}, V\right)$.

10. High Temperature/High Humidity Cycling

The chemical stability of cellular glass materials in meteorology environments will be evaluated by subjecting four-point bend test specimens to high temperature/high humidity cycling. The material will then be examined to determine if corrosive reactions or leaching occur and the dynamic fatigue strength will be measured.

11. Freeze/Thaw Cycling

The freeze thaw sensitivity of cellular glass materials will be determined by subjecting four-point bend test specimens to thermal cycling through $0^{\circ} \mathrm{C}$ with free water present on the surface of the closed cell material or absorbed in open cell material. The material degradation will be determined as a function of the number of cycles and material density. When possible, the specimens will be tested in dynamic 
fatigue to determine if damage other than surface erosion occurs in freeze thaw environments. Specimens with conformal coatings will also be evaluated in the freeze thaw test to determine the effectiveness of the coating in eliminating the availability of water on the cellular glass.

\section{TEST PROCEDURE AND RESULTS}

\section{Tensile Strength}

Both transverse normal and transverse perpendicular celiular glass specimens were machined from blocks as shown in Figure 19. They were then subjected to four-point bend loading at a constant displacement rate of .5 inches per minute. Figure 20 shows the test fixture with failed specimens.

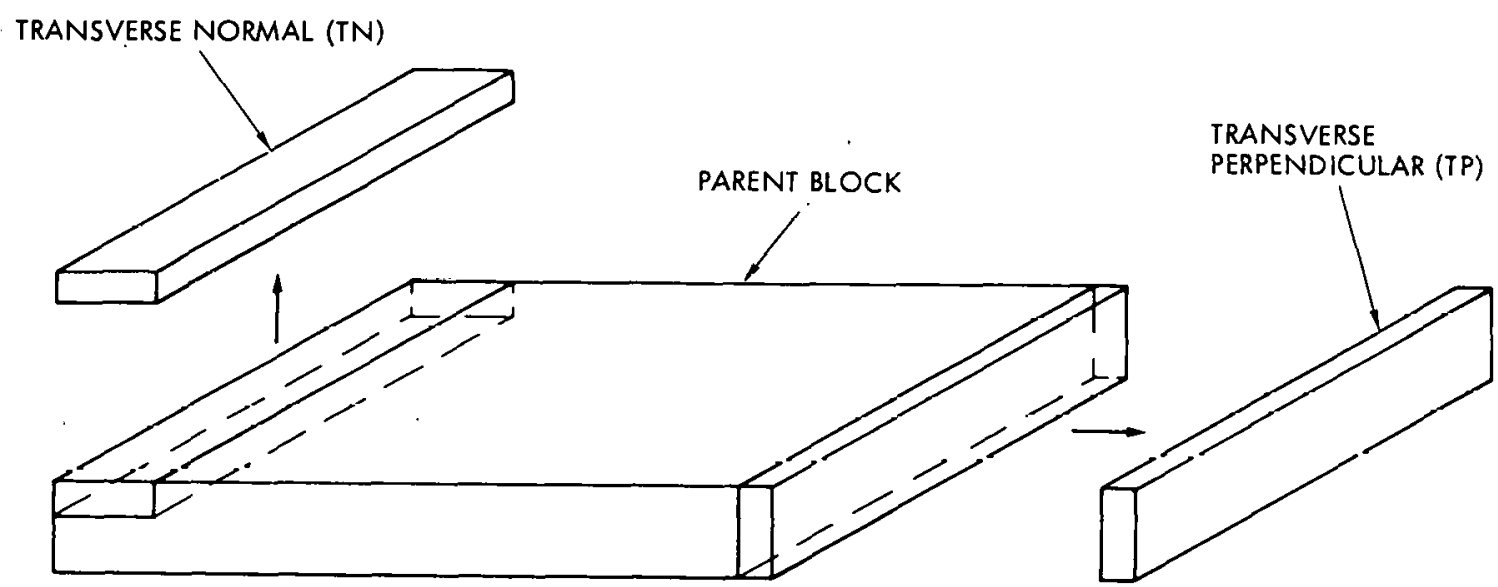

Figure 19. Four-Point Bend Specimen to Rlork Drientation

A summary of the test data for each material tested as a function of the orientation is presented in Table 9. Before each test, the test set-up was examined to ensure the load lines were in contact with specimen surface eliminating torsional stresses. Each specimen failed by the extension of a crack within the test section. 


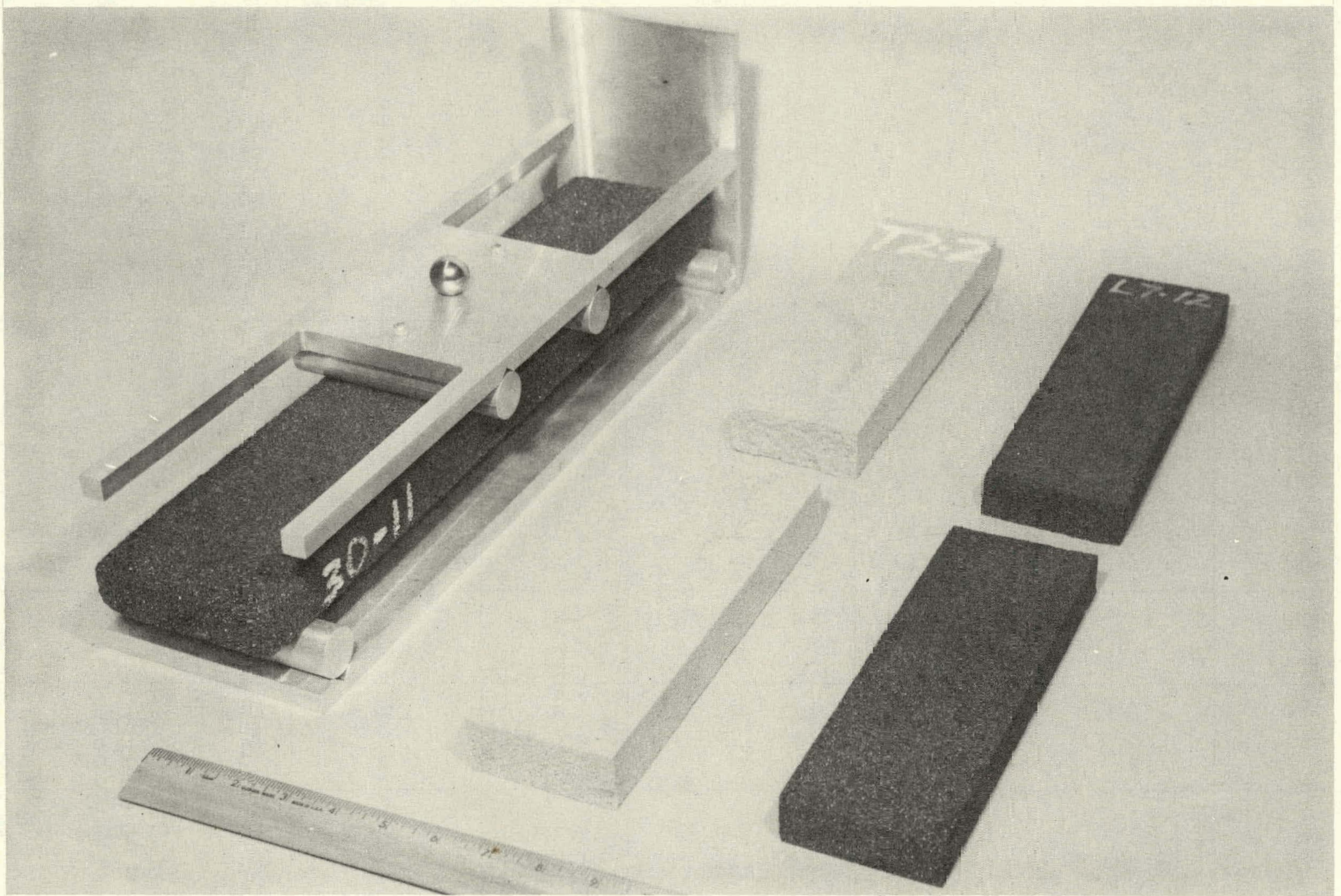

Figure 20. Four-Point Bend Test Fixture with Failed Specimens 
Table 9. Tensile Strength of Several Cellular Glass Materials

\begin{tabular}{|c|c|c|c|c|c|c|}
\hline Material & $\begin{array}{l}\text { Average } \\
\text { Density } \\
\text { (1bs/ft } 3 \text { ) }\end{array}$ & $\begin{array}{l}\text { Number } \\
\text { Tested }\end{array}$ & Orientation* & $\begin{array}{c}\text { Average } \\
\text { Tensile } \\
\text { Strength } \\
\quad \text { (psi) }\end{array}$ & $\begin{array}{l}\text { Standard } \\
\text { Deviation } \\
\text { (psi) }\end{array}$ & C.V.** \\
\hline $\begin{array}{l}\text { Closed Cell Soda } \\
\text { Lime Silicate }\end{array}$ & $\begin{array}{l}8.5 \\
8.5\end{array}$ & $\begin{array}{l}29 \\
30\end{array}$ & $\begin{array}{l}\mathrm{TN} \\
\mathrm{TP}\end{array}$ & $\begin{array}{l}93.2 \\
81.0\end{array}$ & $\begin{array}{l}5.50 \\
3.97\end{array}$ & $\begin{array}{l}0.059 \\
0.049\end{array}$ \\
\hline $\begin{array}{l}\text { Closed Cell } \\
\text { Aluminoborosilicate }\end{array}$ & $\begin{array}{l}11.8 \\
12.0 \\
13.8 \\
14.1 \\
16.3 \\
16.6\end{array}$ & $\begin{array}{r}11 \\
21 \\
33 \\
8 \\
15 \\
24\end{array}$ & $\begin{array}{l}\text { TP } \\
\text { TN } \\
\text { TN } \\
\text { TP } \\
\text { TP } \\
\text { TN }\end{array}$ & $\begin{array}{l}124.4 \\
132.9 \\
178.9 \\
169.4 \\
190.1 \\
209.0\end{array}$ & $\begin{array}{c}13.7 \\
15.1 \\
24.1 \\
6.50 \\
23.7 \\
19.7\end{array}$ & $\begin{array}{l}0.110 \\
0.114 \\
0.135 \\
0.039 \\
0.125 \\
0.094\end{array}$ \\
\hline
\end{tabular}

* See Figure 19

${ }^{* *}$ Coefficient of Variation $=$ standard deviation/average value 


\section{Elastic Modulus}

The elastic modulus was determined from the load deflection relationship during four-point bend testing. Several specimens were loaded and the maximum deflection was measured using a clip gauge between the specimen and the fixture base. The cross head displacement was also measured through the testing machine (Instron) instrumentation. Table 10 presents the measured elastic modulus for several materials and densities.

\section{Stress Corrosion Constant}

Two stressing rates were used to determine the dynamic fatigue tensile strength at a given density for each material tested. From this, the stress corrosion constant for each material was determined. Table 11 presents the measured strengths at different stress rates and the stress corrosion constants as calculated from the average strength. Figure 21 illustrates the dependency of tensile strength to stressing rate for several cellular glass materials. The calculated value of the stress corrosion constant is a function of the failure probability for any material tested as shown in Figure 22.

\section{Static Fatigue}

Soda lime Foamglas ${ }^{\circledR}$ specimens machined in the transverse perpendicular direction from parent blocks (Figure 19) were loaded in four-point bend. Static loads were applied and the time to fail as a function of the stress level was measured. Table 12 presents the findings at the three stress levels, and Figure 23 plots the average failure time as a function of the stress level. 
Tatle 10. Elastic Modulus of Several Cellular Glass Materials in Bending

\begin{tabular}{|c|c|c|c|c|c|c|}
\hline Material & $\begin{array}{l}\text { Average } \\
\text { Density } \\
\left(1 \mathrm{~b} / \mathrm{ft}^{3}\right)\end{array}$ & $\begin{array}{l}\text { Number } \\
\text { Tested }\end{array}$ & Orientation & $\begin{array}{l}\text { Average } \\
\text { Elastic } \\
\text { Modulus, E } \\
\text { (psi x 105) }\end{array}$ & $\begin{array}{c}\text { Standard } \\
\text { Deviation } \\
\left(\text { psi } \times 10^{5}\right)\end{array}$ & C.V. \\
\hline $\begin{array}{l}\text { Closed Cel1 Soda } \\
\text { Lime Silicate }\end{array}$ & 8.5 & 8 & TP & 0.947 & 0.145 & 0.153 \\
\hline $\begin{array}{l}\text { Open Cell Soda Line } \\
\text { Silicate }\end{array}$ & $\begin{array}{l}16.6 \\
16.6\end{array}$ & $\begin{array}{l}36 \\
17\end{array}$ & $\begin{array}{l}\text { TP } \\
\text { TN }\end{array}$ & $\begin{array}{l}1.76 \\
1.85\end{array}$ & $\begin{array}{l}0.165 \\
0.299\end{array}$ & $\begin{array}{l}0.094 \\
0.162\end{array}$ \\
\hline \multirow[t]{6}{*}{$\begin{array}{l}\text { Closed Cell } \\
\text { Aluminoborosilicate }\end{array}$} & & 11 & $\mathrm{TN}$ & 2.21 & 0.151 & \\
\hline & 12.0 & 21 & $\mathrm{TP}$ & 2.25 & 0.259 & 0.115 \\
\hline & 13.8 & 23 & $\mathrm{TP}$ & 2.82 & 0.264 & 0.094 \\
\hline & 14.1 & 10 & $\mathrm{TN}$ & 3.03 & 0.163 & 0.054 \\
\hline & 16.3 & 33 & TN & 3.45 & 0.408 & 0.118 \\
\hline & 16.6 & 22 & $\mathrm{TP}$ & 3.61 & 0.229 & 0.063 \\
\hline
\end{tabular}


Table 11. Stress Corrosion Constant for Several Cellular Glass Materials

\begin{tabular}{|c|c|c|c|c|c|}
\hline Material & $\begin{array}{l}\text { Average } \\
\text { Density } \\
\left(1 \mathrm{~b} / \mathrm{ft} \mathrm{t}^{3}\right)\end{array}$ & $\begin{array}{l}\text { Number } \\
\text { Tested }\end{array}$ & $\begin{array}{l}\text { Stress } \\
\text { Rate } \\
\text { (psi/ } \\
\text { sec.) }\end{array}$ & $\begin{array}{l}\text { Average } \\
\text { Strength } \\
\quad(\text { psi) }\end{array}$ & $\begin{array}{c}\text { Stress } \\
\text { Corrosion } \\
\text { Constant } \\
\mathrm{n}\end{array}$ \\
\hline \multirow{2}{*}{$\begin{array}{l}\text { Closed Cell Soda } \\
\text { Lime Silicate }\end{array}$} & 8.5 & 30 & 17.0 & 81.0 & \multirow{2}{*}{18.2} \\
\hline & 8.5 & 30 & 1.70 & 71.8 & \\
\hline \multirow{2}{*}{$\begin{array}{l}\text { Open Cell Soda } \\
\text { Lime Silicate }\end{array}$} & 16.6 & 18 & 25.3 & 175.1 & \multirow{2}{*}{21.7} \\
\hline & 16.6 & 17 & 2.53 & 158.1 & \\
\hline \multirow{2}{*}{$\begin{array}{l}\text { Closed Cel1 } \\
\text { Aluminoborosilicate }\end{array}$} & 16.3 & 15 & 43.3 & 190.1 & \multirow{2}{*}{18.6} \\
\hline & 16.3 & 17 & 4.33 & 169.2 & \\
\hline
\end{tabular}

Table 12. Failure Time at a Static Stress for Soda Lime Silicate Foamglas (B)

\begin{tabular}{|c|c|c|}
\hline Number Tested & $\begin{array}{c}\text { Stress Leve1 } \\
\text { (psi) }\end{array}$ & $\begin{array}{c}\text { Average } \\
\text { Failure Time }\end{array}$ \\
\hline 10 & 63 & $19.1 \mathrm{~min}$. \\
10 & 52 & $4.1 \mathrm{hrs}$. \\
5 & 43 & 2 days \\
\hline
\end{tabular}

Temperature $\sim 70^{\circ} \mathrm{F}$

Humidity $\sim 40 \%$ 


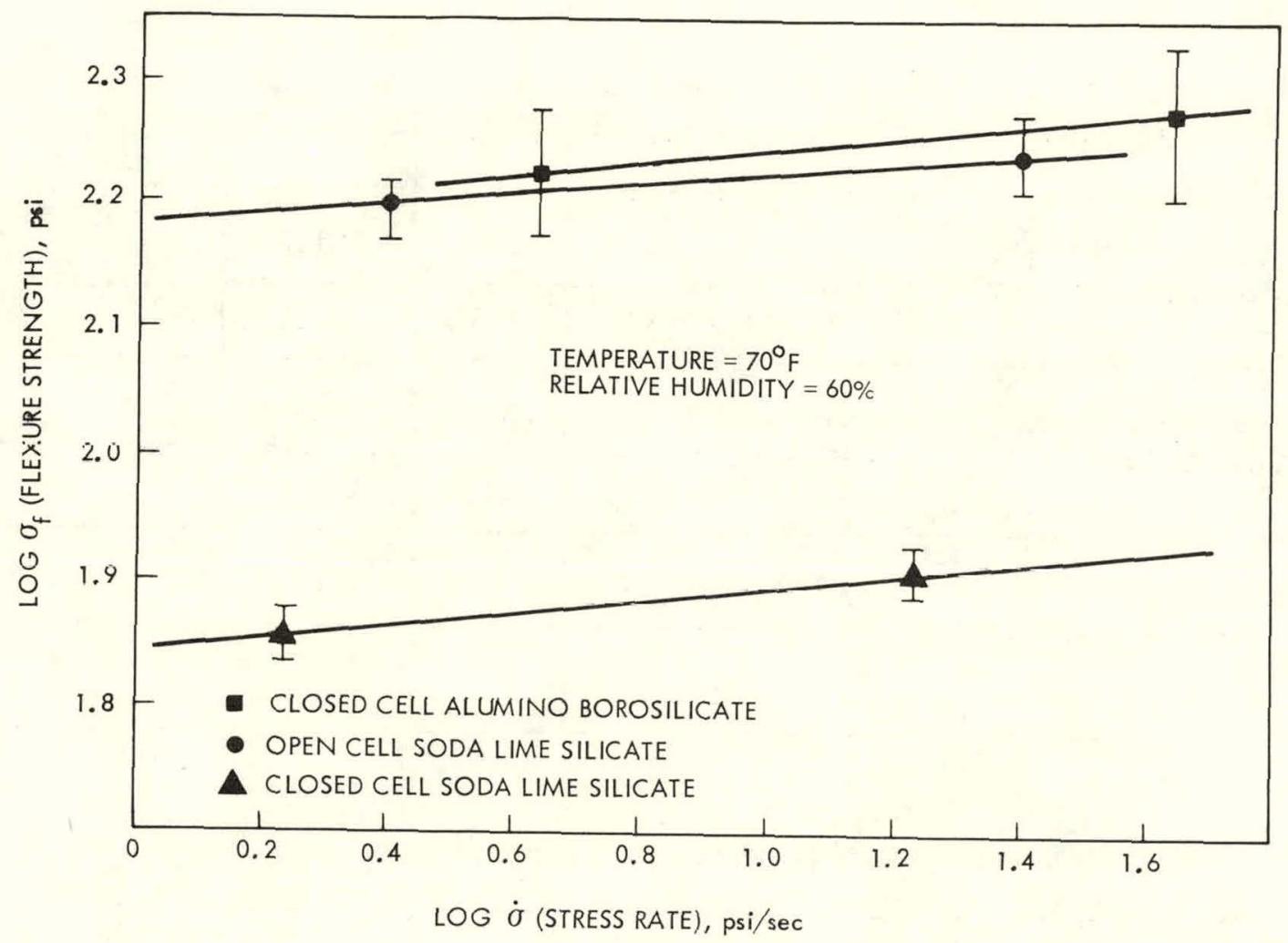

Figure 21. Stressing Rate Effect on the Tensile Strength of Several Cellular Glass Materials 


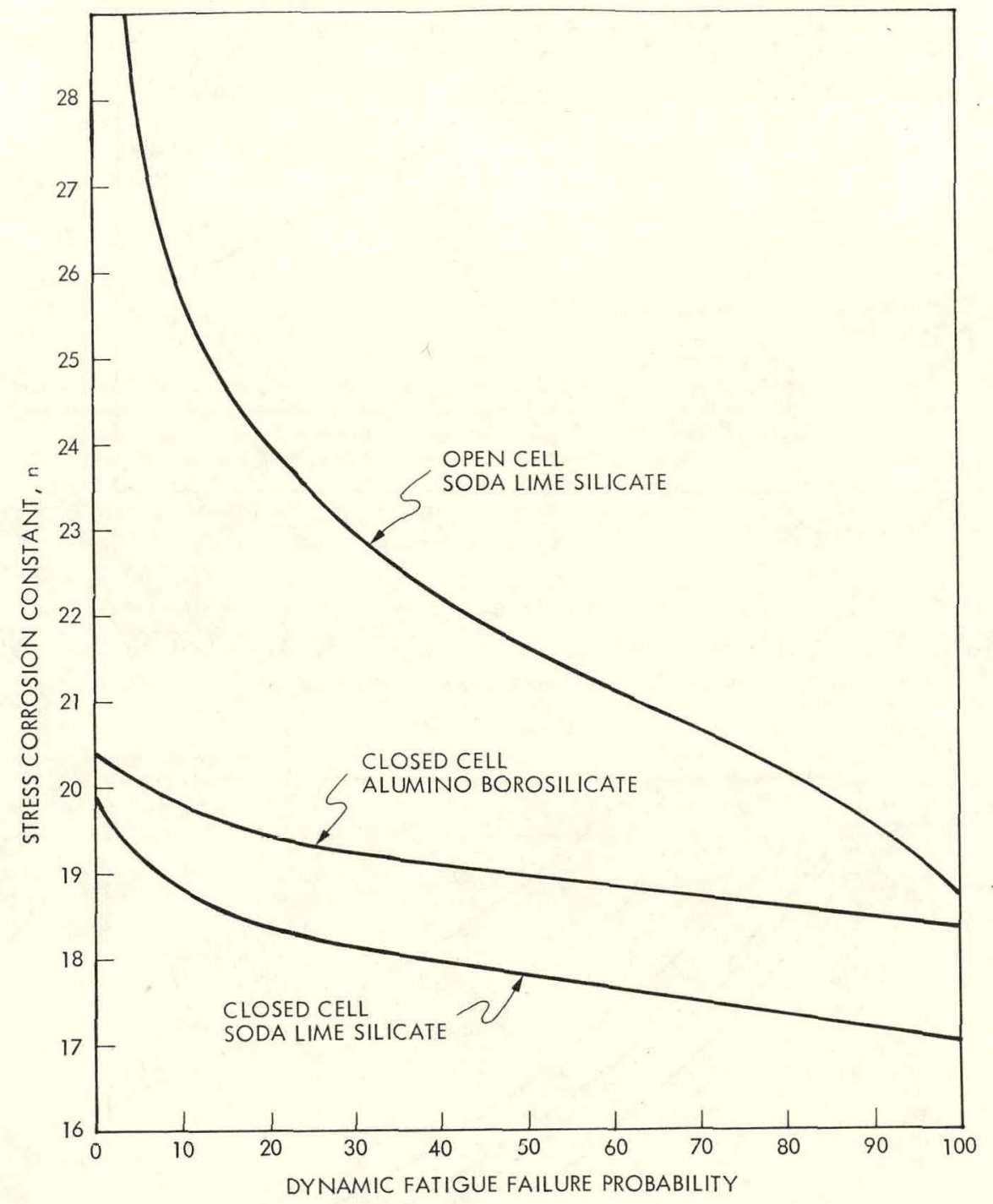

Figure 22. The Stress Corrosion Constant as a Function of Failure Probability

A weakest link statistical analysis was conducted on the Foamglas static fatigue data. The static fatigue design criteria determined by analysis of the limited data are presented in Figure 24. This information is preliminary and it should not be used for design purposes. 


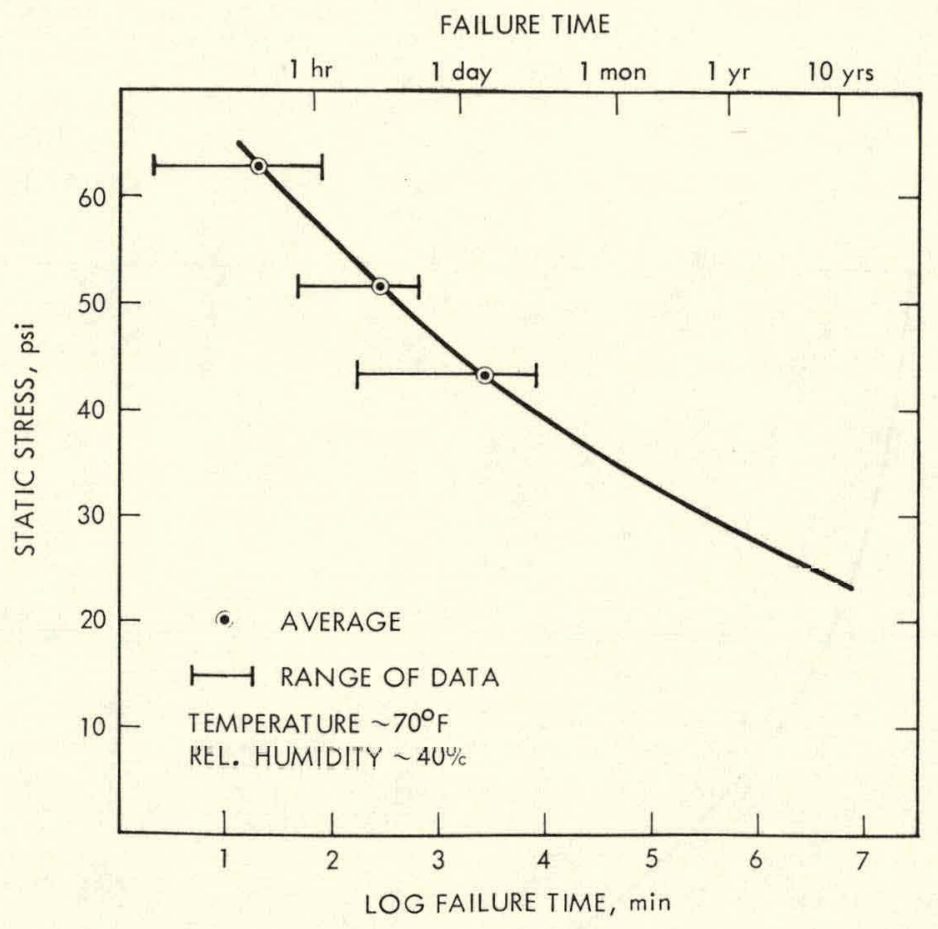

Figure 23. Failure Time as a Function of Applied Static Stress for Soda Lime Silicate Foamglas $($ )

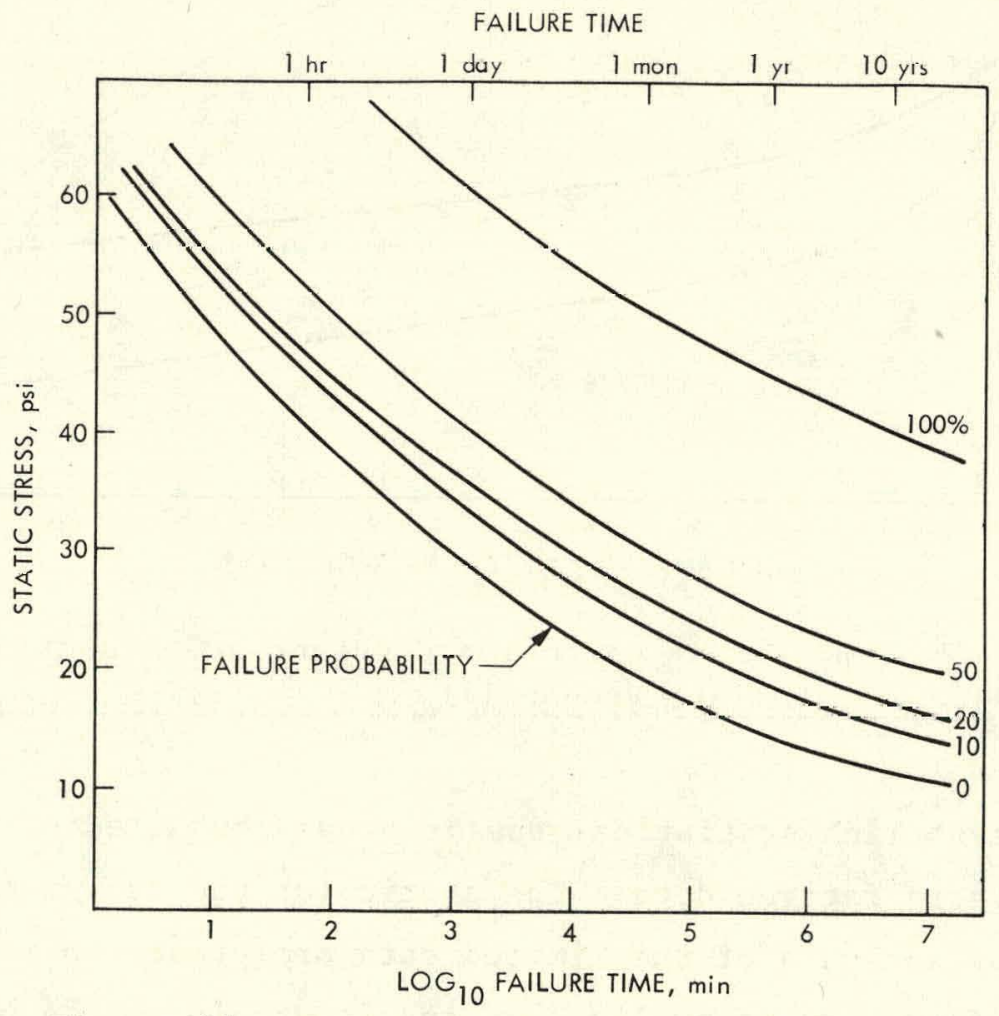

Figure 24. Static Fatigue Design Criteria for Soda Lime Silicate Foamglas ${ }^{\circ}$ 


\section{Compressive Strength}

Compressive specimens were machined from blocks in the transverse normal direction; then subjected to compressive loading at a stressing rate of $55.6 \mathrm{psi} / \mathrm{sec}$ and $5.6 \mathrm{psi} / \mathrm{sec}$. To date only soda lime silicate Foamglas ${ }^{\circledR}$ has been tested. Table 13 presents the results. All the specimens failed in the test section at the edge of the radius as shown in Figure 25. The failure location is due to a $20 \%$ concentration of stress at the point of radius blend into the reduced test section.

\section{Volume/Strength Relationship}

In order to determine the relationship between strength and stressed volume for cellular glass, three sizes of soda lime Foamglas ${ }^{(B)}$ specimens were tested in four-point bend. Figures 20, 26 , and 27 show these sizes. The specimens were machined from blocks in the transverse normal orientation and tested at the same stress rate. Table 14 presents the test results.

A statistical analysis was conducted to determine the size to stressed volume relationship utilizing the two parameter Weibull's analysis. The results of the analysis is presented in Figure 28. This information is preliminary in that it is based on a small number of tests.

Table 13. Compressive Strength of Soda Lime Silicate Foamglas @ at Two Stressing Rates

\begin{tabular}{|c|c|c|c|c|c|}
\hline $\begin{array}{c}\text { Stress } \\
\text { State }\end{array}$ & $\begin{array}{c}\text { Number } \\
\text { Tested }\end{array}$ & $\begin{array}{c}\text { Stressing } \\
\text { Rate } \\
\text { (psi/sec.) }\end{array}$ & $\begin{array}{c}\text { Strength } \\
\text { (psi) }\end{array}$ & $\begin{array}{c}\text { Standard } \\
\text { Deviation } \\
\text { (psi) }\end{array}$ & C.V. \\
\hline \multirow{2}{*}{$\begin{array}{c}\text { Uniaxia1 } \\
\text { Compression }\end{array}$} & 20 & 55.6 & 394.4 & 46.8 & 0.119 \\
\cline { 2 - 6 } & 15 & 5.6 & 385.8 & 42.4 & 0.110 \\
\hline
\end{tabular}




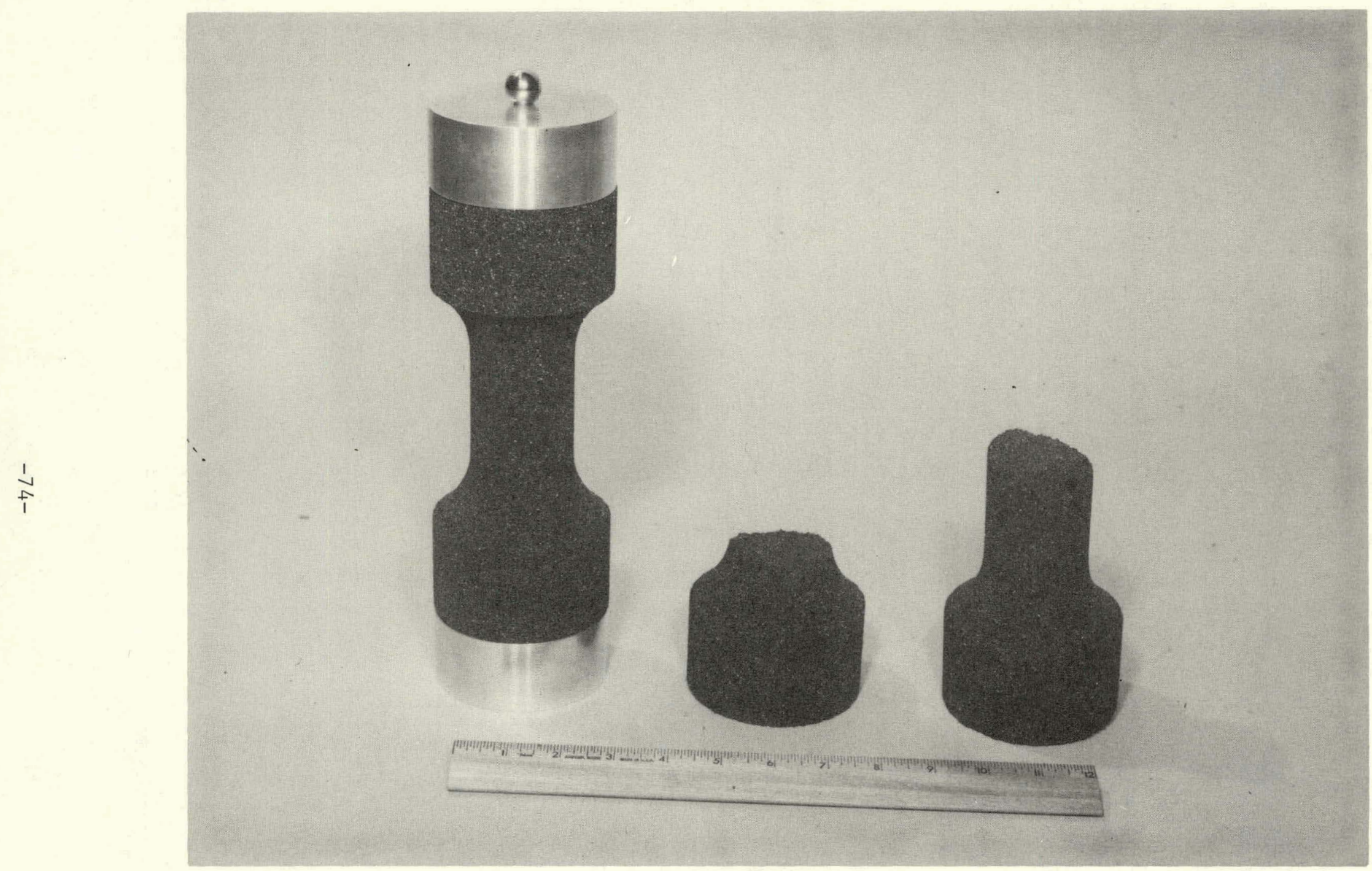

Figure 25. Compression Test Fixture With Failed Specimen 


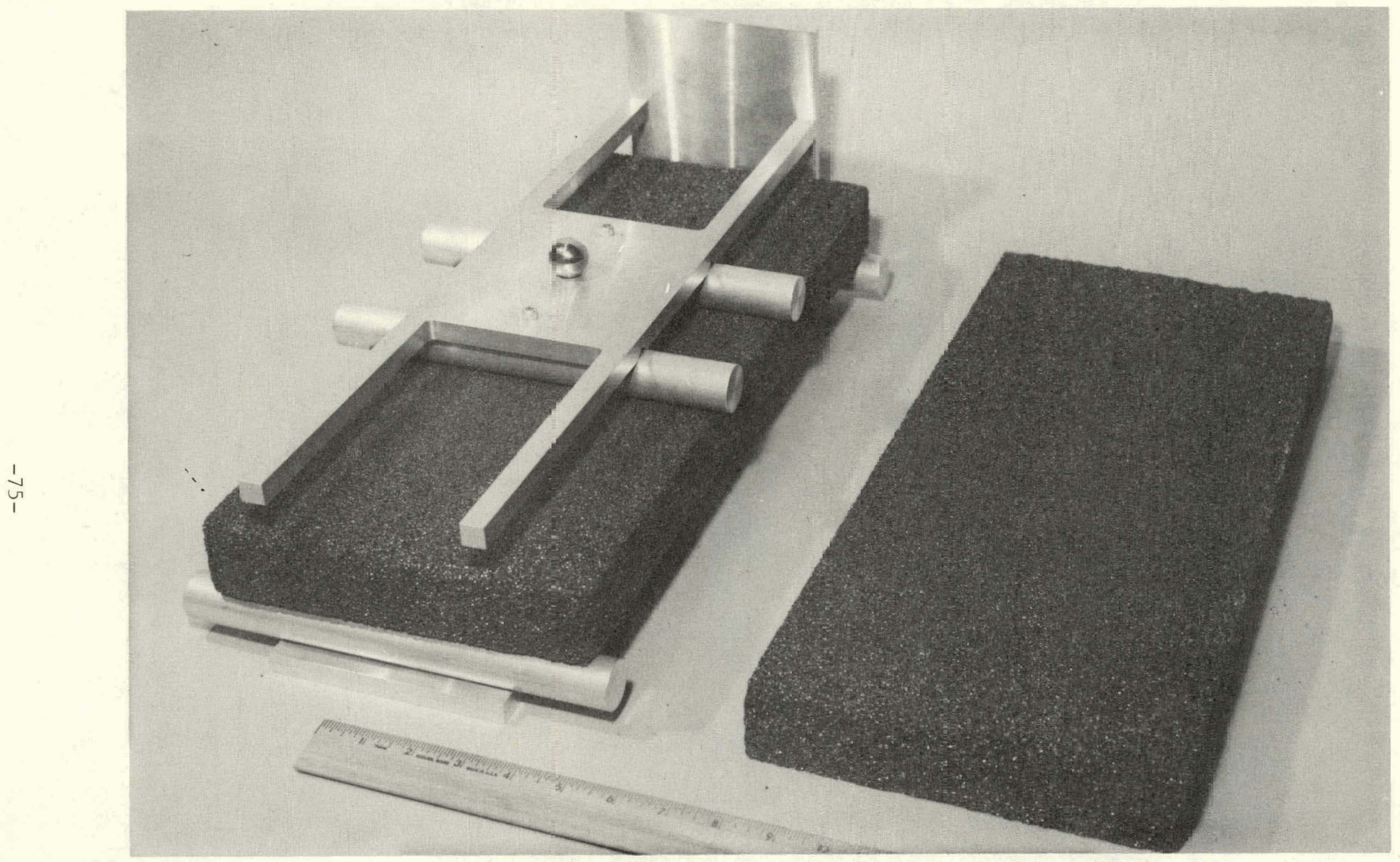

Figure 26. Intermeliate Size Four-Point Bend Test Fixture With Sfeciren 


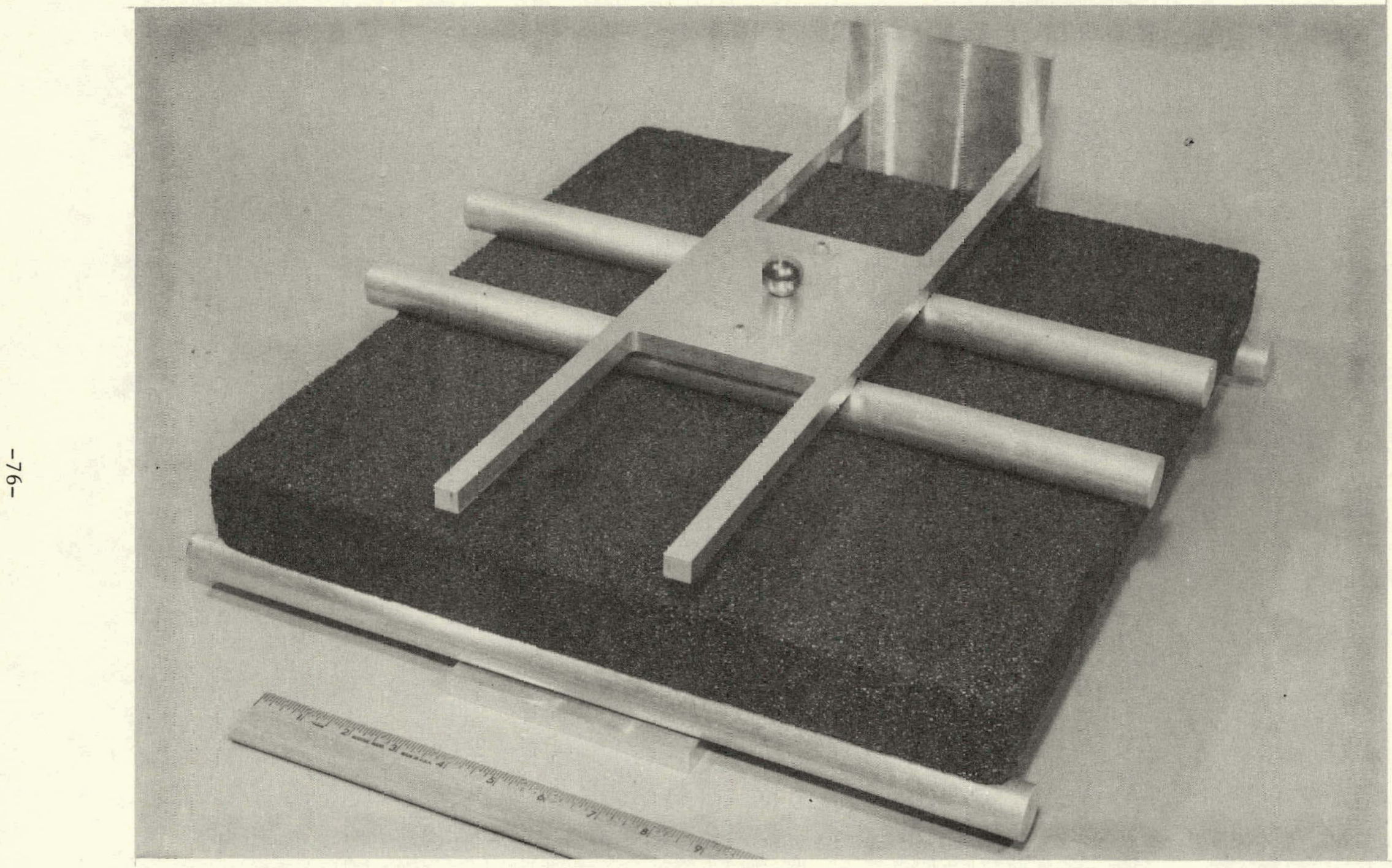

Figure 27. Large Size Fcur-Point Bend Test Fixture With specimen 


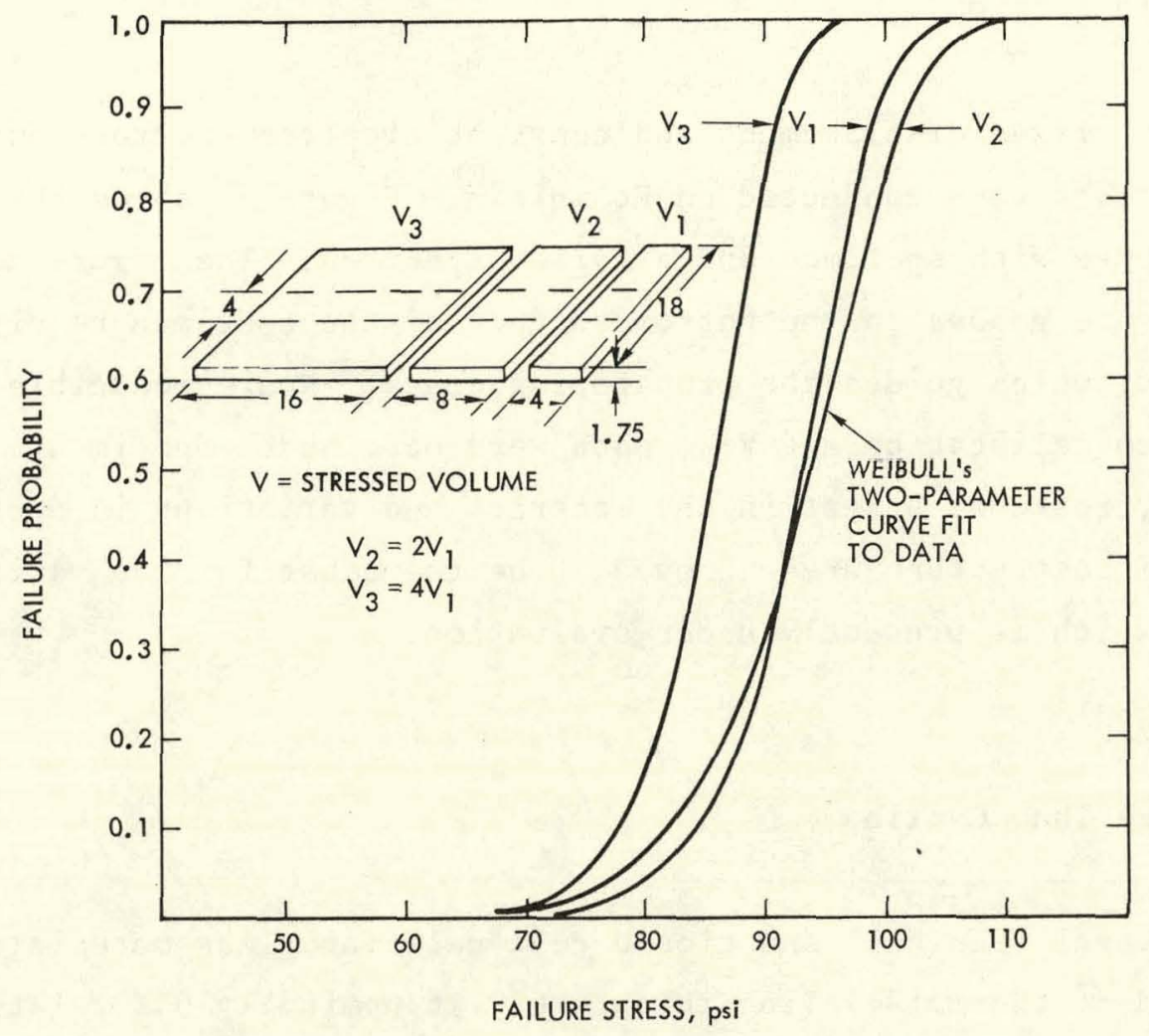
Figure 28. Strength to Volume Effect for
Soda Lime Silicate Foamglas $B$

Table 14. The Tensile Strength of Soda Lime Silicate Foamglas ( as a Function of the Stressed Surface Area

\begin{tabular}{|c|c|c|c|c|c|c|}
\hline & \multicolumn{2}{|c|}{$\begin{array}{c}\text { Surface } \\
\text { Area } \\
\text { Tested }\end{array}$} & $\begin{array}{c}\text { Stress } \\
\text { Rate } \\
\text { (psi/ } \\
\text { sec.) }\end{array}$ & $\begin{array}{c}\text { Average } \\
\text { Tensile } \\
\text { Strength } \\
\text { (psi) }\end{array}$ & $\begin{array}{c}\text { Standard } \\
\text { Deviation } \\
\text { (psi) }\end{array}$ & C.V. \\
\hline 29 & 16 & $\mathrm{~V}_{1}$ & 17.1 & 93.2 & 5.50 & 0.059 \\
18 & 64 & $\mathrm{~V}_{2}$ & 17.1 & 93.2 & 6.65 & 0.071 \\
$\mathrm{~V}_{3}$ & 17.1 & 86.3 & 5.49 & 0.064 \\
\hline
\end{tabular}




\section{Double Torsion}

Both fixed displacement and constant displacement rate double torsion tests were conducted on Foamglas. Figure 29 shows the test fixture with specimen and a failed specimen. The figure does not show the groove on the bottom surface of the specimen required by this test, which guides the propagating crack. Nonreproducible compliance calibration and $\mathrm{V}-\mathrm{K}_{\mathrm{I}}$ data were obtained. Specimen geometry, residual stress in the material and variations in density and/or microstructure are believed to be the cause for the variation in data which is presently under evaluation.

\section{Freeze Thaw Cycling}

Several open cell and closed cell cellular glass materials were subjected to thermal cycling through $0^{\circ} \mathrm{C}$ at nominally $95 \%$ relative humidity as illustrated in Figure 30. During the course of the investigation, it was noted that the failure rate was directly related to the amount of free water present on the specimen surface. Water condensed on the top of the chamber dropping on the specimens nearest the top of the chamber which caused a much higher failure rate for those specimens. Because of this, a quantitative comparison of the freeze/thaw sensitivity between different cellular glass materials cannot be made at this time. Table 15 presents the general findings for the material tested to date without consideration of the varying amounts of water present on the different specimen surfaces. There is a large dispersion in the data resulting from the locally varying freeze/thaw conditions in the test chamber.

Coated Foamglas specimens were also subjected to thermal cycling through $0^{\circ} \mathrm{C}$ at $95 \%$ relative humidity. However, these specimens were evenly spaced near the top of the chamber to ensure the avaibility of large amounts of water on their coated surfaces. They were then tested in dynamic fatigue. Table 16 presents the results. 


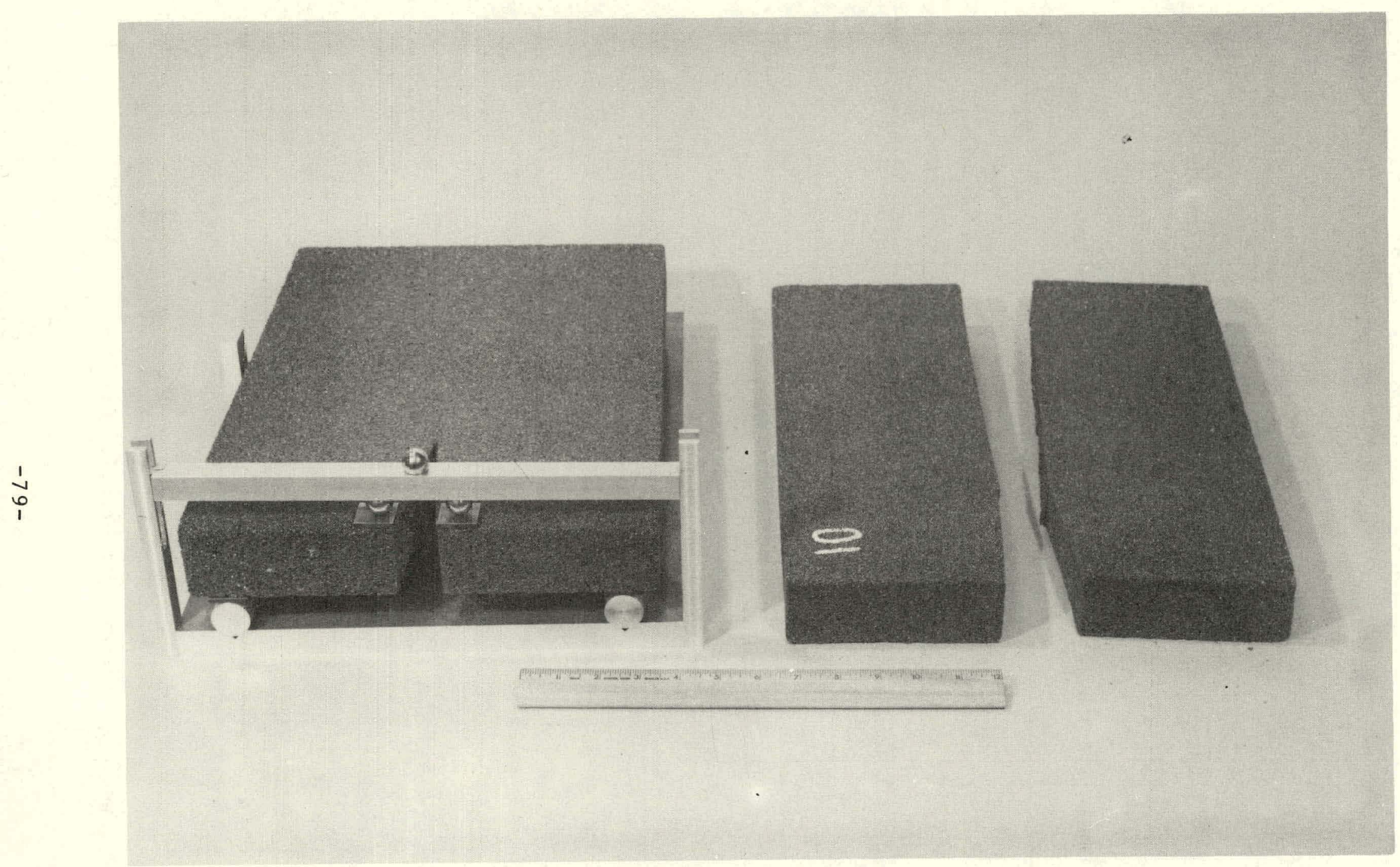


Table 15. Results of Freeze/Thaw Environmental Testing on Severa1 Cellular Glass Materials

\begin{tabular}{|c|c|c|c|c|c|}
\hline Material & $\begin{array}{l}\text { Density } \\
\left(1 \mathrm{bs} / \mathrm{ft}^{3}\right)\end{array}$ & $\begin{array}{l}\text { Number } \\
\text { Tested }\end{array}$ & $\begin{array}{l}\text { Number } \\
\text { of } \\
\text { Cycles }\end{array}$ & $\begin{array}{l}\text { Number of } \\
\text { Structural } \\
\text { Failures* }\end{array}$ & Remarks \\
\hline $\begin{array}{l}\text { Closed Ce11 } \\
\text { Soda Lime } \\
\text { Silicate }\end{array}$ & 8.5 & $\begin{array}{l}14 \\
13\end{array}$ & $\begin{array}{r}42 \\
101\end{array}$ & $\begin{array}{l}5 \\
0\end{array}$ & $\begin{array}{l}\text { A11 Specimens: } \\
\text { Strucural and } \\
\text { Chemical Degrad. }\end{array}$ \\
\hline $\begin{array}{l}\text { Open Cel1 } \\
\text { Soda Lime } \\
\text { Silicate }\end{array}$ & 16.5 & 2 & $\begin{array}{r}42 \\
101\end{array}$ & 0 & $\begin{array}{l}\text { Material Absorbs } \\
\text { Water, No Mate- } \\
\text { rial Spalling }\end{array}$ \\
\hline \multirow[t]{5}{*}{$\begin{array}{l}\text { Closed Cel1 } \\
\text { Alumino- } \\
\text { borosilicate }\end{array}$} & 11.6 & $\begin{array}{l}6 \\
4\end{array}$ & $\begin{array}{r}42 \\
101\end{array}$ & $\begin{array}{l}0 \\
3\end{array}$ & \multirow[t]{5}{*}{$\begin{array}{l}\text { A11 Specimens: } \\
\text { Structural } \\
\text { Degrad. }\end{array}$} \\
\hline & 14.1 & $\begin{array}{l}5 \\
5\end{array}$ & $\begin{array}{r}42 \\
101\end{array}$ & $\begin{array}{l}0 \\
3\end{array}$ & \\
\hline & 16.6 & $\begin{array}{l}5 \\
5\end{array}$ & $\begin{array}{r}42 \\
101\end{array}$ & $\begin{array}{l}0 \\
4\end{array}$ & \\
\hline & 20.0 & 5 & 180 & 5 & \\
\hline & 27.0 & 3 & 180 & 3 & \\
\hline
\end{tabular}

$*$ "Complete erosion through the specimen's one inch thickness

Table 16. Results of Strength Measurements on Coated Soda Lime Silicate Foamglas (B) after Environmental Freeze Thaw Testing

\begin{tabular}{|c|c|c|c|c|c|}
\hline $\begin{array}{l}\text { Number } \\
\text { Tesled }\end{array}$ & $\begin{array}{c}\text { Number } \\
\text { of } \\
\text { Cycles }\end{array}$ & $\begin{array}{l}\text { Number of } \\
\text { Structural } \\
\text { Failures } \\
\text { During } \\
\text { Environmental } \\
\text { Cycling* }\end{array}$ & $\begin{array}{c}\text { Average Tensile } \\
\text { Strength of Intact } \\
\text { Specimens After } \\
\text { Environmental Cycling } \\
\text { (psi) }\end{array}$ & $\begin{array}{c}\text { Standard } \\
\text { Deviation } \\
\text { (psi) }\end{array}$ & C.V. \\
\hline 12 & 143 & 0 & 86.8 & 10.7 & 0.124 \\
\hline 13 & 280 & 4 & 83.8 & 9.4 & 0.112 \\
\hline
\end{tabular}

* Specimen would not support appreciable load 


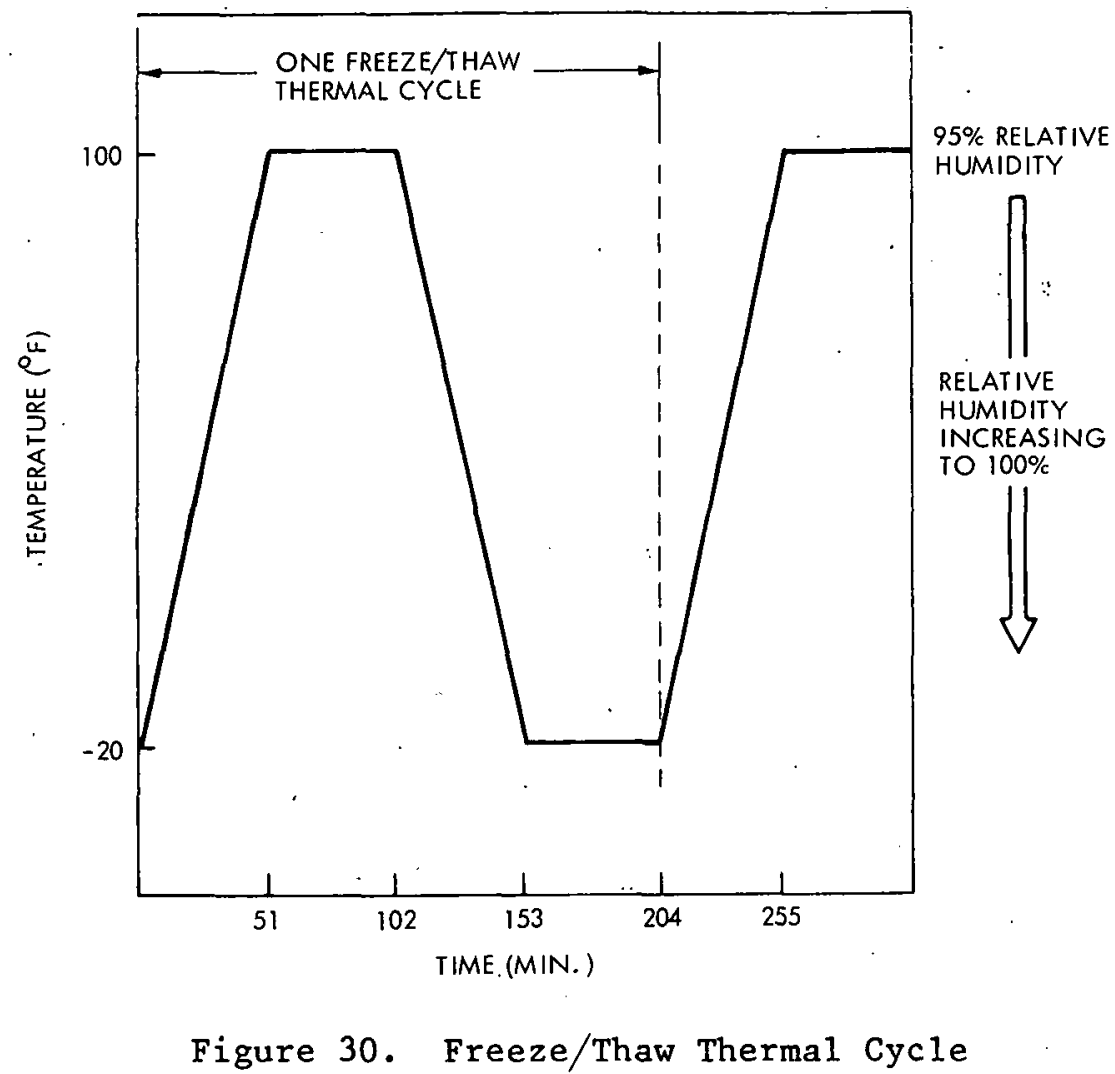

\section{E. DISCUSSION}

Since the cellular glass materials tested in tension were done under identical test conditions, comparisons between the tensile properties can be made. The tensile strength of cellular glass materials appears to be a function of density and not chemical composition or whether they are closed or open cell. This is illustrated in Figure 31 which presents the , tensile strength of three cellular glass materials with different compositions and microstructure as a function of density. Figure 31 also shows the strength of each material as a function of its orientation from the parent block. The material removed from the block in the transverse normal (TN) direction is typically stronger than that material removed in the transverse perpendicular (TP) direction. This variation in strength with test direction probably reflects the anisotropic structure developed during foaming. 


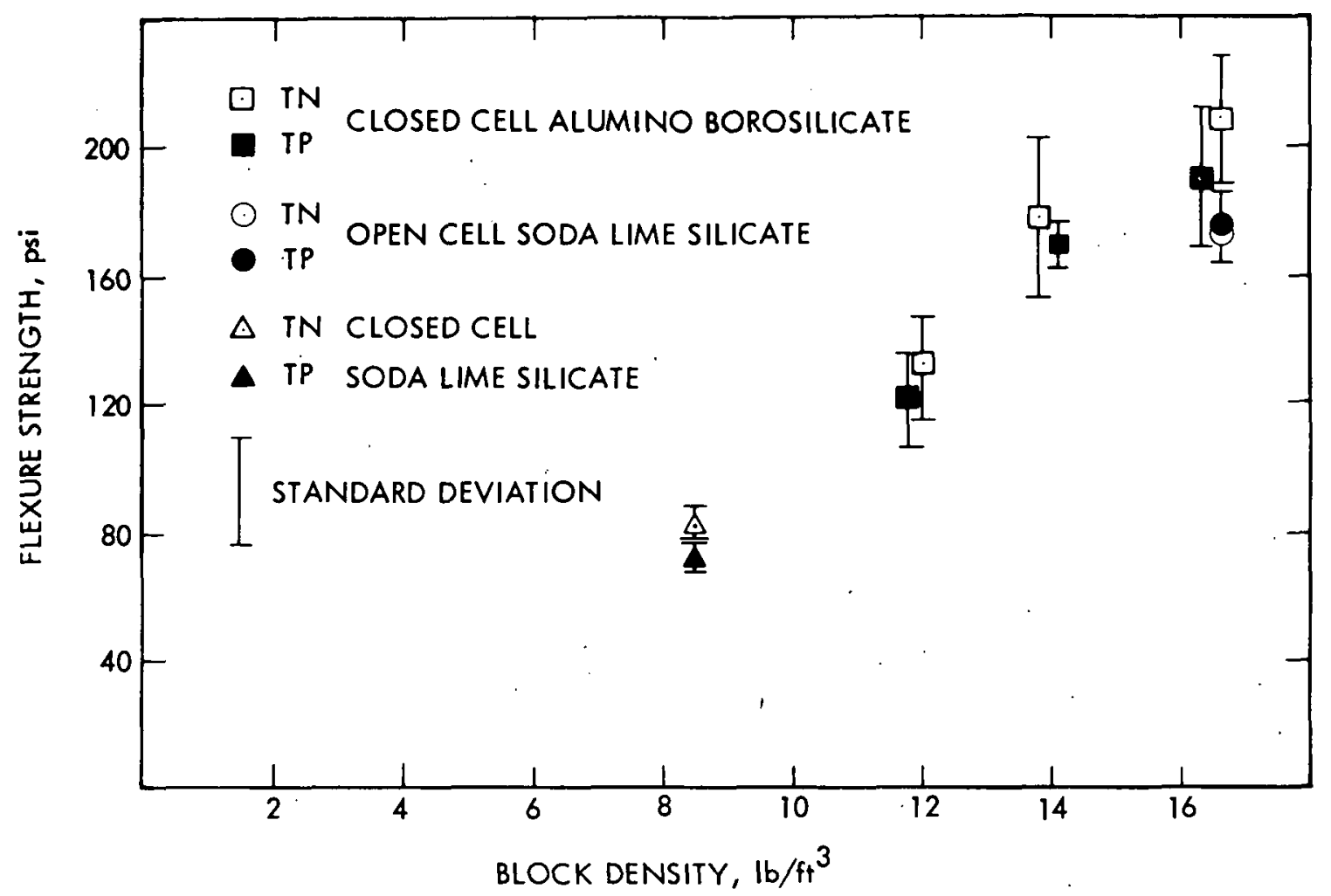

Figure 31. Tensile Strength of Several Cellular Glass Materials as a Function of Density and Orientation

The elastic modulus of cellular glass appears to be dependent on density, chemical composition and microstructure. Figure 32 illustrates this dependency. Soda lime silicate material demonstrates a lower modulus than that of aluminoborsilicate at the same density; however the soda lime silicate had an open cell structure while the aluminoborosilicate was closed cell. Therefore the magnitude of the individual effects of microstructure and chemical composition on the elastic modulus is unknown. Closed cell soda lime silicate material is expected to demonstrate a higher modulus than the open cell soda lime silicate tested to date.

A critical design parameter for structural cellular glass material is its slow crack growth resistivity. The stress corrosion constant is one of the quantifying variables for this property. The stress corrosion constants determined in bending for the materials tested to date are similar and agree reasonably well with those for dense glass of similar 


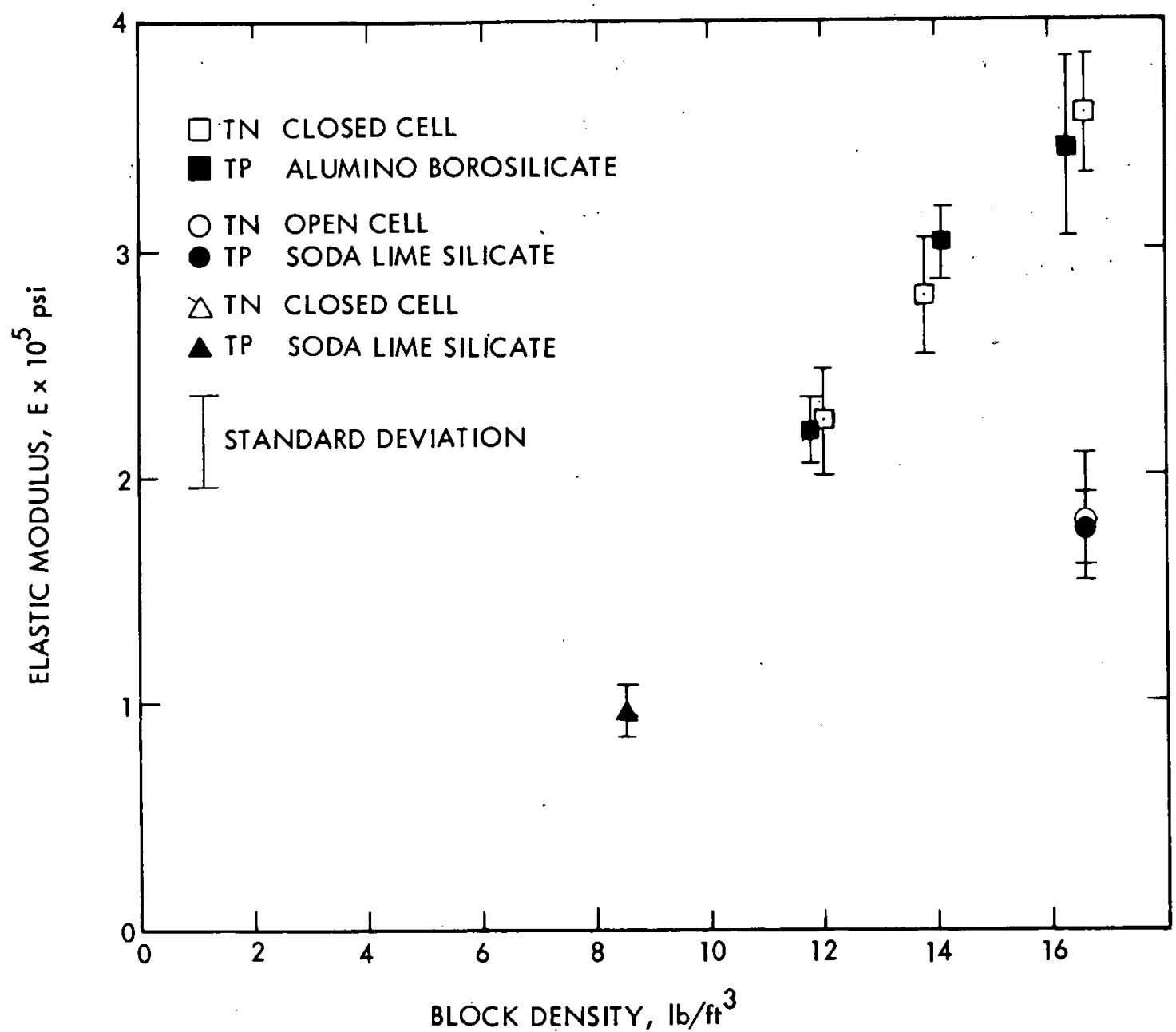

Figure 32. Elastic Modulus in Bending of Several Cellular Glass Materials as a Function of Density and Orientation

composition. Additional testing is required to fully describe or compare the slow crack growth characteristics of the cellular glasses under study including determinations of the "environmental" coefficient A, for each glass.

The failure probability as a function of stressed volume and the static fatigue for soda lime silicate Foamglas ${ }^{\mathbb{R}}$ are preliminary.

The compressive strength of cellular glass materials is more than four times greater than its tensile strength. 
Cellular glass materials are degraded when exposed to freeze thaw environments if free water is available at surfaces. Conformal coatings will reduce or eliminate this degradation as shown by the test data on coated Foamglas ${ }^{\circledR}$ (Table 16). Dense glass skins can be expected to exhibit this protection by a similar mechanism, while increasing resistance to stress failure via higher tensile strength and relative, uniformity. 


\section{CONCLUSIONS}

1. Cellular glass remains a prime candidate for the structural substrate of cantilevered, paraboloidal mirror panels utilizing silvered mirror glass as the reflecting surface.

2. The use of cellular glass materials as the structural support substrate for glass mirrors is not a "state-of-the-art" technology. As such, a development effort is required to demonstrate this technology. Considerable material and process development work, testing, evaluation and analysis will be required before engineers will attain a high dẹgree of confidence in the long term performance of cellular glass materials. Before the low cost potential of this materials technology is realized, a significant fabrication technology development will be required. Present state-of-the-art production materials, produced in large volume primarily for insulation applications cost in the neighborhood of $\$ .30$ per board foot. Due to lack of flexibility in processing large pieces and in varying the density, this material will probably not be a serious contender for large panel applications. Both domestic suppliers of cellular glass have produced different kinds of cellular glass which show greater promise than current material--but they are developmental materials made on a laboratory or pilot plant scale. None of these materials have been optimiscd for structural applications. Control of the process for fabricating these developmental cellular glasses has not been adequately demonstrated to warrant discussion of quality or cost in large volume production. There appears to be no inherent reason why any of the new cellular glass materials should cost more than the present production material in large volume production but their present cost is approximately 20 dollars per board foot. Both suppliers have indicated the 
major hurdle to overcome in reducing the cost of the material and assuring reproducible high quality is to construct a mini plant capable of producing approximately twenty million board feet per year in a continuous line. The cost of such a plant is roughly estimated to be between two and three million dollars. If cellular glass mirror panels are to be made in volume it is clear that a production line co-located with a mirror glass production line and a. silvering line is needed. Clearly such a production facility would have to be supported by a large demonstration project. Until such dedicated facilities are available for making cellular glass panels of other than present'industrial materials, the cost of such panels will remain high.

3. Cellular glass materials characterization is still in the preliminary stage. An inadequate data base presently exists. The testing and evaluation program outlined in Section $V$ is adequate to supply the appropriate information to the design engineer to allow him to choose one material over another with a high degree of confidence. Preliminary testing has indicated that a cellular glass material is defined in a three dimensional matrix by its chemical. composition, its density and its microstructuré. If materials are drawn from such a matrix.and then tested according to the program delineated in Section $V$, with sufficient test data from which to determine confident statistical analyses, it becomes clearly evident that a major testing effort remains to provide this cellular glass materials characterization information.

A comprehensive testing and evaluation program is being developed at JPL. This program will investigate the mechanical and physical properties of cellular glasses as well as the environ- mental durability of the material. The work discussed in this report, which is being funded by the JPL/ASTT project, is targeted at the selection and 
qualification of cellular glass materials for use in advanced concentrator mirror panels. A generic investigation of the effects of chemical composition, density and microstructure on the resulting properties of cellular glasses is being undertaken at JPL under a SERI funded Advanced Solar Materials Contract.

4. Two major limitations on the use of cellular glass, particularly in solar mirror applications, have emerged from the preliminary testing program:

1) the susceptibility of cellular glasses to slow crack growth damage reduces the allowable working stress

2) degradation due to freeze thaw conditions is severe

An impermeable conformal coating would alleviate the damage caused by freeze/thaw by prohibiting the puddling of water on the porous surface. The conformal coating may slightly reduce the effect of slow crack growth by prohibiting the corrosive medium (water) from reaching the glass. In any case the conformal coating will add to the cost of a component because of additional material and manufacturing costs.

5. The present work is intended to explore the properties of selected bulk cellular glass materials. As such, results can be taken as a guide from which conclusions can be extrapolated for realistic applications. Reinforcing, prestressing, densified surface skins, variable density and utilization of established or novel tension-compression sandwich techniques, taken alone or in combination, will enhance the applicability of this essentially virgin technology. The fact that the material class performs well in its homogeneous single phase form without these conventional enhancements should be taken as encouragement for its further exploitation and investigation. 


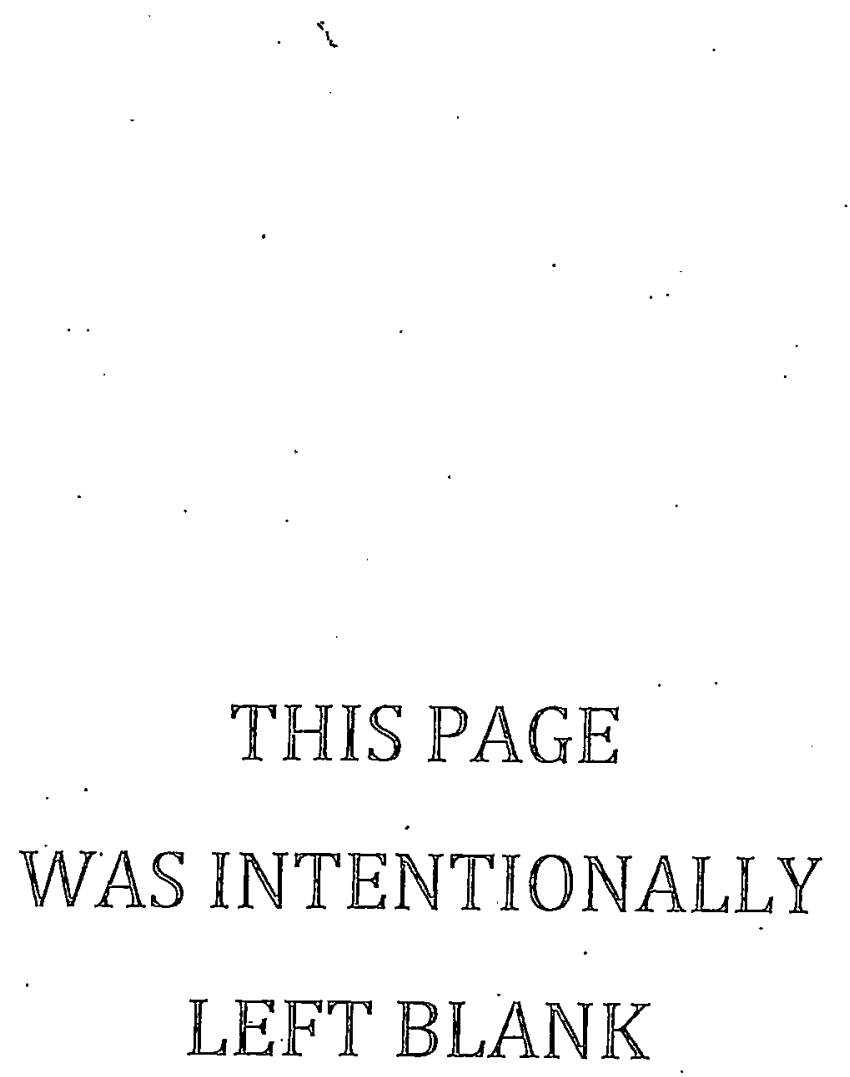




\section{REFERENCES}

1. Cutler, I. B., et al., Foam Glass Insulation From Waste Glass, University of Utah, Department of Material Science and Engineering, Final Report, Contract No. R800937-02, EPA Report No. EPA-600/3-77-030, August 1977.

2. Hedlin, C. P., "Moisture Gains by Foam Plastic Roof Insulations Under Controlled Temperature Gradients," Journal of Cellular Plastics, Sept./Oct. 1977, pp. 313-319, 326.

3. Personal Communication with representatives of Sandia Laboratories, Albuquerque, New Mexico, October 1978.

4. Pittsburgh Corning Corporation, "Foamglas ${ }^{\circledR} \mathrm{H} / \mathrm{T}$ Insulation Systems," Bulletin FI-134 Rev. 2, 15M, May 1977.

5. Weibul1, W., "Statistical Theory of Strength of Materials," Ingenioersvetenskapsakademiens, Handlingar, No. 151, 44, 1939.

6. Wiederhorn, S. M., "Reliability, Life Prediction, and Proof Testing of Ceramics," Ceramics for High-Performance Applications, Proceedings of the Second Army Materials Technology Conference, November 13-16, 1973.

7. Ritter, J. E., Jr., "Engineering Design and Fatigue Failure of Brittle Materials," Fracture Mechanics of Ceramics, Vol. 4, Edited by Bradt, R. C., Hasselman, D. P. H., and Lange, F. F., Plenum Press, 1978.

8. Montgomery, A. G., "Flexural Strength, Stress Intensity Factor and Static Fatigue of Foamglas Cellular Insulation," M. S. thesis in Engineering, University of Pittsburgh, 1977. 
9. Personal Communication with representatives of Pittsburgh Corning Corporation, Pittsburgh, Pa., March 1978.

10. Conley, P. H., "Stressing Rate Effects on the Strength of Foamglass," B.S. thesis in Engineering, Pennsylvania State University, May 1977.

11. Chen, C. P. and Knapp, W. J., "Fatigue Fracture of an Alumina Ceramic at Several Temperatures," Fracture Mechanics of Ceramics; Vol. 2, Edited by Bradt, R. C., Hasselman, D. P. H., and Lange, F. F., Plenum Press, NY, 1974.

12. Duckworth, W. H., "Precise Tensile Properties of Ceramic Bodies," Journal of the American Ceramic Society, Vol. 34, No. 1, January 1951, pp. 1-9.

13. Timoshenko, S. P. and Goddier, J. N., Theory of Elasticity, McGraw-Hi11, 1970, pp. 113-122.

14. Charles, R. L, "Dynamic Fatigue of Glass," Journal of Applied Physics, Vol. 29, No. 12, December 1958, pp. 1657-1662.

15. Evans, A. G. and Langdon, T. G., "Structural Ceramics," Progress in Materials Science, Vol. 22, No. 3/4, 1976.

16. Evans, A. G., Ceramics for High Performance Applications, Brook Hil1; MA, 1975, P. 373.

17. Evans, A. G. and Fuller, E. R., "Crack Propagation in Ceramic Materials Under Cyclic Loading Conditions," Metallurgical Transactions, Vol. 5, January 1974, pp. 27-33.

18. Adams, M. and Sines, G., "Compression Testing of Ceramics," Fracture Mechanics of Ceramics, Vol. 3, Edited by Bradt, R.C., Hasselman, D.P.H and Lange, F. F., Plenum Press, NY, 1978. 
19. Grover, H. J., Fatigue of Aircraft Structures, NAVAIR 01-1A-13, 1966.

20. Adams, M. and Sines, G., "Methods for Determining the Strength of Brittle Materials in Compressive Stress States," Journal of Testing and Evaluation, Vol. 4, No. 6, 1976, pp. 383-396.

21. Wachtman, J. B., Jr., "Highlights of Progress in the Science of Fracture of Ceramics and Glass," Journal of the American Ceramic Society, Vol. 57, No. 12, December 1974, pp. 509-519.

22. Widerhorn, S. M., "Subcritical Crack Growth in Ceramics," Fracture Mechanics of Ceramics, Vol. 2, Edited by Bradt, R.C., Hasselman D.P.H. and Lange, F. F., Plenum Press, NY, 1974.

23. Evans, A. G., "A Simple Method for Evaluating Slow Crack Growth in Brittle Materials," Int. Journal of Fracture, Vol. 9, No. 3, September 1973, Pp. 267-278.

24. Evans, A. G. and Williams, D. P., "A Simple Method for Studying Slow Crack Growth," Journal of Testing and Evaluation, Vol. 1, No. 4, July 1973, pp. 264-270.

25. Beachem, C. D., Kies, J. A., and Brown, B. F., "A Constant K Specimen for Stress Corrosion Cracking Tests," Materials Research and Standards, Vol. 11, No. 4, p. 30. 